\title{
Comparison of MTI Water Temperatures with Ground Truth Measurements at Crater Lake, OR
}

\author{
R. J. Kurzeja* and M. M. Pendergast** \\ * Westinghouse Savannah River Co. \\ Aiken, SC \\ ** SMP Enterprises \\ Martinez. GA
}


This document was prepared in conjunction with work accomplished under Contract No. DE-AC09-96SR18500 with the U. S. Department of Energy.

\section{DISCLAIMER}

This report was prepared as an account of work sponsored by an agency of the United States Government. Neither the United States Government nor any agency thereof, nor any of their employees, makes any warranty, express or implied, or assumes any legal liability or responsibility for the accuracy, completeness, or usefulness of any information, apparatus, product or process disclosed, or represents that its use would not infringe privately owned rights. Reference herein to any specific commercial product, process or service by trade name, trademark, manufacturer, or otherwise does not necessarily constitute or imply its endorsement, recommendation, or favoring by the United States Government or any agency thereof. The views and opinions of authors expressed herein do not necessarily state or reflect those of the United States Government or any agency thereof.

This report has been reproduced directly from the best available copy.

Available for sale to the public, in paper, from: U.S. Department of Commerce, National Technical Information Service, 5285 Port Royal Road, Springfield, VA 22161, phone: (800) 553-6847, fax: (703) 605-6900

email: orders@ntis.fedworld.gov

online ordering: http://www.ntis.gov/help/index.asp

Available electronically at http://www.osti.gov/bridge

Available for a processing fee to U.S. Department of Energy and its contractors, in paper, from: U.S. Department of Energy, Office of Scientific and Technical Information, P.O. Box 62, Oak Ridge, TN 37831-0062,

phone: (865)576-8401,

fax: (865)576-5728

email: $\underline{\text { reports@ adonis.osti.gov }}$ 


\title{
Table of Contents
}

\author{
Abstract \\ 1. Introduction
}

2. Methodology

3. Ground truth

3.1 Seamon Mini sensor

3.1a Accuracy and calibration of the Seamon Mini temperature logger

3.2 OSU Data

3.3 Adjustments to the bulk water measurements

3.3a Adjustments to the OSU bulk temperature

3.3b Skin temperature algorithm

3.3c Warm/cold layer estimates

4. MTI water surface temperature results

4.1 Uncertainty analysis

5. Results

6. Acknowledgements

7. References 


\begin{abstract}
Water surface temperatures calculated with the Los Alamos National Laboratory Robust algorithm were compared with ground truth water temperature measurements near the Oregon State University buoy in Crater Lake, OR. Bulk water measurements at the OSU buoy were corrected for the skin temperature depression and temperature gradient in the top $10 \mathrm{~cm}$ of the water to find the water surface temperature for 18 MTI images for June 2000 to Feb 2002.

The MTI robust temperatures were found to be biased by $0.1 \mathrm{C}$, with an RMS error of $1.9 \mathrm{C}$ compared with the ground truth water surface temperatures. When corrected for the errors in the buoy temperatures the RMS was reduced to $1.3 \mathrm{C}$. This RMS difference is greater than the $1 \mathrm{C}$ found at the Pacific Island of Nauru because of the greater variability in the lake temperature and the atmosphere at Crater Lake and the much smaller target area used in the comparison
\end{abstract}




\section{Introduction}

A primary objective of the MTI (Multi Spectral Thermal Imager) is the accurate measurement of the surface water temperature under a range of conditions, without the need for supplementary atmospheric information. A previous report (WSRC-TR-2002-00294) evaluated MTI surface water temperatures near the tropical island of Nauru, which is characterized by relatively constant, warm waters and an opticallythick atmosphere. It is also important, however, to assess the MTI performance for cold targets and variable atmospheres, which is why Crater Lake is a valuable evaluation target

Background information on the MTI imager and the 'Robust' water temperature retrieval algorithm developed by the Los Alamos National Laboratory are contained in the Nauru report (WSRC-TR-200200294) . Ground truth data at Crater Lake were obtained by SRTC in cooperation with Oregon State University and the US National Park Service at Crater Lake National Park

One benefit of Crater Lake as an MTI target is the much smaller atmospheric correction, and less frequent sub-visible cirrus than in the tropical Pacific. However, Crater Lake weather is more variable, which, coupled with the relatively small lake size and surrounding rim, leads to variable surface currents and temperatures.

\begin{tabular}{|ll|}
\hline Crater Lake Data & \\
\hline Latitude $=42.9330$ & Longitude $=122.117$ West \\
\hline Lake elevation $=1,882$ meters & \\
\hline Average depth $=480$ meters & Maximum depth $=623$ meters \\
\hline Average width $=8 \mathrm{~km}$ & \\
\hline Average rim elevation $=2,160$ meters & \\
\hline
\end{tabular}

Table 1: Crater Lake information

\section{Methodology}

The accuracy of the MTI surface temperature retrievals was evaluated at the Oregon State University research buoy, located in the northeast part of the lake, $~ 1$ mile from shore, and an SRTC temperature sensor near the OSU buoy. Figure 1 shows a picture of Crater Lake and the OSU buoy. Hourly-averaged water temperatures at depths of 10 and $30 \mathrm{~cm}$ and meteorological data were provided by OSU at most MTI image times. Additional atmospheric data were obtained from the National Weather Service upper air sounding station in Medford, OR, - approximately 80 miles from Crater Lake.

The MTI water surface temperature at Crater Lake were provided by Los Alamos National Laboratory with their 'Robust' algorithm. This algorithm determines the water temperature from a linear combination of top-of-atmosphere brightness temperatures of bands J, K, L, M, and $\mathrm{N}$ at night, and bands K-N during the day. The wavelength ranges for each of the bands are shown in Table 2. The algorithm is described in more detail in WSRC-2002-00294.

\begin{tabular}{|l|l|l|}
\hline MTI IR bands & Wavelength range (microns) & Description \\
\hline J & $3.49-4.10$ & Atmosphere \\
\hline K & $4.85-5.05$ & Atmosphere \\
\hline L & $8.01-8.39$ & Surface \\
\hline M & $8.42-8.83$ & Surface \\
\hline N & $10.15-10.7$ & Surface \\
\hline
\end{tabular}

Table 2: MTI Infrared bands 
The robust algorithm uses 4 sets of coefficients to retrieve surface temperatures, depending on day or night and on the water surface temperature. Robust coefficients were derived for every 5 degrees of zenith angle and the nadir values are shown in Fig. 3 (taken from Atkins et al, 2001). The 'cold' coefficients were used at Crater Lake because the temperature is always less than 300C.

The MTI images the surface with 3 adjacent sensor chip assemblies (SCA's). Usually, either the SCA2 or SCA3 imaged the east side of Crater Lake, during the night, or day, respectively, where the OSU buoy is located. Because of the limited number of usable images (18), we have grouped results from SCA's 2 and 3 together. This is consistent with results for Nauru, where water surface temperatures from SCA's 2 and 3 were comparable (within $0.5 \mathrm{C}$ ), and cooler than SCA1.

The water surface temperature measured by MTI, will differ from the bulk water temperature at the OSU buoy mainly because of the cool skin and heating of the lake's top layer by the sun. The skin effect is present all the time, but the warm layer correction is important during midday in light winds. These issues are discussed in the next section.

\section{Ground Truth water temperature measurements.}

Evaluation of MTI-derived surface temperatures requires accurate bulk water measurements and adjustments to account for the difference between bulk and surface temperatures at the MTI image time. It is necessary to distinguish between the bulk, near-surface, and water surface temperatures (WST). In this report, the bulk temperature is defined to be at $10 \mathrm{~cm}$ in open water, the near-surface temperature is just below the skin layer (at a depth of $\sim 1 \mathrm{~mm}$ ), whereas the WST is in the top few microns of the water surface, i.e., the variablle that MTI measures. In this section we discuss the accuracy of the temperature sensors and corrections required to find the WST from the corresponding bulk temperature.

\subsection{Seamon Mini temperature sensor}

SRTC, in cooperation with the US Park Sevice, installed a Seamon Mini temperature logger at Crater Lake during the MTI mission. The Mini is a small, cigar-sized recording thermistor temperature sensor, made by the Hugrun company. The Mini was suspended $10 \mathrm{~cm}$ below a float, $4 \mathrm{~cm}$ in diameter by $30 \mathrm{~cm}$ long. A weight was suspended $20 \mathrm{~cm}$ below the Mini to ensure that it remained at a depth of $10 \mathrm{~cm}$, even with wind and wave action. Reflecting tape on the top of the Mini reduced the sensor's solar heating.

The Seamon Mini measured the water temperature at 15- and 30-minute intervals during most of the MTI mission. The history of the Mini deployment is given in Table 3.

\begin{tabular}{|l|l|l|l|l|l|l|}
\hline S/N & Initialization & Deployment & Removal & Download & Interval & Comments \\
\hline 00D922 & June 26, 00 & July 7, ${ }^{\circ} 00$ & $\sim \operatorname{Sep~28,~}{ }^{\circ} 00$ & Oct 24, 00 & $15 \mathrm{~min}$ & $2.5 \mathrm{~min}$ slow on $10 / 24 / 00$ \\
\hline 00D468 & Sept $18,{ }^{\circ} 00$ & Sept 22, ${ }^{\circ} 00$ & Jul 12, 01 & Aug 30, 01 & $30 \mathrm{~min}$ & $15 \mathrm{~min}$ slow on 8/30/01 \\
\hline
\end{tabular}

Table 3: Deployment history of the Seamon Mini at Crater Lake

\section{1a Accuracy and calibration of the Seamon-mini temperature loggers}

The Seamon-mini temperature loggers have a specified accuracy of $0.1 \mathrm{C}$, a resolution of $0.025 \mathrm{C}$ and a response time of 2 minutes. The accuracy of each Mini was checked with a NIST-traceable standard between 10 and 30C before shipment to Crater Lake and were found to be within $0.1 \mathrm{C}$. The Mini's experienced no change in calibration over their deployment period. The only effect during deployment was a $\sim 15$ minute loss of time over a year. (see Table 3 ).

Even though the Seamon-mini is accurate to within $0.1 \mathrm{C}$, solar heating can cause the recorded temperature to exceed the true near-surface temperature during light winds and clear skies. The effect of solar heating on the Mini was evaluated with a test at L-Lake at the Savannah River Site on Oct 24, 2000 at noon. During this test the Mini was alternately exposed to sunlight and then shaded for several minutes. The wind 
speed was $8 \mathrm{mph}$. The results, shown in Fig. 4, show a 0.1C elevation in temperature when the Mini was exposed to the sun. The results are not definitive but give an estimate of the solar heating effect. In periods of light wind, with nearly overhead sun, the heating will probably be greater. We estimate a worst case increase of $0.3 \mathrm{C}$.

\subsection{OSU data}

A list of OSU sensors is given in Table 4. The T probe sensor is located directly under the OSU buoy $(\sim 10 \mathrm{~cm}$ below the surface) and the Seabird SBE 39 is $30 \mathrm{~cm}$ deep. The T Probe may be affected by the OSU buoy in several ways: by heat conduction through the buoy, by thermal inertia of the buoy, by reduced heating and cooling of the top ocean layer under the buoy, and by restricted mixing in light winds. The T Probe sensor operated most of the time during the MTI mission and the SBE sensor functioned $\sim 70 \%$ of the time between July of 2000 and May of 2002.

\begin{tabular}{|l|l|}
\hline OSU sensors & Elevation \\
\hline SBE (Seabird SBE39) & $-10 \mathrm{~cm}$ \\
\hline T Probe (Campbell Scientific thermistor) & $-30 \mathrm{~cm}$ \\
\hline Campbell Scientific Temp/RH probe & $+2.5 \mathrm{~m}$ \\
\hline RM Young Wind Monitor & $+3.0 \mathrm{~m}$ \\
\hline
\end{tabular}

Table 4: OSU water and meteorological sensors

Crater Lake is not accessible during half the year and service and calibration takes place during the summer months. The water temperature sensors are calibrated to an accuracy of $0.1 \mathrm{C}$ and inspection of the data shows that the two OSU sensors were within $0.1 \mathrm{C}$ most of the time. The only exceptions were in light winds at midday with solar heating.

Fig. 5 shows a particularly dramatic example of differences between the sensors. At around 2 pm on July 9 and July 10, of 2000, the T Probe temperature was $\sim 0.5 \mathrm{C}$ greater than the SBE's, while the Mini temperature was $1-3 \mathrm{C}$ greater the T Probe. Since the SBE is at a depth of $30 \mathrm{~cm}$ and the T Probe and Hugrun are at $10 \mathrm{~cm}$, the SBE's lower temperatures are understandable. However, differences between the $\mathrm{T}$ Probe and Min are more difficult to explain. Buoy effects were discussed above and thermal inertia of the OSU buoy can be seen in Fig 5, and explains why the T Probe temperature is cooler than the Mini's before maximum solar heating, but warmer afterwards. The T Probe and Mini temperatures can also differ because the latter are single point measurements, whereas the former are one-hour averages.

Figure 5 also illustrates temporal variability in the water measurements. During mid-day heating the nearly instantaneous Mini measurements differ from the one-hour averages of the OSU buoy by 0.2 to $3 \mathrm{C}$, with an RMS difference of $\sim 0.5 \mathrm{C}$.

\subsection{Adjustments to the bulk water measurements}

The ground truth bulk water temperatures are listed in Table 5. The columns ' $\mathrm{T}$ Pr', 'SBE' and 'Mini' denote the temperature at MTI image time of the T Probe, Seabird SBE 39 and Seamon Mini, respectively. The column 'Bulk' is the first-choice bulk water temperature, i.e., the Mini, when available, or the T Probe otherwise.

As noted above, three adjustments are required to the bulk water temperature measurements to determine the WST. The first must be applied to the T Probe to account for the buoy. The second is for the warm (or cold) layer which forms between the bulk water measurement level and the near-surface. Warm layers are more common than cool layers because they are statically stable, i.e., do not overturn from density differences. However, near-surface cool layers can also form when surface cooling is faster than convective overturning. The final adjustment accounts for the skin, the top millimeter of water, in which 
the temperature is $0.2-1.2 \mathrm{C}$ below its near-surface value. All of the effects discussed above are most important when the winds are light, i.e., less that $2 \mathrm{~m} / \mathrm{sec}$.

Finally, as noted above, because the OSU measurements are one-hour averages, they only approximate the instantaneous value measured by the MTI.

The skin temperature was studied by SRTC on September 15 and 16 of 1999 during routine sensor maintenance. A floating apparatus, tied to the OSU buoy, measured the WST, water temperature, and meteorological variables. The surface temperature was measured with an 8-14 micron IR radiometer, 0.75 meter above the water. Every 10 minutes a pump, $10 \mathrm{~cm}$ below the surface, pumped a jet of water to the surface under the radiometer for 10 seconds. Since the cool skin takes several seconds to form, the skin temperature can be calculated by subtracting the pump-off temperatures (water from $10 \mathrm{~cm}$ deep, without skin) from the pump-on (surface) value. Since biases in the radiometer and reflection from the sky will be the same for pump-on as for pump-off measurements, the difference will be an accurate measure of the difference between the skin and the bulk water temperature (depth of $10 \mathrm{~cm}$ ). The technique can not distinguish between the skin depression and a possible temperature gradient between the surface and 10 $\mathrm{cm}$, so we will restrict the comparison to the late afternoon and evening, when surface cooling ensures uniform temperatures between the surface and a depth of $10 \mathrm{~cm}$.

Fig. 6 shows data from the late afternoon of Sept 15 to the morning of Sept 16. On the afternoon of the $15^{\prime}$ th, the skin temperature depressions were $\sim 0.2 \mathrm{C}$. This small value is caused by cloudy skies, which significantly increased the downward IR radiation and reduced the skin cooling.

In the period between 19:15 and 1:15PDT, the skin depression was less than 0.1C, except from 20:30 to 22:00 PDT. These small skin depressions may be partly due to cloud coverage. The difference between the pump-on and pump-off temperatures may also indicate near-surface cooling between 20:45 and 22:15 PDT. Later in the morning a skin temperature depression of 0.7 to $0.8 \mathrm{C}$ was observed.

\section{3a Adjustment to the OSU bulk temperature}

The OSU buoy affects the T Probe temperature during midday heating with light winds. Since the midday maximum in the bulk water temperature is also a function of these same conditions, it is reasonable to parameterize the buoy effect as a function of the midday maximum. This functional dependence can also include the temporal variability not present in the one-hour averages. For example, Fig. 5 shows that the difference between the $\mathrm{T}$ Probe and the Mini increases with the amplitude of the midday maximum. For the three days the greatest difference between the Mini and the T Probe was $0.5 \mathrm{C}, 1.5 \mathrm{C}$, and $2.5 \mathrm{C}$, wihen the daytime temperature maxima were 1,3 and $3.7 \mathrm{C}$, respectively. Similarly, before the diurnal maximum, the average Mini temperature was greater than the T Probe temperature by $0.2 \mathrm{C}, 0.4 \mathrm{C}$ and $0.6 \mathrm{C}$, respectively. Since the daytime MTI images were usually taken before the daytime maximum, these results suggest an adjustment to the $\mathrm{T}$ Probe temperature of $+20 \%$ of the diurnal maximum.

Similarly, solar heating of the Mini, discussed in Section 3.1, can also be parameterized. A simple quantitative relationship is to assume it to be $5 \%$ of the diurnal maximum, or up to $\sim 0.3 \mathrm{C}$.

The advantage of this functional dependence is that it combines the effects of the wind and solar heating in one simple relationship, which is correct in the limits of overhead sun and light winds and also for weak solar heating and strong winds. 


\section{3b Skin temperature algorithm}

As noted in the Introduction, the skin temperature depression is particularly important at Crater Lake because winds are often very light and the IR sky temperature is low - factors which can result in depressions of up to $1 \mathrm{C}$ or more. Most meteorological variables required to calculate the skin temperature were measured at the OSU buoy. The downward IR radiation was calculated from routine Weather Service soundings and a radiative transfer code, i.e., Modtran.

The calculation of the skin temperature depression is based on Fairall et al. (1996). The skin temperature depression is given by,

$\Delta \mathrm{T}=\mathrm{Q} \delta / \mathrm{k}$

where,

$$
\begin{aligned}
& \delta=\text { thickness of the skin } \\
& =\frac{\lambda v}{(\rho \mathrm{a} / \rho \mathrm{w})^{1 / 2} \mathrm{u}^{* a}} \\
& \mathrm{k}=\text { thermal conductivity of water } \\
& \mathrm{Q}=\text { heat loss of the water surface } \\
& \rho \mathrm{a}=\text { density of air } \\
& \rho \mathrm{w}=\text { density of water } \\
& \mathrm{u}^{* a}=\text { friction velocity of air } \\
& v \quad=\text { kinematic viscosity of water } \\
& \lambda \quad=\text { empirical coefficient }
\end{aligned}
$$

The skin temperature depression is inversely dependent on the friction velocity, which, in turn, is a function of the wind velocity. The heat loss Q is comprised of IR loss to the sky, and sensible and latent heat loss from the water surface to the air. These quantities can be calculated from the wind speed, air temperature, skin temperature, and humidity.

The sensible and latent heat fluxes are complicated functions of the vertical gradients of moisture, temperature, and wind speed. Following Fairall et al. (1996), an interative procedure was used to calculate the heat loss for each of the MTI images in Table 5. The variables used in the calculations are listed in Table 6, along with the derived skin temperature. The meteorological data was obtained from the OSU buoy and are shown in Figures 7 to 22. In these also show the MTI image time. OSU data were not available for Sept 18, 2000. However, much information about this day can be inferred from the Mini data shown in Fig. 12.

Table 6 indicates that the skin temperature difference for the MTI images is between 0.5 and $1.2 \mathrm{C}$, which is greater than a typical ocean range $0.2 \mathrm{C}-0.6 \mathrm{C}$. However, the results are more consistent with measurements obtained by SRTC over other inland lakes $(0.2 \mathrm{C}$ to $1.0 \mathrm{C})$. The relatively large values at Crater Lake are the result of the small downward IR radiation from the high altitude 'cold' sky at Crater Lake.

The validity of Eq 1 was tested by calculating the skin depression at Crater Lake on Sept 15/16 of 1999 . The predicted depression for the early morning period was calculated with the data shown in Fig. 3 and Equation 1, and found to be $1.0 \mathrm{C}$, which is considerably greater than the $0.7 \mathrm{C}$ observed. There are several possible reasons for this discrepancy. At Crater Lake, unlike Nauru, the IR cooling dominates the skin heat loss. For Sept 16, the IR cooling was calculated with NWS upper air data from Bedford, OR, which is approximately 70 miles from Crater Lake, and the assumption of clear skies. Possible differences in the atmosphere between Crater Lake and Medford are too small to affect the IR radiation by more than a few per cent. Nighttime clouds would have increased the IR radiation significantly. The sky was partly cloudy 
at Crater Lake in the late afternoon on Sept 15 but the Sept 16, 00Z Medford sounding suggests clear skies in the evening. Another possilbility is that lake currents in Crater Lake, driven by highly variable heating and winds, cause increased shear stress, a larger value of $\mathrm{u}^{*}$ in Eq. (1), and smaller skin temperature depressions. This effect could be important for all the skin temperatures given in Table 6, i.e., the calculated values may be biased high by 25 to $50 \%$.

\section{3c Warm/Cold Layer estimates}

The skin temperature depression discussed in the previous section accounts for only part of the correction to the bulk water temperature required for comparison with MTI measurements. Heating of the water layer between the 'bulk' measurement at $10 \mathrm{~cm}$ and the surface must also be considered as well as rapid cooling of the top layer of water, which can exceed the rate of convective overturning. This effect is applicable to both the T Probe and the Mini.

The warm layer adjustment can be derived in the same manner as for the buoy correction since warm layer heating is dependent on solar heating and inversely dependent on wind speed. Figure 5 shows that the difference between the SBE (30cm deep) and the T Probe $(10 \mathrm{~cm}$ deep) is $0.2 \mathrm{C}, 0.3 \mathrm{C}$ and $0.5 \mathrm{C}$ on July 7,8 and 9'th, respectively. Assuming a linear variation of temperature with depth, the variation from $10 \mathrm{~cm}$ to the surface will be $0.1 \mathrm{C}, 0.15 \mathrm{C}$ and $0.25 \mathrm{C}$, respectively. As before, we use the daytime maxima for the three days of $1 \mathrm{C}, 3 \mathrm{C}$ and $3.7 \mathrm{C}$ to obtain an average warm layer heating of $0.07 \mathrm{C}$ for each degree of diurnal heating of the $10 \mathrm{~cm}$ probes.

Cooling of the layer between the surface and $10 \mathrm{~cm}$ can be estimated as was done for the warm layer. We expect the most significant nighttime overturning to occur in the fall when the lake water is warm but the air temperature is cool. Inspection of Figs 9-11 shows the Mini to be $\sim 0.1 \mathrm{C}$ cooler than the $\mathrm{T}$ Probe in three fall nights in 2000. On the other hand, no significant differences in the nighttime temperatures were seen at other times of the year. Thus, we assume a nighttime, fall, cool layer correction of $-0.2 \mathrm{C}$ for the $\mathrm{T}$ Probe and $-0.1 \mathrm{C}$ for the Mini.

The adjustments described above are summarized in Table 7 Relevant data were taken from Figures 7-22. Also listed in this table is the skin correction from Table 6.

\section{MTI water temperature results}

Robust WST's for eighteen nadir MTI water surface images were compared with ground truth temperatures in this study. Table 5 gives information about these images and also corresponding backward-looking images, which were not analyzed. Color contour maps of the MTI WST's are shown in Figs. 23-40. These maps exhibit considerable vertical streaking from individual pixels and wider bands, $\sim 1 / 2$ to $1 \mathrm{~km}$ wide, near the boundaries of the SCA's, as well as obvious differences between the SCA's. The effect of wind speed on the surface temperature is also apparent. For example, there is much more variability in surface temperature in the 2'nd and 3'rd images (Figs. 24 and 25) than in the 1'st and 4'th (Figs. 23 and 26) when the winds were weak and strong, respectively.

Wide bands of warm and cold temperature are more prominent in the Crater Lake WST retrievals than observed at Nauru and increase the uncertainty in the evaluation since their width is comparable to the regions of interest from which the average temperature is calculated. For example, the image on Sept 18, 2000 (Fig. 29) shows a cool band in SCA 3 next to SCA 1, and a warm band in SCA 1 next to SCA 2.

These bands are shown more clearly in a WST cross-section (Fig. 41), which shows pixel-to-pixel variability of $0.2 \mathrm{C}$ and variability in bands (20-30 pixels wide) of $0.5 \mathrm{C}$. These bands are common on light wind days but note the prominent bands on Sept 6 and Nov 6, 2001 (Figs 36 and 37) when the wind was greater than $2 \mathrm{~m} / \mathrm{s}$. Figure 41 also shows the bias in the SCA1 water temperature of $1.3 \mathrm{C}$ with respect to SCA2, and $0.5 \mathrm{C}$ with respect to SCA3. 
The radiance from bands $\mathrm{K}-\mathrm{N}$ for Sept 18, 2001 is shown in Figure 42. This figure shows a negative bias in the L band of $\sim 1.5 \%$ compared with SCA's 2 and 3, which accounts for the warmer water surface temperatures in SCA 1. (The L band is multiplied by a negative coefficient, see Fig 3). This bias is comparable to that found at Nauru. Figure 42 also shows a negative $3 \%$ bias in band $\mathrm{K}$ that reduces the derived WST because its coefficient is positive (Figure 3). However, this effect is not large enough to balance the temperature increase due to the $\mathrm{L}$ band bias.

The bias in the SCA's could be seen in nearly all of the Crater Lake images, but varied from image to image. Figure 43 shows a cross-section of radiances on May 3, 2001. The negative bias in SCA1 for the L band is clearly visible, but the $\mathrm{K}$ band bias is much less than on September 18 .

The MTI WST was obtained from a region of interest, ROI, centered at the buoy location on the MTI WST image. The ROI contains between 50 to 250 pixels. The OSU buoy was located on the MTI images by drawing straight lines between the 8 landmarks shown in Fig. 1. Note that the 4 intersecting pairs of lines yield a total of 6 estimates of the buoy location. These points were separated by up to 100 meters. However, since the OSU buoy was positioned on the average of the 6 intersections, the uncertainty in the buoy location is $\sim 20$ meters.

In some cases the OSU buoy was located near the intersection of two SCA's, or the WST image did not include the part of the lake with the OSU buoy. In these cases the ROI was located as close to the buoy as possible, and the uncertainty in the buoy temperature was increased accordingly. These special situations are summarized below.

Sept 4, 2000 : The intersection of SCA's 1 and 2 occurred near the buoy. The ROI was selected $\sim 500$ meters west of the buoy location.

Jan 17, 2001 The east side of the lake was not imaged. The MTI ROIwas about 500 meters west of the OSU buoy location.

Feb 2, 2001: The east side of the lake was not imaged. The MTI ROI is $\sim 1 \mathrm{~km}$ west of the OSU buoy.

Aug 12, 2001: In this nighttime image the buoy is in SCA 1 and the ROI was positioned in the middle of the lake in the eastern side of SCA 3,1 km from the buoy.

Sept 6, 2001: Extreme banding near the buoy is apparent in the image. The MTI temperature was chosen $\sim 500$ meters east of the buoy.

Dec 21, 2001: The buoy is located at the SCA 1 and SCA 2 boundary. The MTI temperature was selected $\sim 500$ meters east of the buoy. 


\begin{tabular}{|c|c|c|c|c|c|c|c|c|c|c|c|c|c|c|c|c|c|c|}
\hline Mo & Dy $Y$ & $\mathrm{Yr}$ & $\mathrm{D} / \mathrm{N}$ & IM\# & Tim & $\%$, loc & $\mathrm{TPr}$ & SBE & Mini & Bulk & SCA1 & $\mathrm{SCA} 2$ & SCA3 & $\mathrm{s} 2 / \mathrm{S} 3$ & skin & Bulk & RMS & RMS \\
\hline & & & & & & & & & & & & & & & +wrm & -skn+wrm & skn+wrm & Bulk \\
\hline 6 & $\begin{array}{ll}16 & 0 \\
\end{array}$ & 00 & $\mathrm{D}$ & 0018796 & $20: 23$ & 90 ,west & $5.5 \mathrm{n}$ & $\mathrm{N}$ & $\mathrm{N}$ & 5.5 & & & 4.2 & 4.2 & -0.2 & 5.3 & 1.21 & 1.69 \\
\hline 6 & 160 & 00 & D & 0018803 & $20: 25$ & 90 ,west & $5.5 \mathrm{~A}$ & $\mathrm{~N}$ & $\mathrm{~N}$ & 5.5 & & & & & & 5.5 & & \\
\hline 6 & 170 & 00 & $\mathrm{D}$ & 0018874 & $20: 32$ & 90, west & 6.5 i & $\mathrm{N}$ & $\mathrm{N}$ & 6.5 & & & 7.4 & 7.4 & -0.7 & 5.8 & 2.56 & 0.81 \\
\hline 6 & 170 & 00 & D & 0018881 & $20: 33$ & 90 ,west & $6.1 \mathrm{~N}$ & $\mathrm{~N}$ & $\mathrm{~N}$ & & & & & & & & & \\
\hline 6 & 280 & 00 & $\mathrm{D}$ & 0019543 & $20: 28$ & 70 ,west & $12.5 \mathrm{~A}$ & $\mathrm{~N}$ & $\mathrm{~N}$ & 12.5 & & & 16.5 & 16.5 & 0.2 & 12.7 & 14.44 & 16.00 \\
\hline 6 & 280 & 00 & D & 0019550 & $20: 30$ & 90, west & $12.5 \mathrm{~N}$ & $\mathrm{~N}$ & $\mathrm{~N}$ & & & & & & & & & \\
\hline 8 & 130 & 00 & D & 0023444 & $20: 22$ & 100 & 16.15 & 16.1 & 16.2 & \begin{tabular}{|l|}
16.15 \\
\end{tabular} & & & 15.7 & 15.7 & -0.7 & 15.45 & 0.06 & 0.20 \\
\hline 8 & 130 & 00 & $\mathrm{D}$ & 0023451 & $20: 20$ & 100 & 16.15 & 16.1 & 16.2 & & & & & & & & & \\
\hline 8 & 250 & 00 & D & 0026674 & $20: 18$ & 100 & $15.7 \mathrm{n}$ & $\mathrm{N}$ & 15.6 & 15.6 & & & 15.1 & 15.1 & -0.6 & 15 & 0.01 & 0.25 \\
\hline 8 & 250 & 00 & D & 0026681 & $20: 20$ & 100 & $15.7 \mathrm{r}$ & $\mathrm{N}$ & 15.6 & & & & & & & & & \\
\hline 9 & 180 & 00 & $\mathrm{D}$ & 0029474 & $20: 11$ & 100 & $15.1 \mathrm{~N}$ & $\mathrm{~N}$ & 15.1 & 15.3 & & & 14.4 & 14.4 & -0.9 & 14.4 & 0.00 & 0.81 \\
\hline 9 & 180 & 00 & $\mathrm{D}$ & 0029481 & $20: 13$ & 100 & $15.1 \mathrm{~N}$ & $\mathrm{~N}$ & 15.1 & & & & & & & & & \\
\hline 5 & 30 & 01 & D & 0103952 & 19:30 & 100 & 3.9 & 3.9 & 4.1 & 3.9 & & & 4.1 & 4.1 & -1 & 2.9 & 1.44 & 0.04 \\
\hline 5 & 250 & 01 & $\mathrm{D}$ & 0104279 & 19:36 & 100 & 9.8 & 9.8 & 9.2 & 9.2 & & & 9.7 & 9.7 & -0.7 & 8.5 & 1.44 & 0.25 \\
\hline 7 & 270 & 01 & D & 0105387 & 19:22 & 75 ,south & & & & & & & & & & & & \\
\hline 11 & 70 & 01 & D & 0107522 & 19:09 & 100 & 8.55 & \begin{tabular}{|l|} 
\\
\end{tabular} & $\mathrm{N}$ & & & & & & & & & \\
\hline 12 & 210 & 01 & D & 0108174 & 19:04 & 100 & 4.1 & 4.1 & $\mathrm{~N}$ & 4.1 & & & 6.5 & 6.5 & -0.6 & 3.5 & 9.00 & 5.76 \\
\hline 9 & 40 & 00 & $\mathrm{~N}$ & 0027640 & 09:10 & 95 ,east & $13.5 \mathrm{~N}$ & $\mathrm{~N}$ & 13.4 & 13.4 & & 11.3 & & 11.3 & -1 & 12.4 & 1.21 & 4.41 \\
\hline 9 & 40 & 00 & $\mathrm{~N}$ & 0027647 & 09:11 & 10 ,east & $13.5 \mathrm{~A}$ & $\mathrm{~N}$ & 13.4 & & & & & & & & & \\
\hline 1 & 170 & 01 & $\mathrm{~N}$ & 0101349 & 08:38 & 50 ,east & 3.9 & 3.9 & 3.9 & 3.9 & & -0.2 & & -0.2 & -1.2 & 2.7 & 8.41 & 16.81 \\
\hline 2 & 20 & 01 & $\mathrm{~N}$ & 0101714 & 08:31 & 50 ,east & 3.7 & 3.7 & 3.7 & 3.7 & & -0.5 & & -0.5 & -0.4 & 3.3 & 14.44 & 17.64 \\
\hline 2 & 200 & 01 & $\mathrm{~N}$ & 0102226 & 08:45 & 70 ,east & 3.7 & 3.7 & 3.7 & 3.7 & & 2.4 & & 2.4 & -0.5 & 3.2 & 0.64 & 1.69 \\
\hline 8 & 120 & 01 & $\mathrm{~N}$ & 0105773 & 08:03 & 80, west & 16.5 & 16.5 & 16.5 & 16.5 & 15.4 & & 15.8 & 15.8 & -0.8 & 15.7 & 0.01 & 0.49 \\
\hline 9 & 60 & 01 & $\mathrm{~N}$ & 0106342 & 08:07 & 100 & 14.5 & \begin{tabular}{|l|}
14.5 \\
\end{tabular} & 14.5 & 14.5 & 10 & 12.2 & & 12.2 & -1.2 & 13.3 & 1.21 & 5.29 \\
\hline 9 & 60 & 01 & $\mathrm{~N}$ & 0106343 & 08:09 & 100 & 14.5 & \begin{tabular}{|l|} 
\\
\end{tabular} & 14.5 & & & & & & & & & \\
\hline 11 & \begin{tabular}{l|l}
7 & 0 \\
\end{tabular} & 01 & $\mathrm{~N}$ & 0107521 & $08: 38$ & 100 & 8.55 & 8.55 & $\mathrm{~N}$ & 8.55 & & 8.8 & & 8.8 & -1.2 & 7.35 & 2.10 & 0.06 \\
\hline 2 & 240 & 02 & $\mathrm{~N}$ & 0109074 & 07:32 & 90, clds & 3 & & $\mathrm{~N}$ & 3 & & 3.4 & & 3.4 & -0.4 & 2.6 & 0.64 & 0.16 \\
\hline 2 & 240 & 02 & $\mathrm{~N}$ & 0109075 & 07:34 & 90, clds & 3 & 3 & $\mathrm{~N}$ & & & & & & & & & \\
\hline 2 & 260 & 02 & $\mathrm{~N}$ & 0109242 & 07:32 & 100 & 3 & & $\mathrm{~N}$ & 3 & & 2.3 & & 2.3 & -0.6 & 2.4 & 0.01 & 0.49 \\
\hline 2 & \begin{tabular}{l|l}
26 & 0 \\
\end{tabular} & 02 & $\mathrm{~N}$ & 0109243 & 07:34 & 100 & & & $\mathrm{~N}$ & & & & & & & & & \\
\hline & & & & & & & & & AV & \begin{tabular}{|l|l|}
9.139 \\
\end{tabular} & & & & 8.28 & & 8.44 & 1.81 & 2.01 \\
\hline
\end{tabular}

Table 5: MTI and ground truth data. Temperatures in ${ }^{\circ} \mathrm{C}$.
IM\#
Time
$\%$,loc
$\mathrm{T}$ Pr
SBE
Mini
Bulk
SCA1
SCA2
$\mathrm{SCA} 3$
SCA2/SCA3
MTI image number
Image time, GMT
Percent of lake covered by image and sector imaged, if less than $100 \%$.
$\mathrm{Skn}+\mathrm{Wrm}$
OSU T Probe temperature
OSU Seabird (SBE 99) sensor
Hugrun-mini temperature
Bulk-skin+wrm Ground truth temperature corrected for skin depression and warm (cold) layer.
$\begin{array}{ll}\text { RMS skin+wrm } & \text { Squared difference between SCA2/SCA3 and bulk-skin+warm temperature. } \\ \text { RMS bulk } & \text { Squared difference between SCA2/SCA3 and bulk temperatures. }\end{array}$
RMS bulk
Ground truth temperature used for comparison with MTI (Mini or T Probe).
MTI robust temperature retrieval from SCA1 at the OSU buoy
MTI robust temperature retrieval from SCA2 at the OSU buoy
MTI robust temperature retrieval from SCA3 at the OSU buoy
Either SCA2 or SCA3 temperature
Warm/cold layer adjustment to the bulk temperature 


\begin{tabular}{|r|r|r|l|l|l|l|r|r|r|r|r|r|r|r|r|}
\hline Mo & Dy & $Y r$ & D/N & Tim & IR dwn IR up & T air & RH & bulk & speed & lstar & Hs & HI & delta & skin \\
\hline 6 & 16 & 00 & $\mathrm{D}$ & $20: 23$ & 160 & 330 & 9.5 & 60 & 5.5 & 9 & 0.35 & -63 & 40 & 0.7 & 0.2 \\
\hline 6 & 17 & 00 & $\mathrm{D}$ & $20: 32$ & 160 & 331 & 11 & 55 & 6.5 & 1.5 & 0.05 & -11 & 6 & 3.6 & 1.1 \\
\hline 6 & 28 & 00 & $\mathrm{D}$ & $20: 28$ & 160 & 361 & 17.5 & 60 & 12.5 & 0.6 & 0.02 & -7 & 25 & 2.5 & 0.9 \\
\hline 8 & 13 & 00 & $\mathrm{D}$ & $20: 20$ & 160 & 382 & 15 & 45 & 16.1 & 4.5 & 0.16 & 4 & 133 & 1.1 & 0.7 \\
\hline 8 & 25 & 00 & $\mathrm{D}$ & $20: 18$ & 160 & 379 & 12 & 48 & 15.7 & 5 & 0.19 & 30 & 161 & 0.9 & 0.7 \\
\hline 9 & 4 & 00 & $\mathrm{~N}$ & $09: 10$ & 160 & 366 & 3 & 88 & 13.45 & 3 & 0.13 & 70 & 90 & 1.4 & 0.9 \\
\hline 9 & 18 & 00 & $\mathrm{D}$ & $20: 11$ & 160 & & & & 15.1 & & & & & & 1.2 \\
\hline 1 & 17 & 01 & $\mathrm{~N}$ & $8: 38$ & 140 & 318 & -1.5 & 57 & 3.9 & 1.2 & 0.05 & 16 & 24 & 3.2 & 1.2 \\
\hline 2 & 2 & 01 & $\mathrm{~N}$ & $8: 31$ & 140 & 321 & -0.5 & 90 & 3.7 & 7 & 0.28 & 50 & 51 & 0.9 & 0.4 \\
\hline 2 & 20 & 01 & $\mathrm{~N}$ & $8: 45$ & 140 & 320 & -1.5 & 91 & 3.7 & 7 & 0.28 & 64 & 58 & 0.9 & 0.5 \\
\hline 5 & 3 & 01 & $\mathrm{D}$ & $19: 30$ & 170 & 326 & 5 & 45 & 4.1 & 2.5 & 0.06 & -6 & 16 & 3.5 & 1.1 \\
\hline 5 & 25 & 01 & $\mathrm{D}$ & $19: 36$ & 170 & 349 & 14 & 70 & 10 & 1 & 0.03 & -8 & 1 & 2.8 & 0.9 \\
\hline 8 & 12 & 01 & $\mathrm{~N}$ & $08: 03$ & 170 & 385 & 15.5 & 80 & 16.5 & 0.5 & 0.03 & -1 & 11 & 2 & 0.8 \\
\hline 9 & 6 & 01 & $\mathrm{~N}$ & $08: 07$ & 160 & 371 & 4 & 75 & 14.5 & 2 & 0.09 & 56 & 86 & 1.6 & 1 \\
\hline 11 & 7 & 01 & $\mathrm{~N}$ & $08: 38$ & 155 & 342 & 0.5 & 62 & 8.6 & 2.5 & 0.11 & 44 & 62 & 1.9 & 1 \\
\hline 12 & 21 & 01 & $\mathrm{D}$ & $19: 04$ & 140 & 323 & -2 & 85 & 4 & 6 & 0.25 & 105 & 61 & 1.1 & 0.6 \\
\hline 2 & 24 & 02 & $\mathrm{~N}$ & $07: 34$ & 140 & 318 & -1.5 & 90 & 3 & 10 & 0.42 & 81 & 71 & 0.6 & 0.4 \\
\hline 2 & 26 & 02 & $\mathrm{~N}$ & $07: 34$ & 140 & 317 & 0 & 70 & 3 & 5.5 & 0.21 & 25 & 48 & 1.3 & 0.6 \\
\hline
\end{tabular}

Table 6: Variables used in the skin temperature calculation

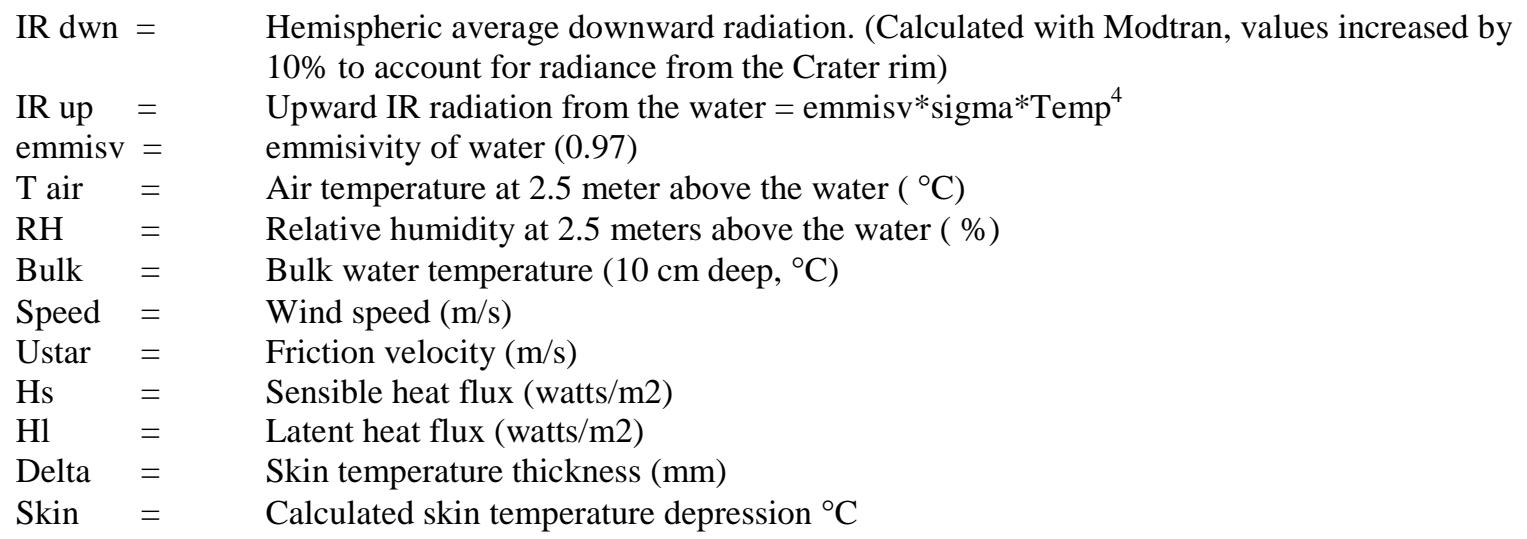




\begin{tabular}{|l|l|l|l|l|l|l|l|l|}
\hline Date & D/N & Sensor & Max & Wind & $\begin{array}{l}\text { Bulk } \\
\text { Adj }\end{array}$ & $\begin{array}{l}\text { Wrm/ } \\
\text { Cld }\end{array}$ & skin & total \\
\hline $6 / 16 / 00$ & D & T Pr & 0 & 9 & 0 & 0 & -0.2 & -0.2 \\
\hline $6 / 17 / 00$ & D & T Pr & 1.5 & 1.5 & 0.3 & 0.1 & -1.1 & -0.7 \\
\hline $6 / 28 / 00$ & D & T Pr & 5.0 & 0.6 & 1.0 & 0.1 & -0.9 & +0.2 \\
\hline $8 / 13 / 00$ & D & Mini & 0 & 4.5 & 0 & 0 & -0.7 & -0.7 \\
\hline $8 / 25 / 00$ & D & Mini & 0.6 & 5 & 0.05 & 0.05 & -0.7 & -0.6 \\
\hline $9 / 4 / 00$ & N & Mini & NA & 3 & 0 & -0.1 & -0.9 & -1.0 \\
\hline $9 / 18 / 00$ & D & Mini & 2.5 & NA & 0.1 & 0.2 & -1.2 & -0.9 \\
\hline $1 / 17 / 01$ & N & Mini & NA & 1.2 & 0 & 0 & -1.2 & -1.2 \\
\hline $2 / 2 / 01$ & N & Mini & NA & 7 & 0 & 0 & -0.5 & -0.4 \\
\hline $2 / 20 / 01$ & N & Mini & NA & 7 & 0 & 0 & -0.5 & -0.5 \\
\hline $5 / 3 / 01$ & D & Mini & 0.5 & 2.5 & 0 & 0.05 & -1.1 & -1.0 \\
\hline $5 / 25 / 01$ & D & Mini & 2.0 & 1 & 0.1 & 0.15 & -0.9 & -0.7 \\
\hline $8 / 12 / 01$ & N & T Pr & NA & 0.5 & 0 & 0 & -0.8 & -0.8 \\
\hline $9 / 6 / 01$ & N & T Pr & NA & 2 & 0 & -0.2 & -1.0 & -1.2 \\
\hline $11 / 7 / 01$ & N & T Pr & NA & 2.5 & 0 & -0.2 & -1.0 & -1.2 \\
\hline $12 / 21 / 01$ & D & T Pr & 0 & 6 & 0 & 0 & -0.6 & -0.6 \\
\hline $2 / 24 / 02$ & N & T Pr & NA & 10 & 0 & 0 & -0.4 & -0.4 \\
\hline $2 / 26 / 02$ & N & T Pr & NA & 5.5 & 0 & 0 & -0.6 & -0.6 \\
\hline
\end{tabular}

Table 7: Summary of adjustments to the bulk temperature to determine the surface temperature

Daytime adjustments

Bulk adjustment $($ T Probe $)=0.20 \times$ Max

Bulk adjustmnet(Mini) $\quad=0.05 \times$ Max

Wrm adjustment
Nighttime adjustments, Fall season only

Cool adjustment $(\mathrm{T}$ Probe $)=-0.2 \mathrm{C}$

Cool adjustment(Mini) $\quad=-0.1 \mathrm{C}$

Max $=$ Daytime temperature maximum $\left({ }^{\circ} \mathrm{C}\right)$

Wind $\quad=$ wind speed $(\mathrm{m} / \mathrm{s})$

Bulk Adj $\quad=$ adjustment to the bulk temperature $\left({ }^{\circ} \mathrm{C}\right)$

$\mathrm{Wrm} / \mathrm{Cld}=$ adjustment to the layer between $10 \mathrm{~cm}$ and the surface $\left({ }^{\circ} \mathrm{C}\right)$

Skin $\quad=$ skin temperature depression $\left({ }^{\circ} \mathrm{C}\right)$

total $=$ total adjustment to the bulk temperature $\left({ }^{\circ} \mathrm{C}\right)$ 


\begin{tabular}{|c|c|c|c|c|c|c|c|c|c|c|c|}
\hline Date & $\mathrm{D} / \mathrm{N}$ & Senso & Sensor & Bulk & $\mathrm{W} / \mathrm{C}$ & Skin & Grad & Wind & $\mathrm{dP}$ & $S p$ & Total \\
\hline & & & Uncer & Uncer & Uncer & Uncer & $\mathrm{C} / \mathrm{km}$ & & & Uncer & \\
\hline $6 / 16 / 00$ & $\mathrm{D}$ & $\mathrm{TPr}$ & 0.1 & 0.1 & 0.1 & 0.1 & 0.5 & 9 & 457 & 0.2 & 0.30 \\
\hline $6 / 17 / 00$ & $\bar{D}$ & $\mathrm{TPr}$ & 0.1 & 0.3 & 0.1 & 0.4 & 2 & 1.5 & 108 & 0.2 & 0.56 \\
\hline $6 / 28 / 00$ & $\bar{D}$ & $\mathrm{TPr}$ & 0.1 & 0.5 & 0.1 & 0.3 & 2 & 1.5 & 108 & 0.2 & 0.64 \\
\hline $8 / 13 / 00$ & $\bar{D}$ & Mini & 0.1 & 0.1 & 0.1 & 0.3 & 0.5 & 4.5 & 238 & 0.1 & 0.37 \\
\hline $8 / 25 / 00$ & D & Mini & 0.1 & 0.1 & 0.1 & 0.2 & 0.4 & 5 & 262 & 0.1 & 0.28 \\
\hline $9 / 4 / 00$ & $\bar{N}$ & Mini & 0.1 & 0.1 & 0.1 & 0.3 & 0.5 & 3 & 500 & 0.3 & 0.43 \\
\hline $9 / 18 / 00$ & $\bar{D}$ & Mini & 0.1 & 0.2 & 0.1 & 0.4 & 0.5 & 1 & 93 & 0.0 & 0.47 \\
\hline $1 / 17 / 01$ & $\bar{N}$ & Mini & 0.1 & 0.1 & 0.1 & 0.4 & 0.5 & 1.2 & 500 & 0.3 & 0.50 \\
\hline $2 / 2 / 01$ & $\bar{N}$ & Mini & 0.1 & 0.1 & 0.1 & 0.1 & 0.5 & 7 & 1000 & 0.5 & 0.54 \\
\hline $2 / 20 / 01$ & $\bar{N}$ & Mini & 0.1 & 0.1 & 0.1 & 0.1 & 0.5 & 7 & 359 & 0.2 & 0.27 \\
\hline $5 / 3 / 01$ & $\mathrm{D}$ & Mini & 0.1 & 0.1 & 0.1 & 0.4 & 0.5 & 2.5 & 147 & 0.1 & 0.44 \\
\hline $5 / 25 / 01$ & $\mathrm{D}$ & Mini & 0.1 & 0.2 & 0.1 & 0.3 & 2 & 1 & 93 & 0.2 & 0.43 \\
\hline $8 / 12 / 01$ & $\bar{N}$ & $\mathrm{TPr}$ & 0.1 & 0.1 & 0.1 & 0.3 & 2 & 0.5 & 500 & 1.0 & 1.06 \\
\hline $9 / 6 / 01$ & $\mathrm{~N}$ & $\mathrm{TPr}$ & 0.1 & 0.1 & 0.1 & 0.4 & 1 & 2 & 500 & 0.5 & 0.66 \\
\hline $11 / 7 / 01$ & $\mathrm{~N}$ & $\mathrm{TPr}$ & 0.1 & 0.1 & 0.1 & 0.3 & 0.5 & 2.5 & 147 & 0.1 & 0.35 \\
\hline $12 / 21 / 01$ & $\bar{D}$ & $\mathrm{TPr}$ & 0.1 & 0.1 & 0.1 & 0.2 & 0.5 & 6 & 500 & 0.3 & 0.36 \\
\hline $2 / 24 / 02$ & $\bar{N}$ & $\mathrm{TPr}$ & 0.1 & 0.1 & 0.1 & 0.1 & 1 & 10 & 506 & 0.5 & 0.54 \\
\hline $2 / 26 / 02$ & $\bar{N}$ & $\mathrm{TPr}$ & 0.1 & 0.1 & 0.1 & 0.4 & 1 & 1.5 & 108 & 0.1 & 0.45 \\
\hline
\end{tabular}

Table 8: Uncertainty in the ground truth data, in deg C. The entries in bold face were chosen based on the discussion in Section 4.

Sensor Uncer $=$ Uncertainty in the T Probe or Seamon Mini

Bulk Uncer = Uncertainty in the bulk $(10 \mathrm{~cm})$ temperature. (greater of $20 \%$ of the daytime T Probe maximum, or 0.1C: See Section 4.1)

$\mathrm{W} / \mathrm{C}$ Uncer = Unceratainty in the warm/cold layer.

Skin Uncer $=$ Uncertainty in the skin temperature depression $=0.3 \mathrm{x}$ skin depression

Grad $\mathrm{C} / \mathrm{km}=$ Gradient of temperature near the OSU buoy at image time $(\mathrm{C} / \mathrm{km})$.

Wind $\quad=$ Wind speed $(\mathrm{m} / \mathrm{s})$

$\mathrm{dP} \quad=$ Uncertainty in the buoy position $(\mathrm{m})$

Sp Uncer $\quad=$ Spatial Uncertainty

Total $\quad=$ Total uncertainty 


\subsection{Uncertainty analysis}

The uncertainly in the observed surface water temperature near the OSU buoy is strongly dependent on the wind speed and solar heating. As discussed in Section 3.3, a useful measure of these effects is the daytime maximum in the bulk temperature. This variable will be used for both the temporal and buoy-related uncertainty

Sensor accuracy: As noted in Section 3.1 and 3.2, both the Seamon-Mini and the T Probe have an absolute accuracy of $0.1 \mathrm{C}$.

Bulk water correction: The OSU T Probe can differ from the instantaneous open water bulk water temperature because of buoy effects and temporal averaging. This uncertainty can be estimated by calculating the standard deviation of the Seamon Mini 15-minute temperatures with respect to one-hour averages and relating this to the daytime maximum. Analysis of July 2000 data indicates that the standard deviation was $\sim 20 \%$ of the diurnal maximum. This relationship was assumed for the uncertainty in daytime $\mathrm{T}$ Probe values. For all other times, an uncertainty of $0.1 \mathrm{C}$ was assumed for both the Mini and $\mathrm{T}$ Probe.

Warm/cold layer formation: The warm layer correction was estimated to be as large as $0.3 \mathrm{C}$ for the Mini and $0.1 \mathrm{C}$ for the $\mathrm{T}$ Probe and nighttime cooling was 0.1 to $0.2 \mathrm{C}$. We estimate this uncertainty to be $0.1 \mathrm{C}$.

Skin temperature: The uncertainty in the skin temperature calculation will increase with the magnitude of the skin depression. The results at Crater Lake on Sept $15 / 16$ indicated a variation of $\sim 0.2 \mathrm{C}$ for a skin depression of $\sim 0.7 \mathrm{C}$. This implies an uncertainty of $30 \%$ of the depression. We will assume this relationship for the other days as well.

Spatial Variability: Spatial variability is caused by uncertainty in locating the buoy in the MTI WST image and because the buoy's location varies with the wind and lake currents. We must also take into account the special cases discussed in Section 4 where the ROI was up to $1 \mathrm{~km}$ away from the buoy. As discussed in Section 4.0, the uncertainty in the buoy location on the MTI image is $20 \mathrm{~m}$. However, the movement of the buoy from the wind speed and current can be as large as 500 meters (personal communication with R. Collier of OSU ). We assume a minimum uncertainty of 50 meters and a wind speed-dependent component of 500 meters for a wind speed of $10 \mathrm{~m} / \mathrm{s}$. The uncertainty in the buoy location is then the square root of the variances of the three components. For cases in Section 4.0, where the ROI was separated from the buoy location, we have used the separation distance as the location uncertainty. The temperature gradient is estimated from Figures $23-40$ and is listed in Table 8.

Spatial var $=(\mathrm{dT} / \mathrm{ds}) * \mathrm{dP}$

where $\mathrm{dP}=\operatorname{sqrt}\left(20^{2}+50^{2}+\left(\mathrm{sp}^{*} 50\right)^{2}\right)$

The uncertainty in the ground truth temperatures for the 18 images varies between $0.3 \mathrm{C}$ and $0.6 \mathrm{C}$, with an average of $0.5 \mathrm{C}$. Note that this uncertainty includes a small component due to errors in locating the buoy on the MTI image, i.e., it is not a ground truth uncertainty.

An average uncertainty of $0.5 \mathrm{C}$ is slightly larger than calculated for Nauru because of the greater spatial and skin variability.

\section{Results}

Table 5 shows the MTI temperatures derived with the robust WST retrieval near the OSU buoy and the corresponding ground truth temperatures at the buoy. The MTI water surface temperatures are compared with the bulk water temperatures (uncorrected) in Fig 44 and with the adjusted values in Fig. 45. The RMS difference between the MTI and the bulk temperature is $2.0 \mathrm{C}$ with an MTI bias of $-0.9 \mathrm{C}$. When the bulk 
water temperatures is corrected for skin and the warm/cold layer, the RMS error and bias are reduced to $1.9 \mathrm{C}$ and $-0.1 \mathrm{C}$, respectively. These results contrast with Nauru where the RMS and bias were $\sim 1.2 \mathrm{C}$ and $\sim 0.7$, respectively.

Figs 44 and 45 show no significant functional dependence of the MTI retrievals on the surface temperature. In addition, the small bias in the MTI temperatures suggests that sub-visible cirrus are much less common at Crater Lake than in the tropics.

Figures 44 and 45 distinguish between day (SCA3) and night (SCA2) results. A daytime positive MTI bias is apparent for both bulk and adjusted buoy temperatures. This may reflect a difference between SCA's 2 and 3 since the daytime results are mainly from SCA 3 and the nighttime results are from SCA2. The Nauru study found a $0.3 \mathrm{C}$ positive bias of SCA3 with respect to SCA2. This accounts for some of the larger RMS in the present study compared with the Nauru results.

Since the estimated error of the ground truth is $0.5 \mathrm{C}$, the RMS attributed only to MTI is $1.7 \mathrm{C}$. This is mainly attributable to three data points, which account for $\sim 60 \%$ of the variance. Two of these points are January 17 and February 2 of 2001, when the MTI temperature (0.2C and $-0.5 \mathrm{C}$, respectively) was $\sim 4 \mathrm{C}$ less than the ground truth. The third point is June 28, 2000 when the MTI temperature was $4 \mathrm{C}$ greater than the ground truth.

The low MTI temperatures on Jan 17 and Feb 2 may be the result of ice on the surface of the lake. According to Robert Collier of OSU, ice can form with light winds but breaks up when the wind increases. The wind speed on the $1 / 17,2 / 2$, and $2 / 20$ at image time was $1.2,7.0$ and $7.0 \mathrm{~m} / \mathrm{sec}$, respectively, which suggests that ice was not present on Feb 2 and Feb 20. Ice is also unlikely on Jan 17 because the wind speed was greater than $4 \mathrm{~m} / \mathrm{s}$ only four hours before the MTI image. Further evidence against ice on the lake is shown in Fig. 46, which shows the water temperatures, air temperature and wind speed for Jan 13 to Feb 5. This figure shows minima in buoy temperatures and good correlation between the air and water temperatures during periods of light winds, when mixing of the top layer of the ocean is weak. This is not consistent with an insulating cover of ice.

A better understanding of the differences between Jan 17/Feb 2 and Feb 20 is possible by comparing the the brightness temperatures of the IR bands for the three nights, shown in Fig 47. Also shown in the figure are the WST's at the OSU buoy (Table 5) and the MTI-derived temperatures. (As shown in Figures 30 and 31, the MTI temperatures on Jan 17 and Feb 2 are actually 1 and $1 / 2 \mathrm{~km}$ west of the buoy, but the temperature gradient on the east side of the lake was small on both days.)

The reason why the Feb 20 MTI retrieval is $2.5 \mathrm{C}$ warmer than on the other days is explained by the brightness temperatures and the robust coefficents shown in Fig. 3. Note that the L and M brightness temperatures on Feb 20 (multiplied by negative coefficients) are significantly smaller than the $\mathrm{N}$ band brightness temperature. This result is in contrast to the Jan 17 and Feb 2, and accounts for the significantly larger inferred temperature.

Differences between the three days can also be seen in the Medford, OR soundings for $12 \mathrm{Z}$ on each day, shown in Figs. 48-50. The Jan 17 and Feb 2 soundings both exhibit Pacific maritime properties with a warm layer between 400 and $700 \mathrm{mb}$ and a cool surface layer. In contrast, the Feb 20 sounding is more characteristic of continental winter air with a much cooler middle troposphere It is also more consistent with the Modtran simulations used to develop the coefficients in the robust algorithm.

Another curious feature of Fig. 47 is the very small temperature difference between the L band brightness temperatures and the adjusted surface temperature on Feb 2 and Feb 20 (0.7-1.0C) which suggests a very high transmissivity for these nights. This may be due to the large skin temperature depressions calculated with Eq 1(-0.5C) despite the brisk $7 \mathrm{~m} / \mathrm{s}$ winds. SRTC experience at other fresh water lakes is consistent with skin depressions of $\sim 0.2 \mathrm{C}$ for comparable winds. Hence, ground truth temperatures of $3.5 \mathrm{C}$ instead of $3.2 \mathrm{C}$ are more likely on these two days, with a corresponding $1 \mathrm{C}$ to $1.3 \mathrm{C}$ difference between the $\mathrm{L}$ band brightness and the surface temperature. 
The other anomalous data point shown in Figs. 45 and 46 is the 16.5C MTI temperature on June 28, 2000, which is 4 degrees warmer than the corrected buoy temperature of $12.5 \mathrm{C}$, and 8 degrees warmer than the MTI temperature on June 17, of 2000. June 28 was an unusual day because of the positive adjustment to the T Probe temperature $(+0.2 \mathrm{C}$, Table 7$)$ and the large uncertainty (Table 8$)$, based on the light winds and 5C daytime maximum in the T Probe temperature. This day is similar to July 9 and 10, 2000 (Fig. 5) where the daytime T Probe maximum was 3.2 and $3.5 \mathrm{C}$, respectively, and the Mini temperature was up to twice as great. Thus, it is possible that the water surface temperature may have been several degrees warmer than the $12.5 \mathrm{C}$ measured at image time by the $\mathrm{T}$ Probe.

We can summarize this discussion by calculating a revised RMS error for the MTI robust WST retrieval. If we assume uncorrelated random errors, the RMS of $1.7 \mathrm{C}$ can be reduced by subtracting the ground truth error $(0.5 \mathrm{C})$ and deleting the June 28,2000 data point which accounts for $30 \%$ of the total variance (Table 6). With these two adjustments the variance due to the MTI alone is reduced to $1.3 \mathrm{C}$, which is slighly greater than found at Nauru. We attribute the greater RMS at Crater Lake to larger atmospheric variability than contained in the Modtran simulations used to calculate the robust coefficients, and also to the small number of pixels that make up the MTI averaging areas at Crater Lake. These small areas are comparable to the width of the MTI bands and result in greater variance in the MTI temperatures than found with the much larger averaging areas used at Nauru.

\section{Acknolwdgements}

The authors thank Robert Collier of Oregon State University for providing data from the OSU Crater Lake buoy, and Mark Buktenica and Scott Girdner of the US National Park Service for installing the Seamon Mini near the OSU buoy. We also thank Bill Clodius of the Los Alamos National Laboratory for information on the robust algorithm and Kim Pollock and Kim Starkevich of LANL for providing the MTI images used in this study.

\section{References}

Atkins, W., S. Bender, W. Christensen, C. Little E. Riddle, 2001. The Multispectral Thermal Imager Calibration. Presented at the MultiSpectral Thermal Imager Symposium, Sandia National Laboratory, March 12-13, 2001.

Fairall, C. W. , E. F. Bradley, J. S. Godfrey, G.A.Wick, J.B. Edson, and G.S. Young. Cool-skin and warmlayer effects on sea surface temperature. J. Geophys. Res., 101,1996, pp 1295-1308.

Fairall, C. W. , E. F. Bradley, J.B. Edson, and G.S. Young. Bulk parameterization of air-sea fluxes for Tropical Ocean-Global atmospheric coupled-ocean atmospheric response experiment. J. Geophys. Res., 101,1996, pp 3747-3764. 


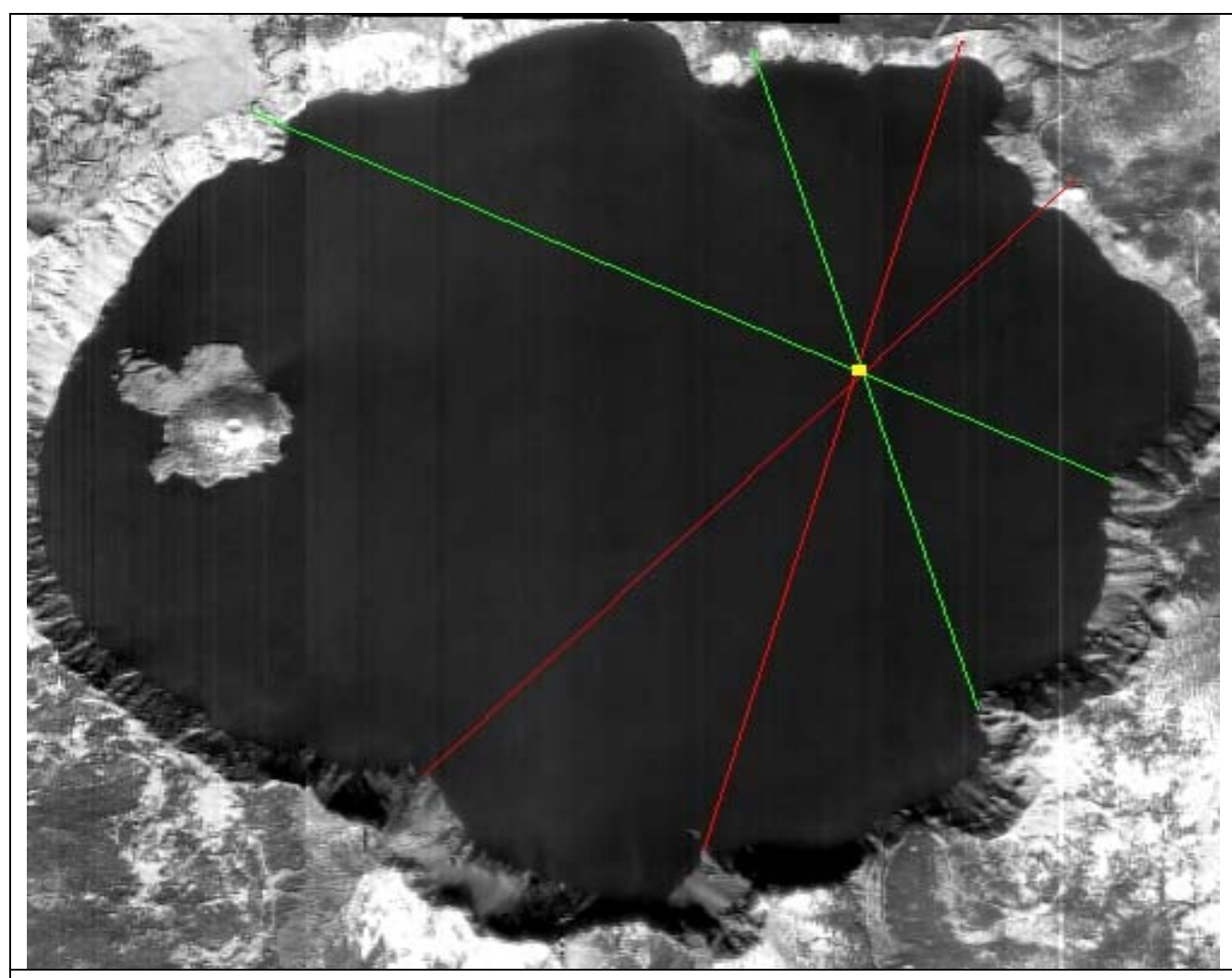

Fig. 1: Crater Lake showing the location of the OSU buoy and landmarks to locate region of interest

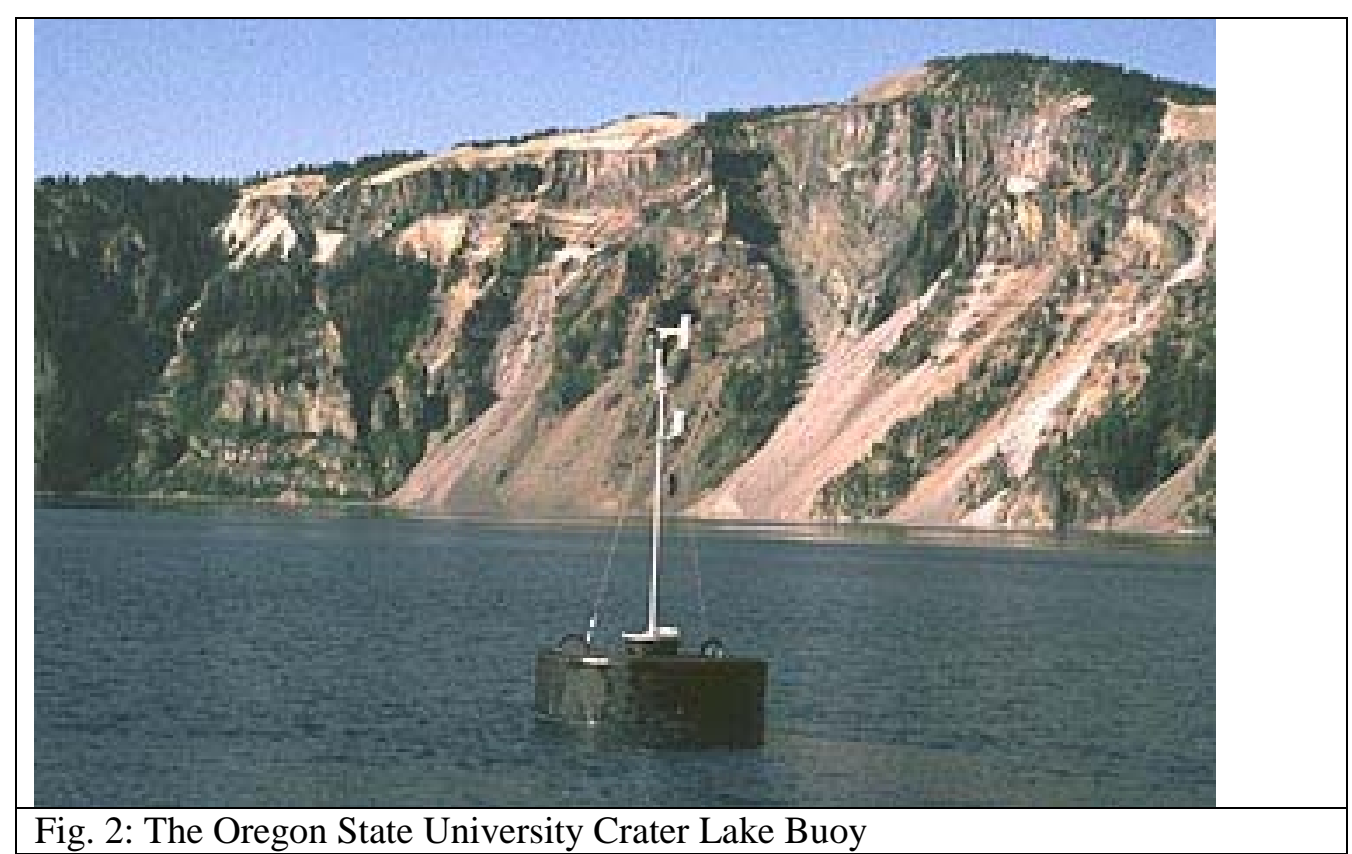




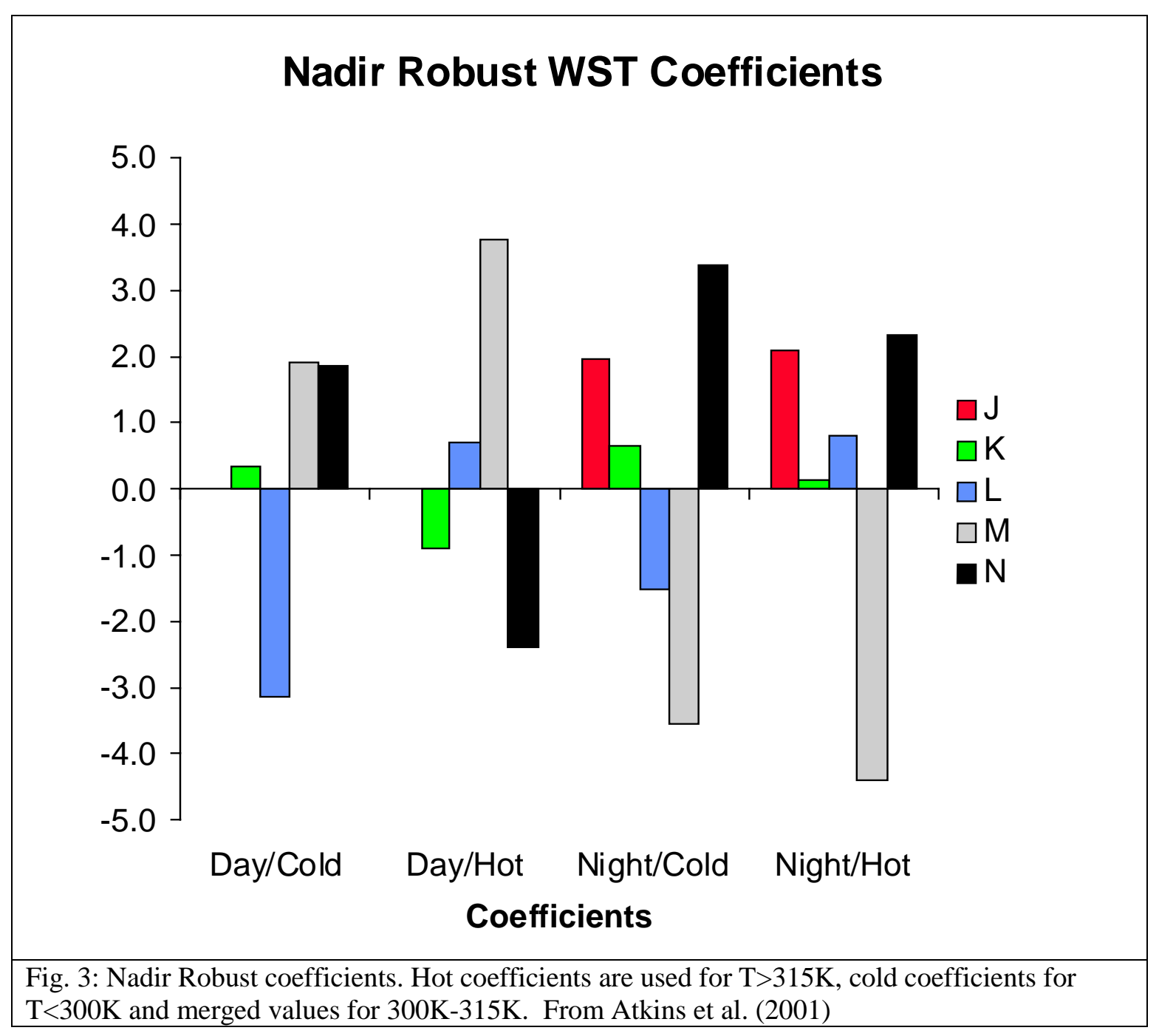




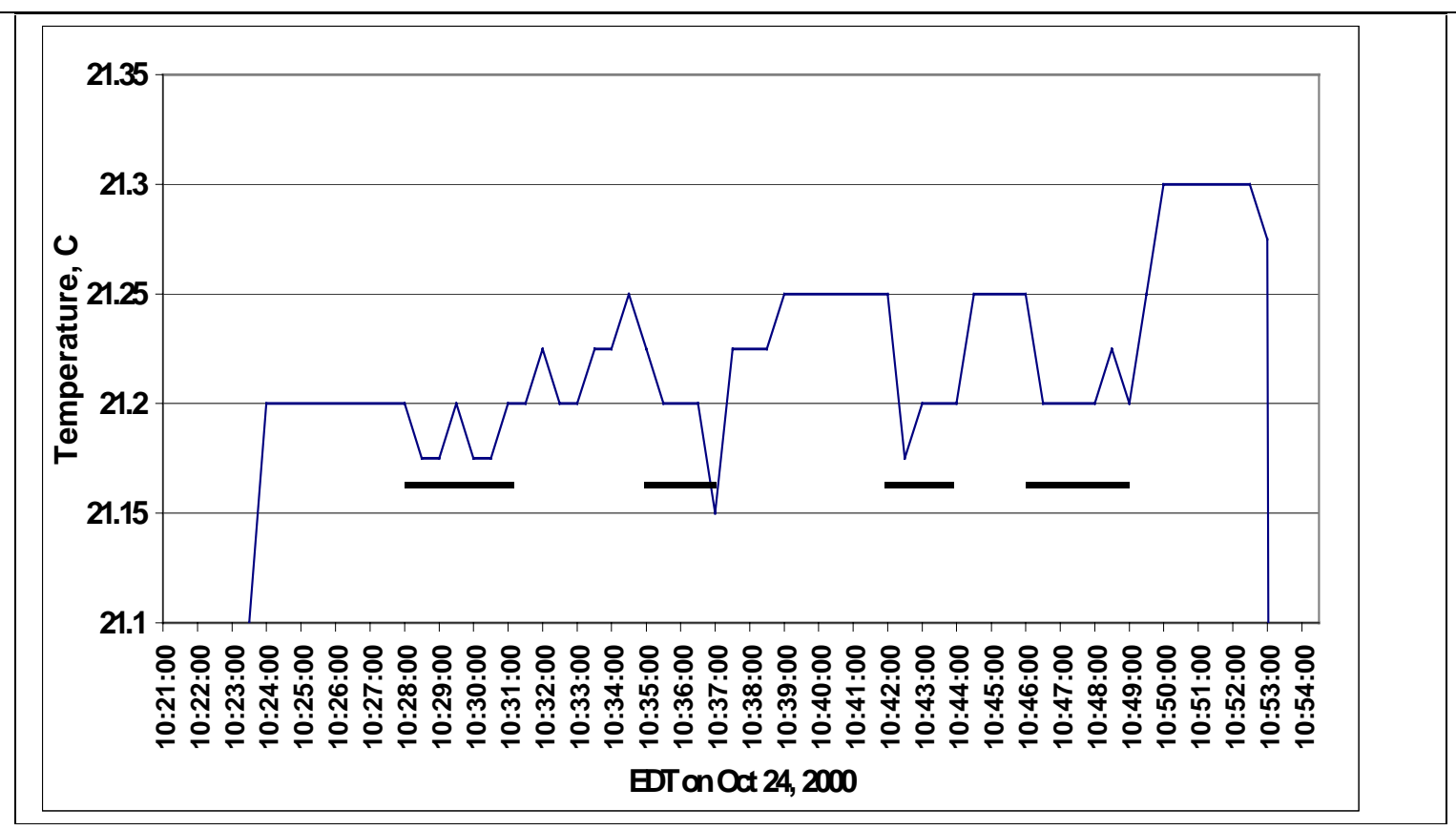

Fig. 4: Seamon Mini temperature at L Lake on Oct 24, 2000 at noon. Periods of sun shading are shown with a heavy solid line.

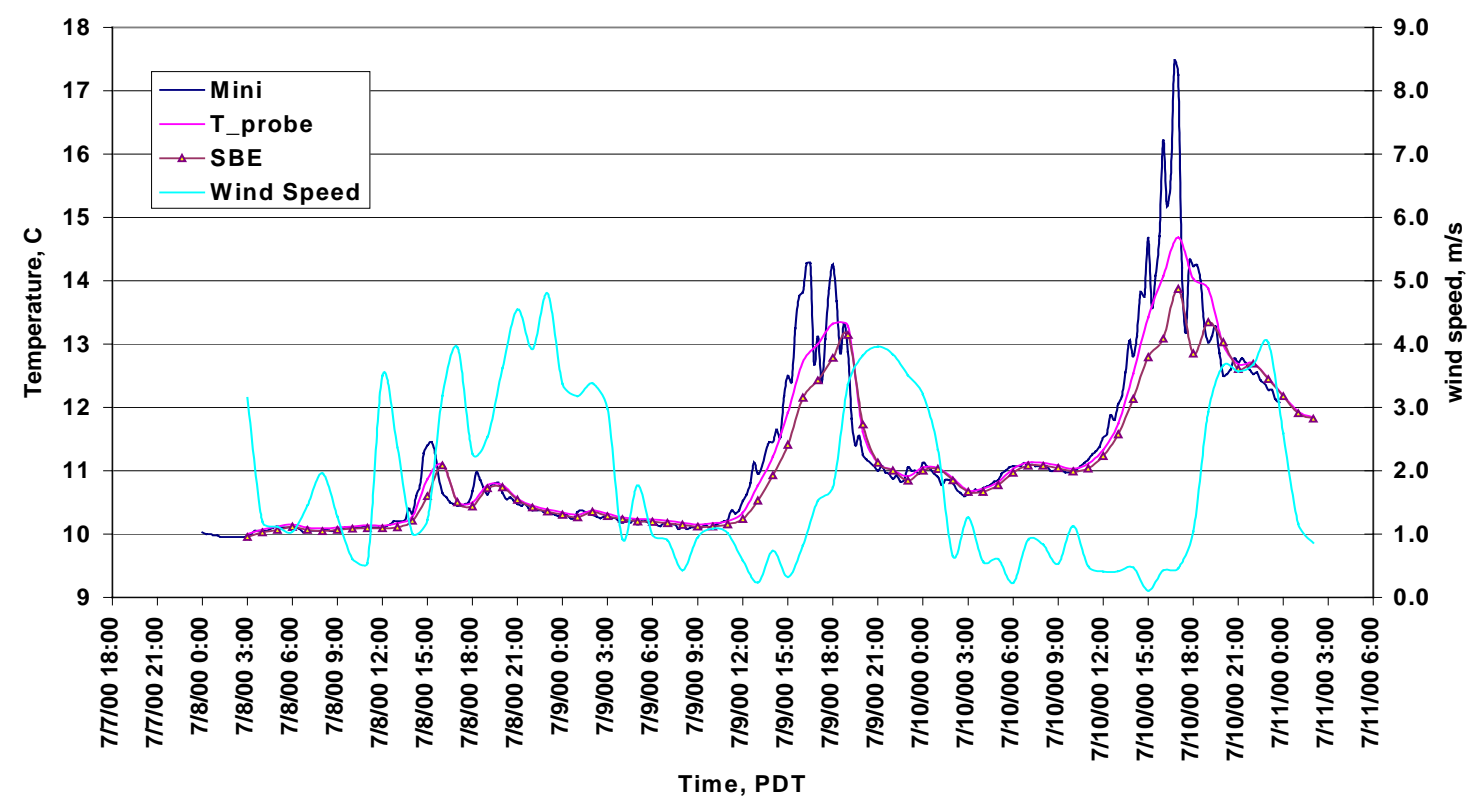

Fig. 5: Water temperatures and wind speed at the OSU buoy on July 7-9, 2000 

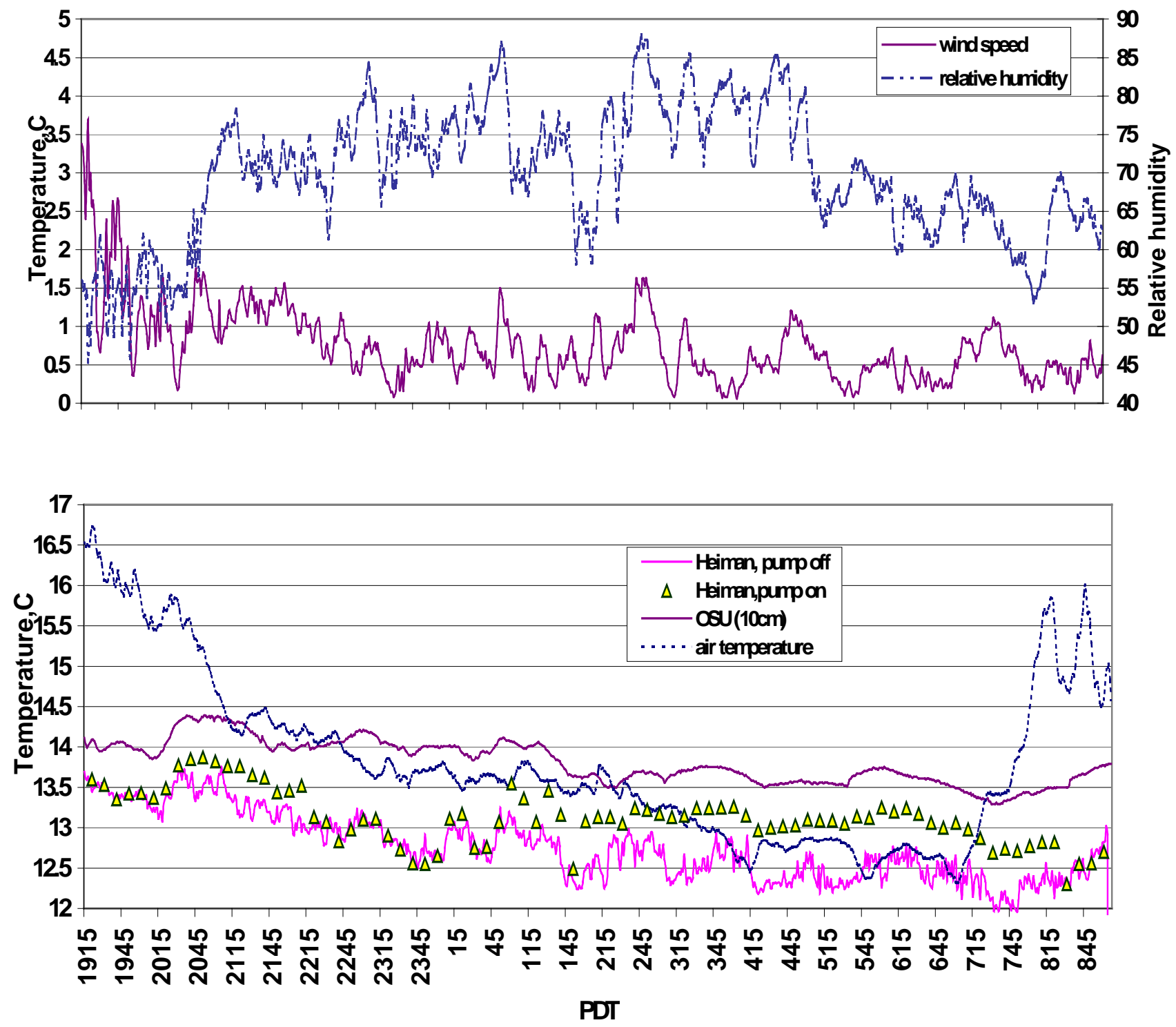

Fig. 6: Data from Sept 15/16, 1999 at Crater Lake 

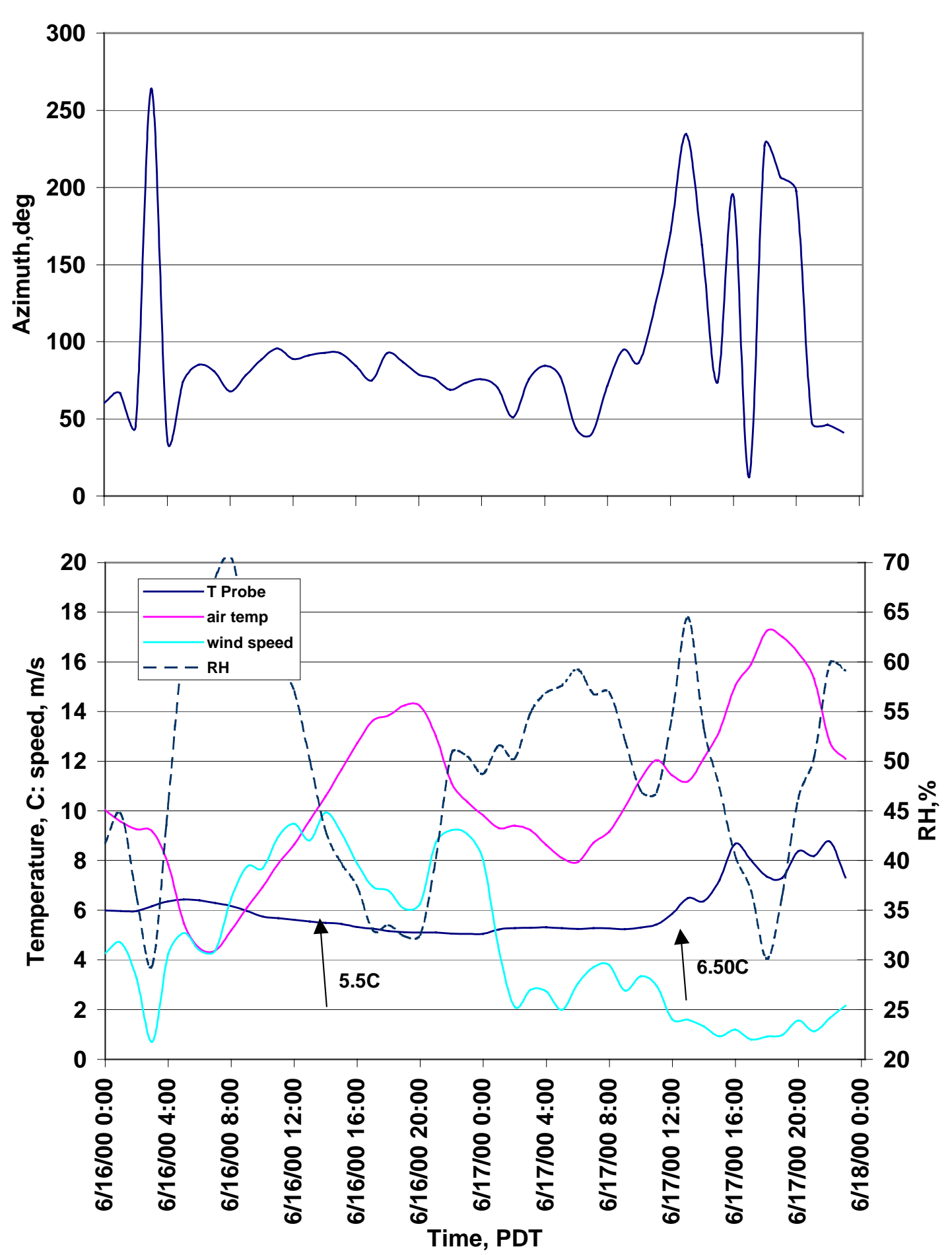

Fig 7: June 16-17, 2000 Crater Lake data. The arrows show the 10-cm water temperature at MTI image time. 


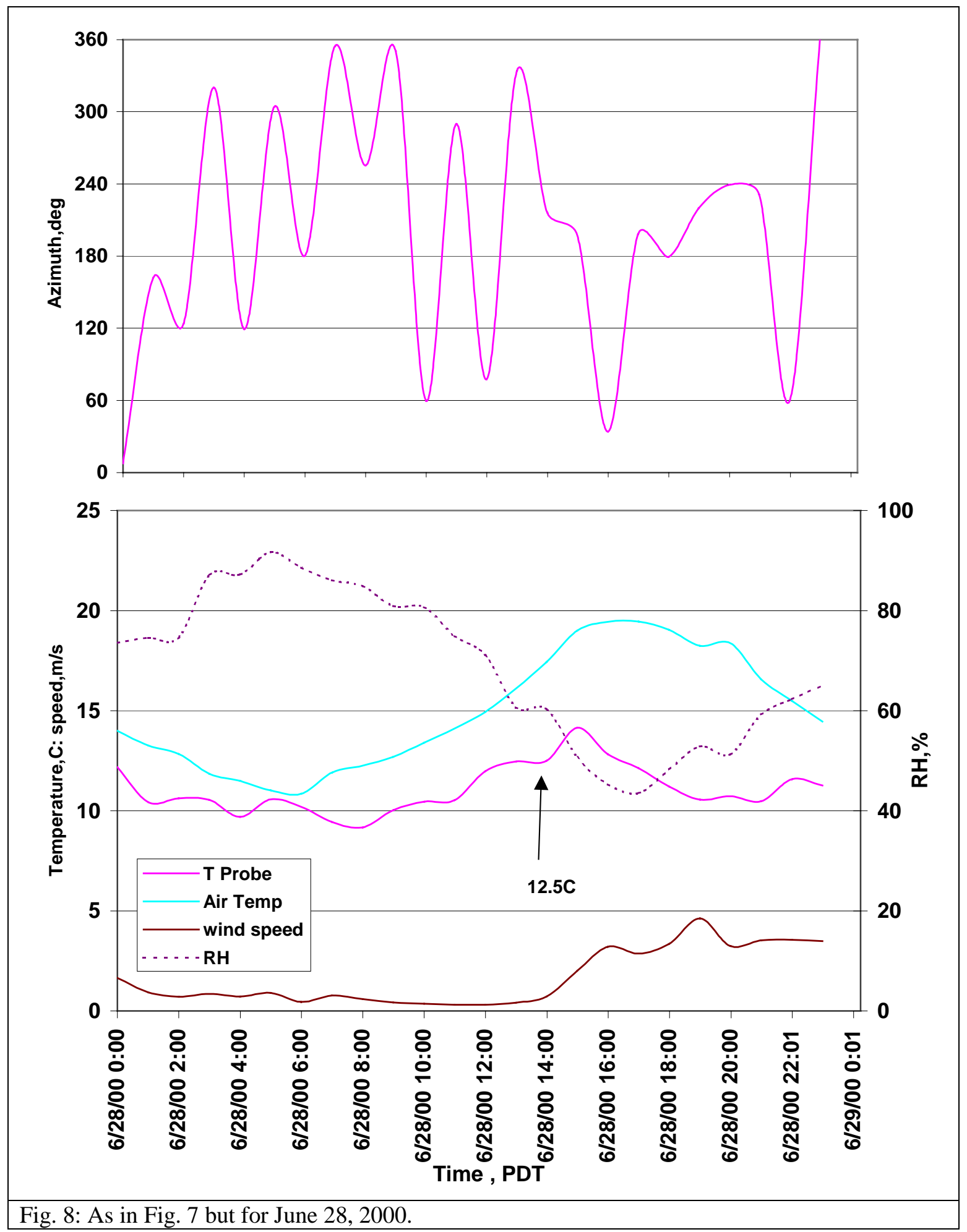



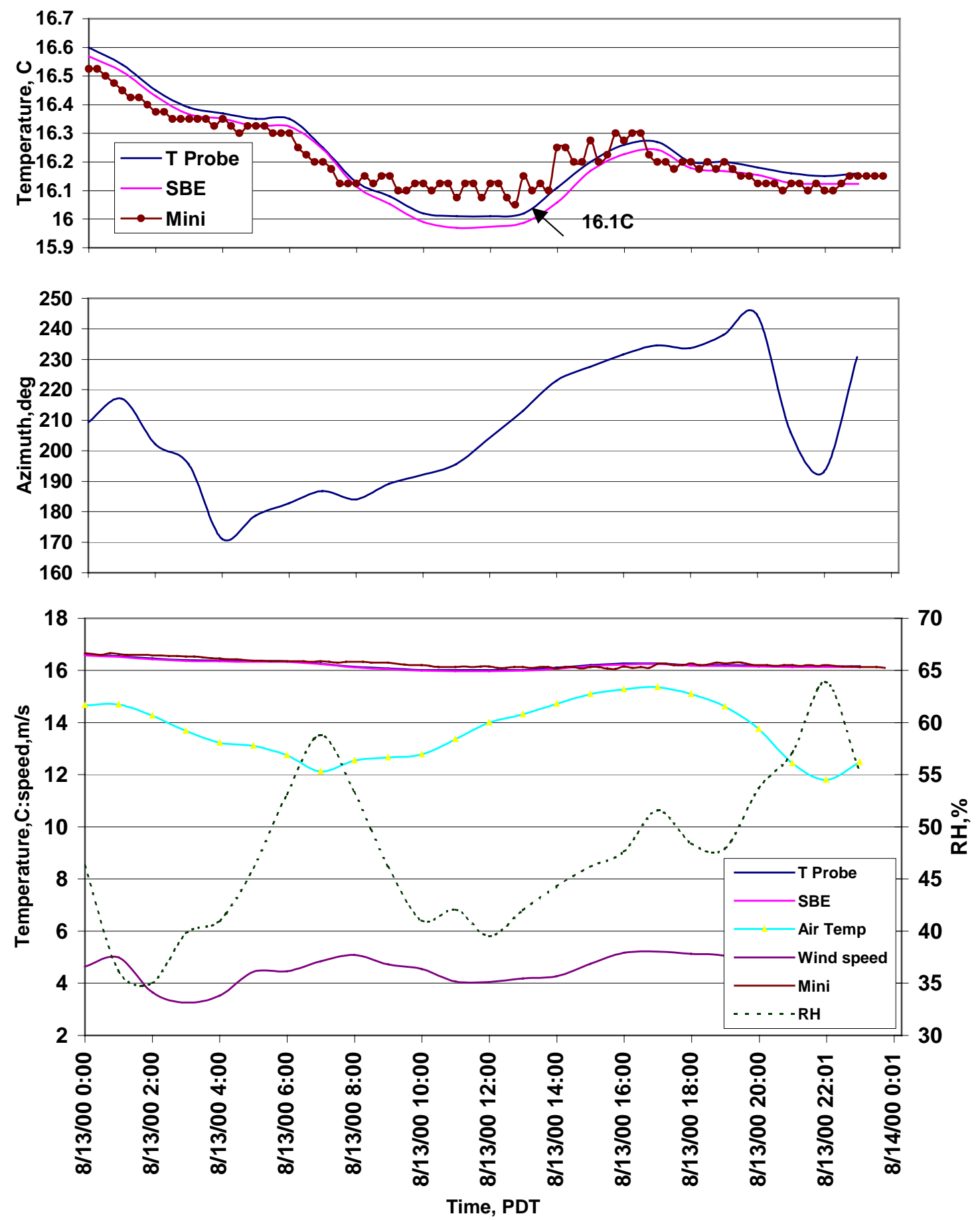

Fig 9: As in Fig. 7 but for Aug 13, 2000. 

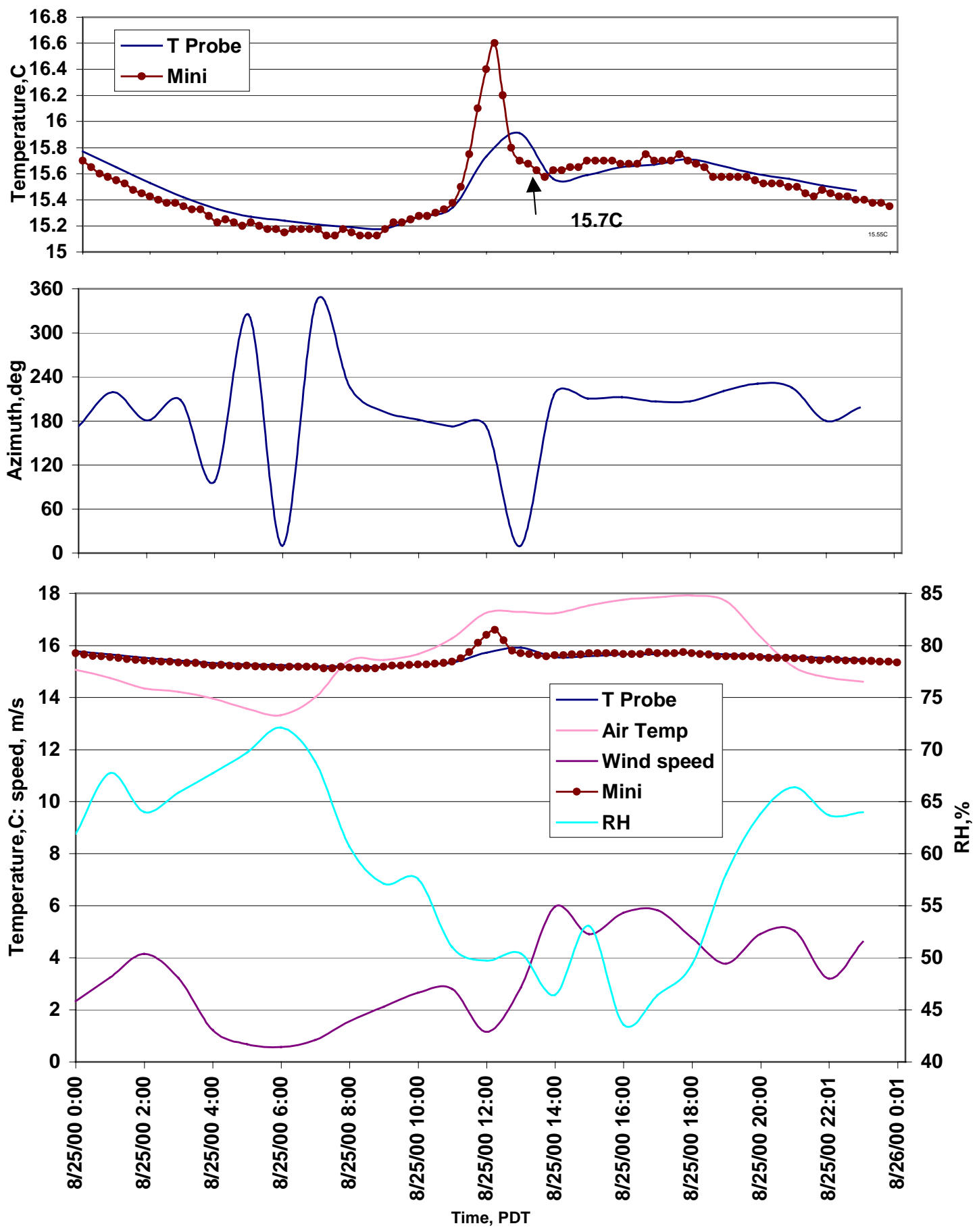

Fig 10: As in Fig. 7 but for Aug 25, 2000. 

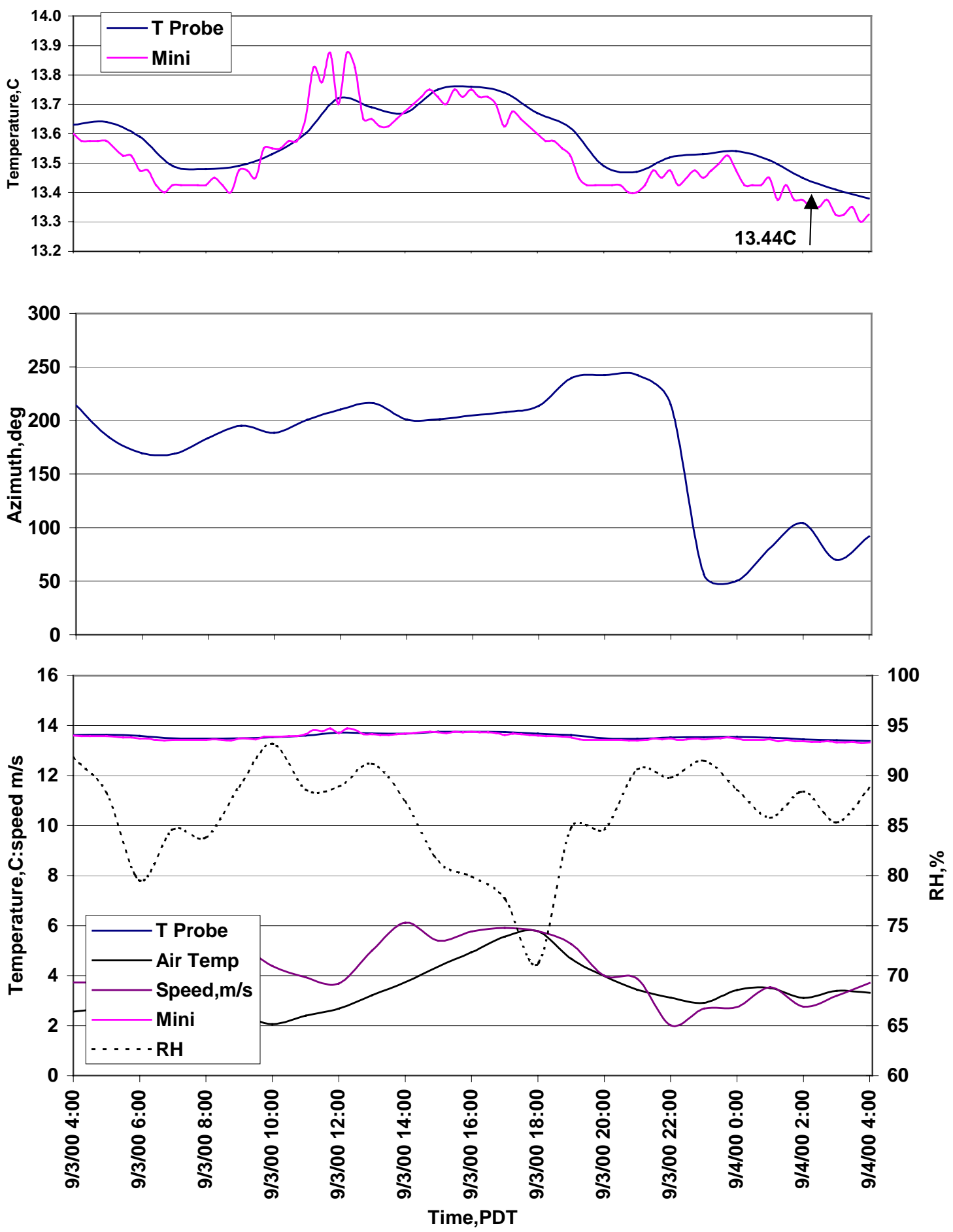

Fig 11: As in Fig. 7 but for Sept 4, 2000. 


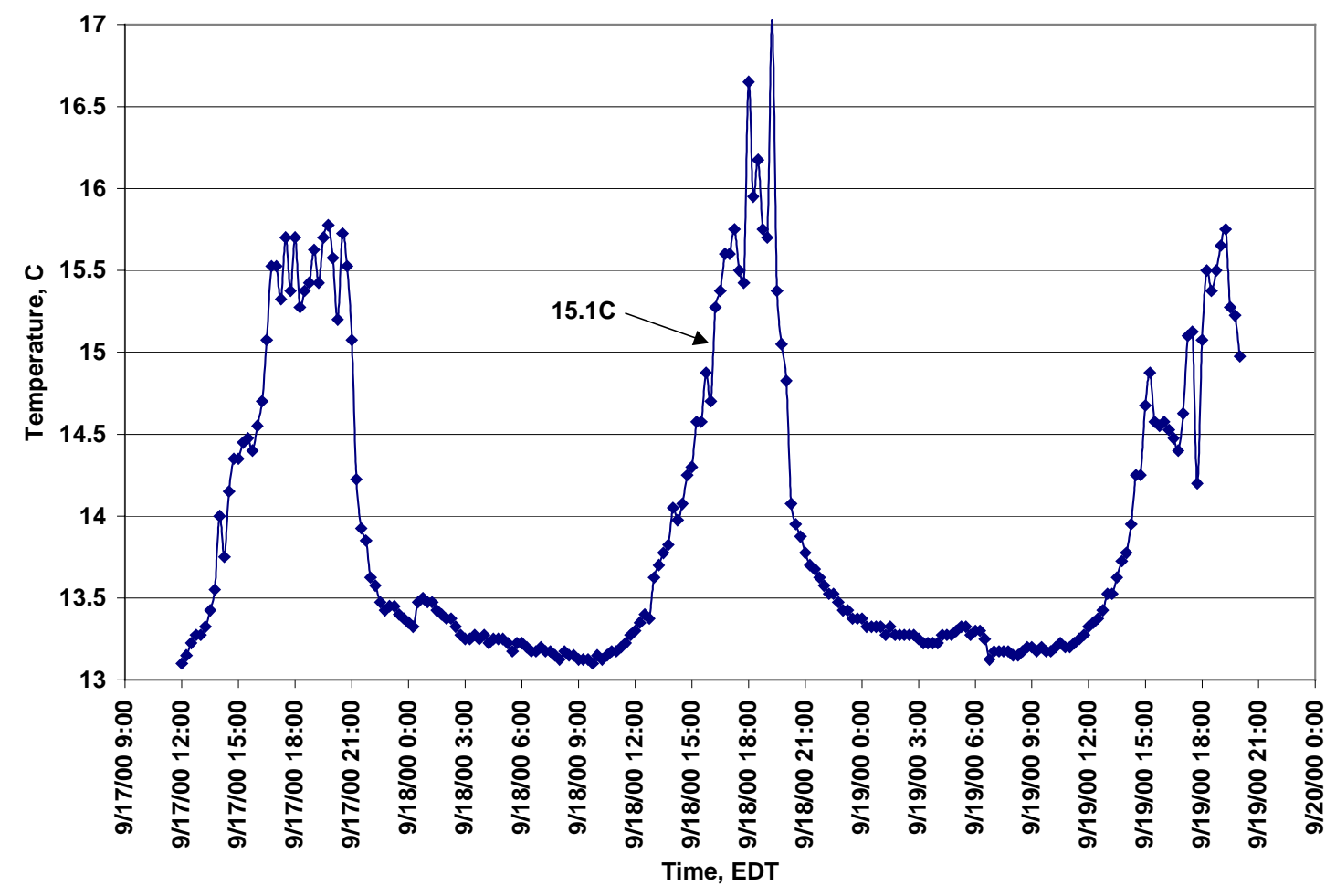

Fig 12: Sept 17-19, 2000 Seamon-Mini water temperature at Crater Lake. 

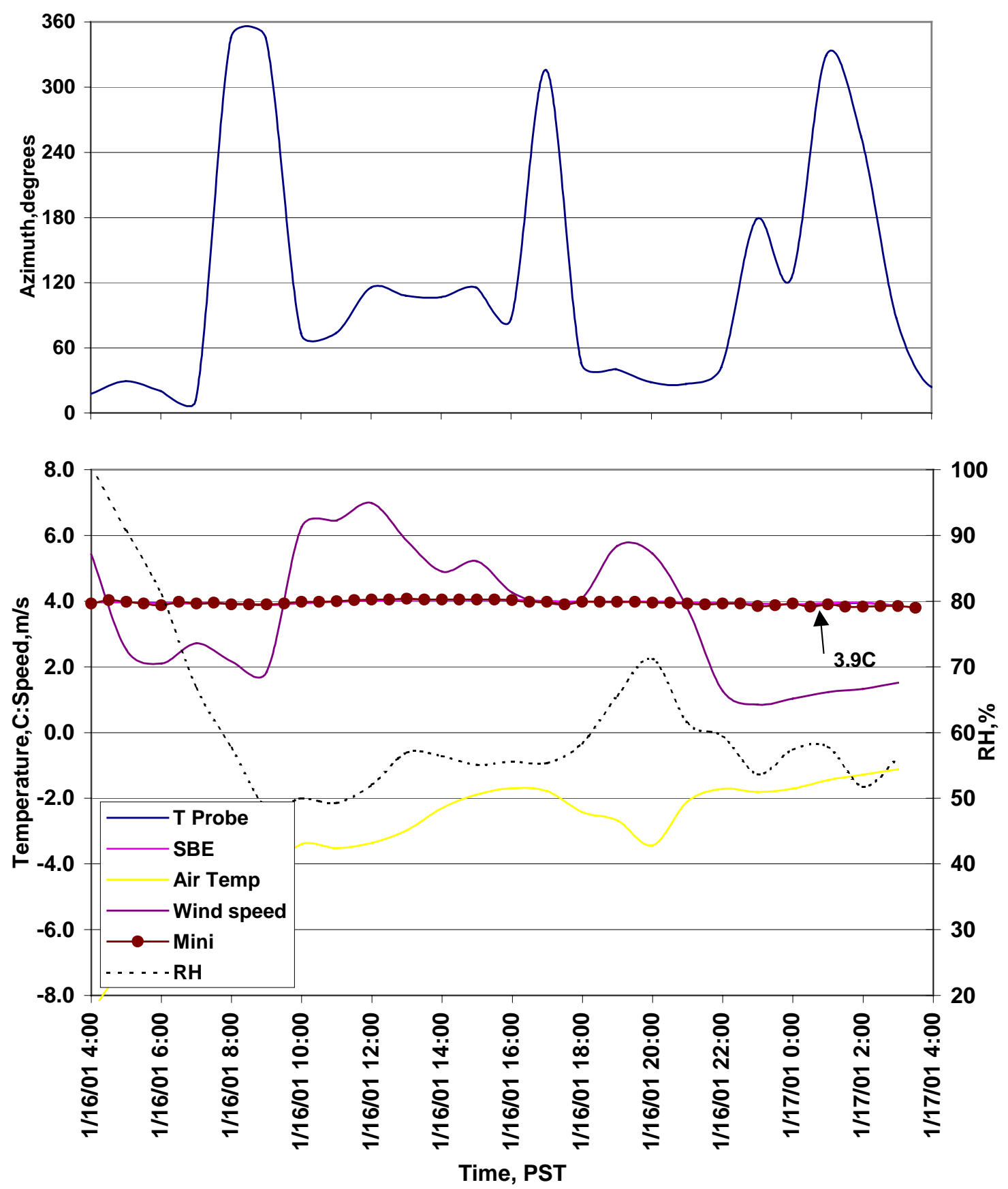

Fig. 13: As in Fig. 7 but for Jan 17, 2001. 

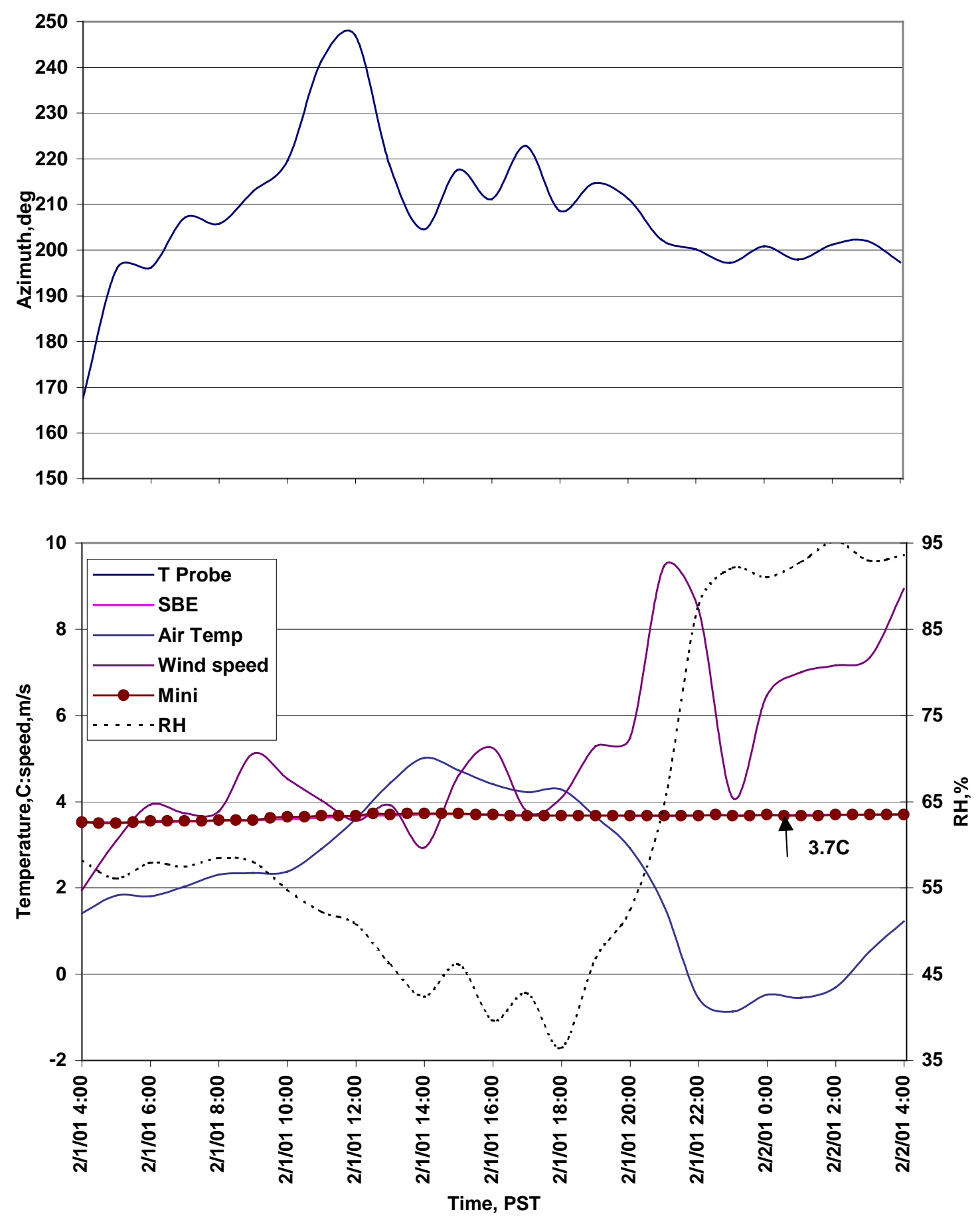

Fig. 14: As in Fig. 7 but for Feb 2, 2001. 


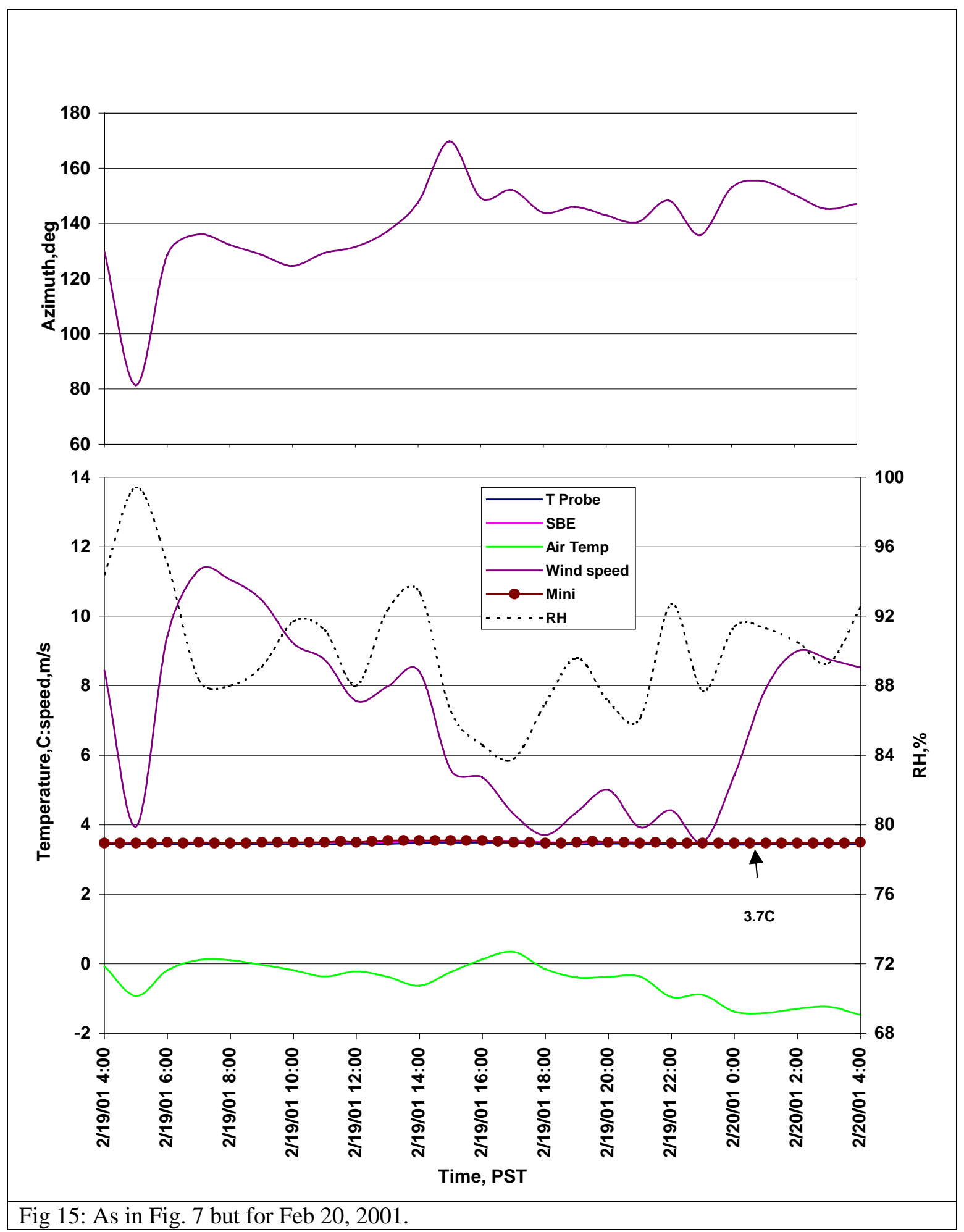



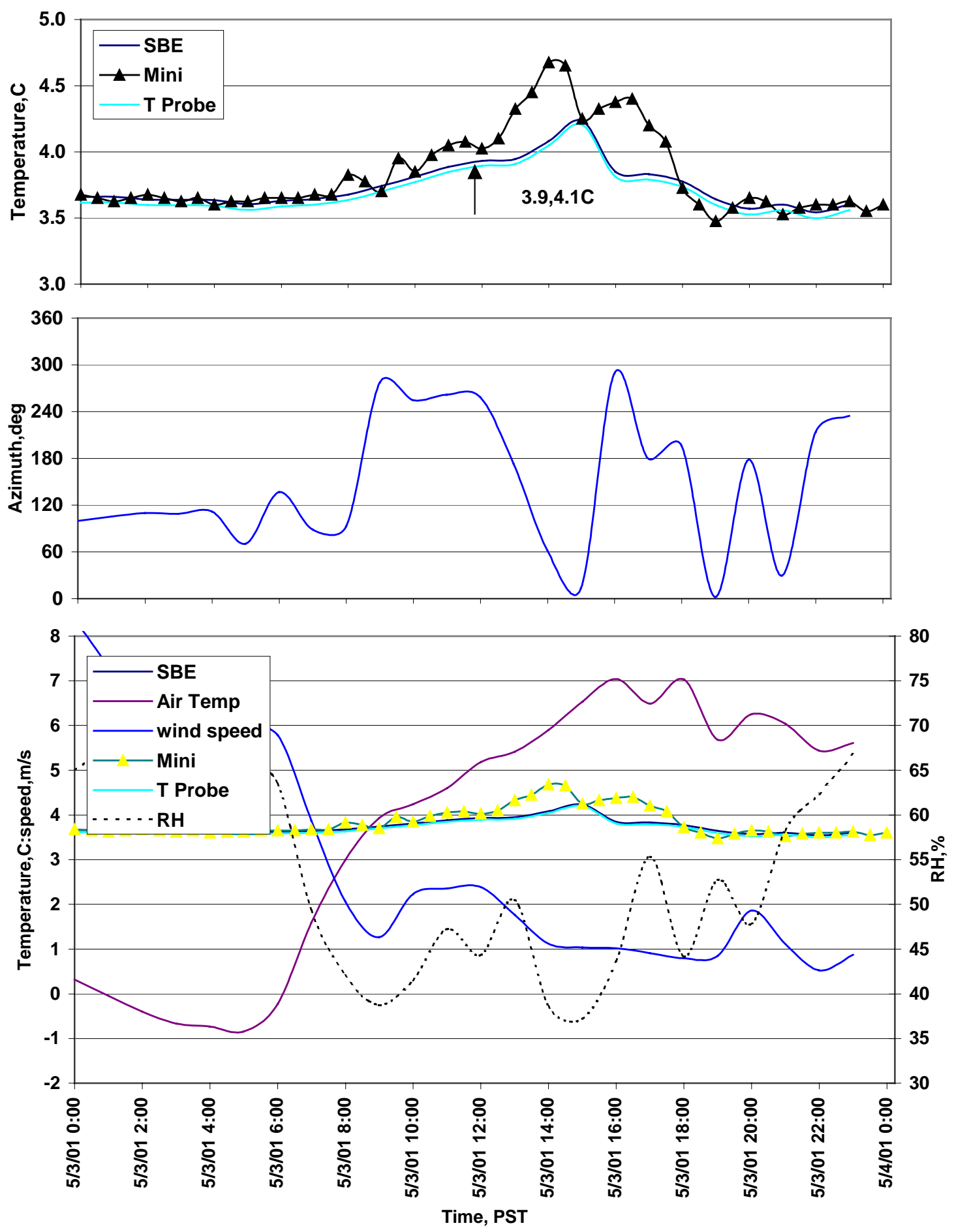

Fig. 16: As in Fig .7 but for May 3, 2001. 

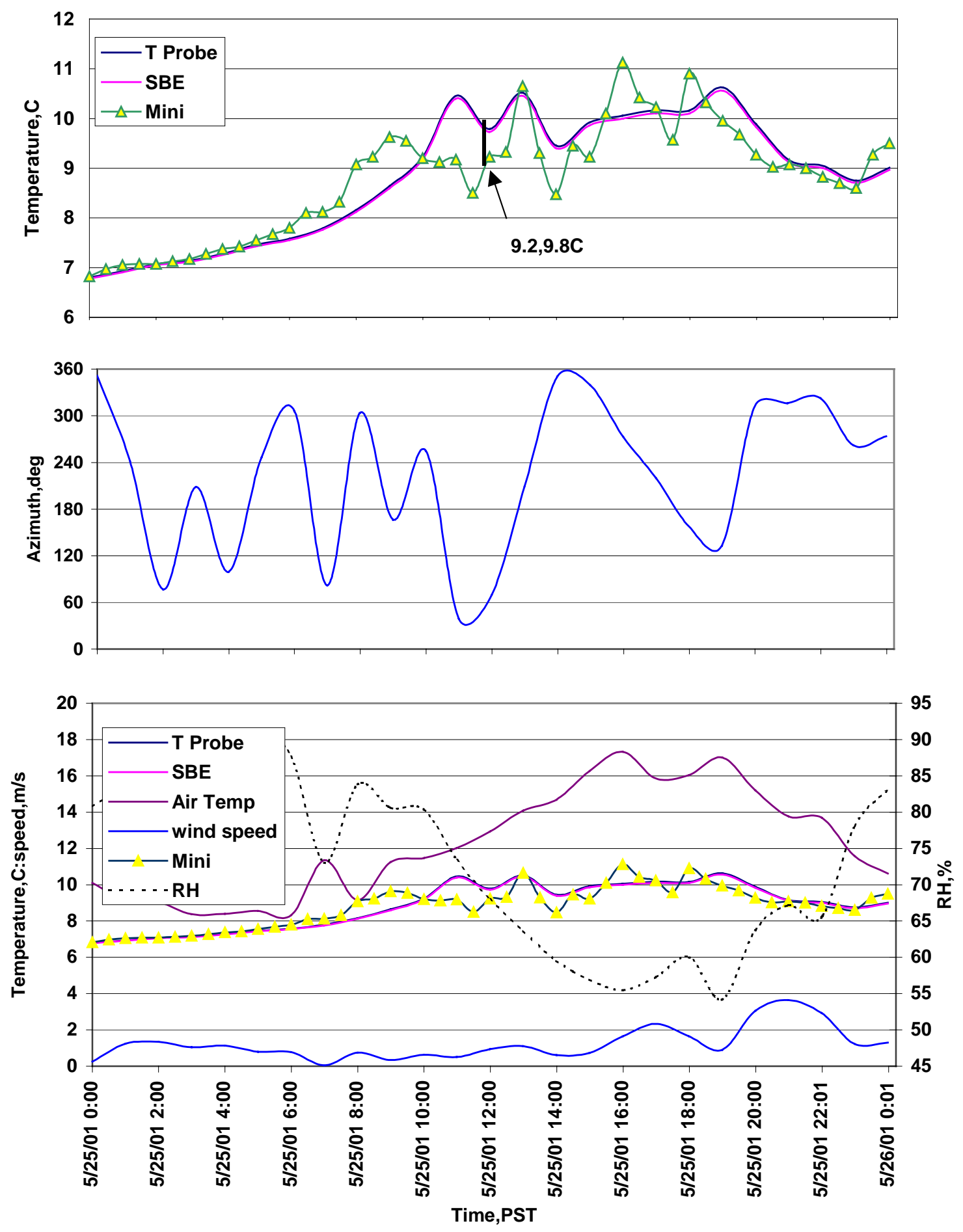

Fig 17: as in Fig. 7 but for May 25, 2001. 

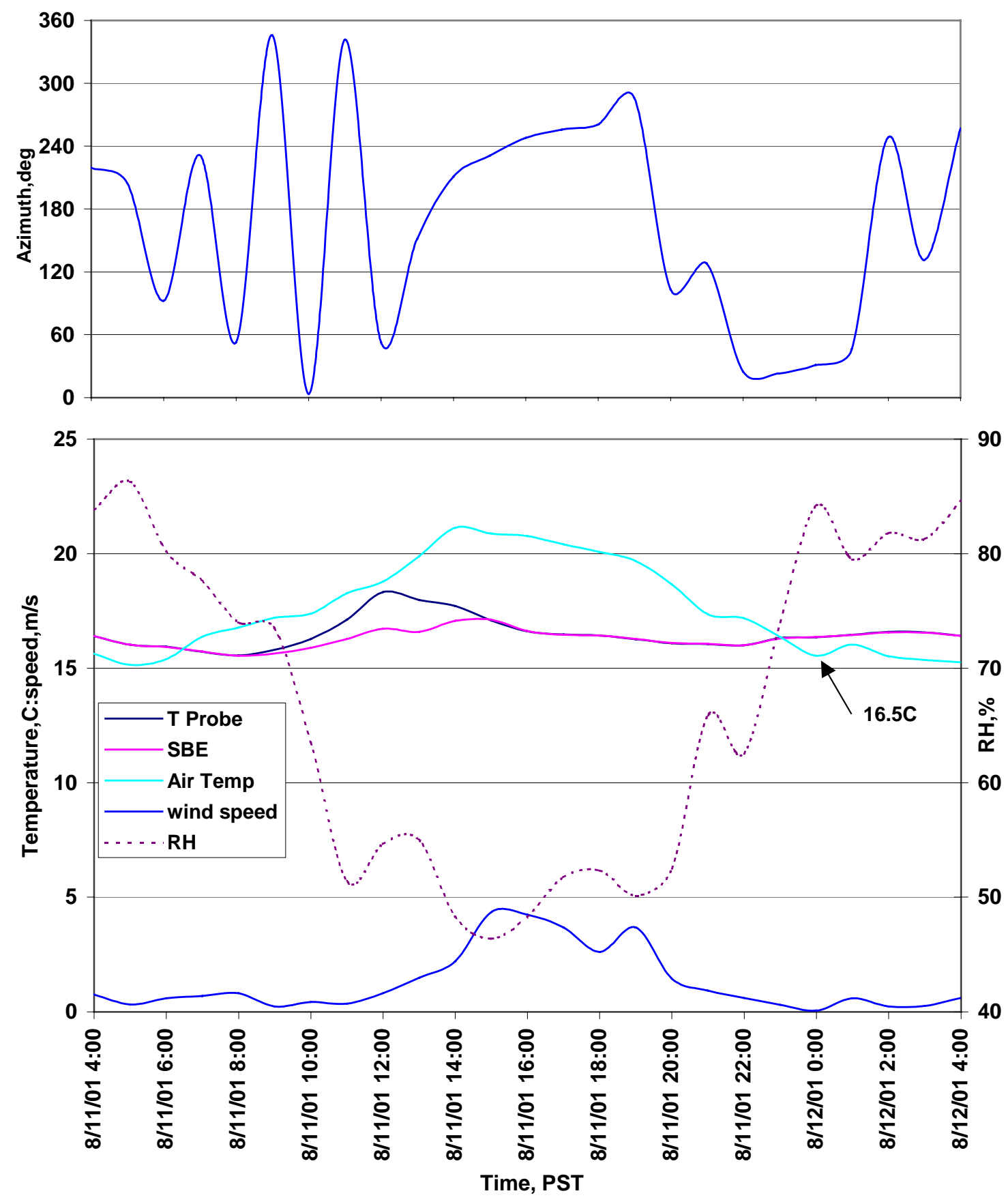

Fig 18: As in Fig. 7 but for Aug 12, 2001. 


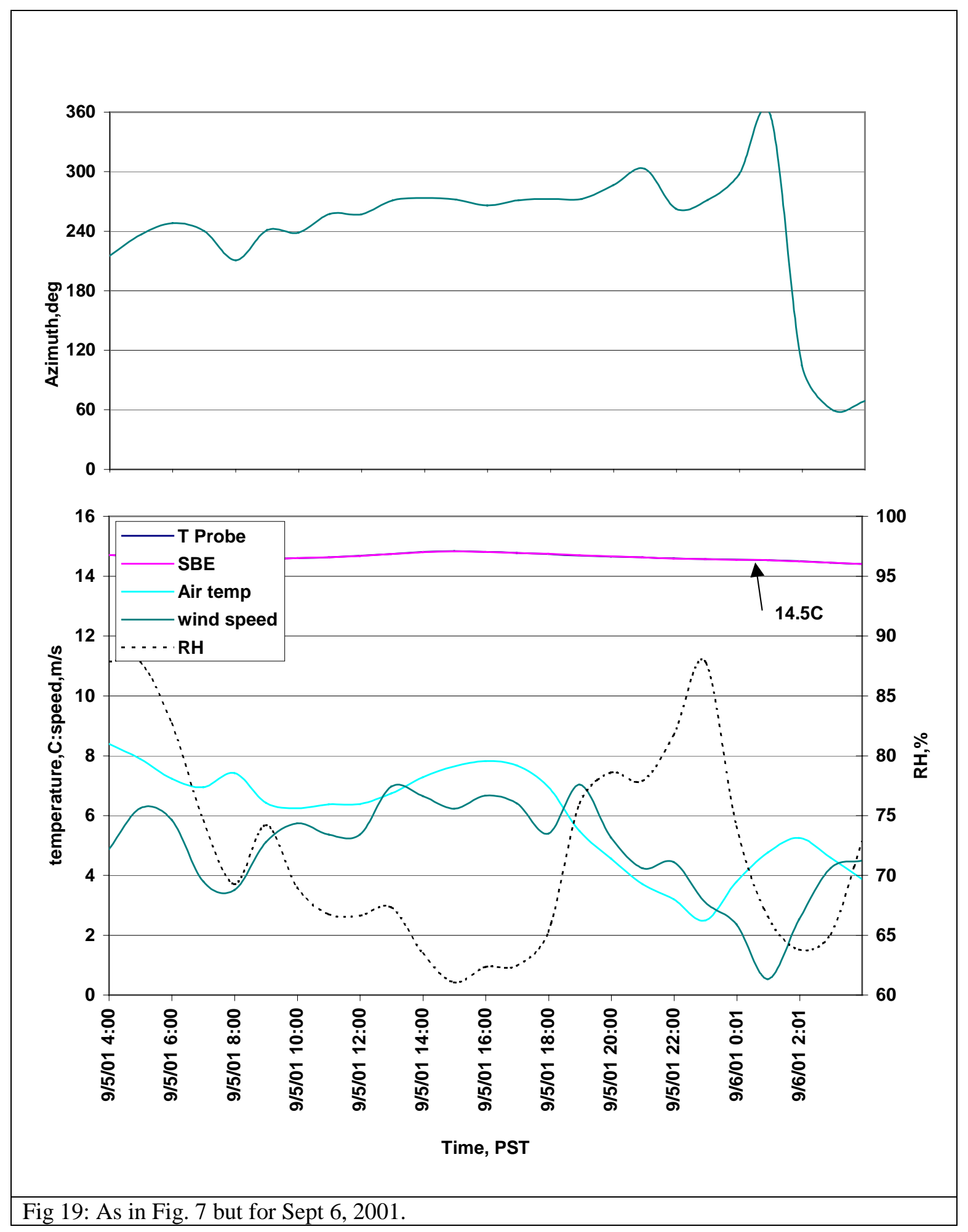




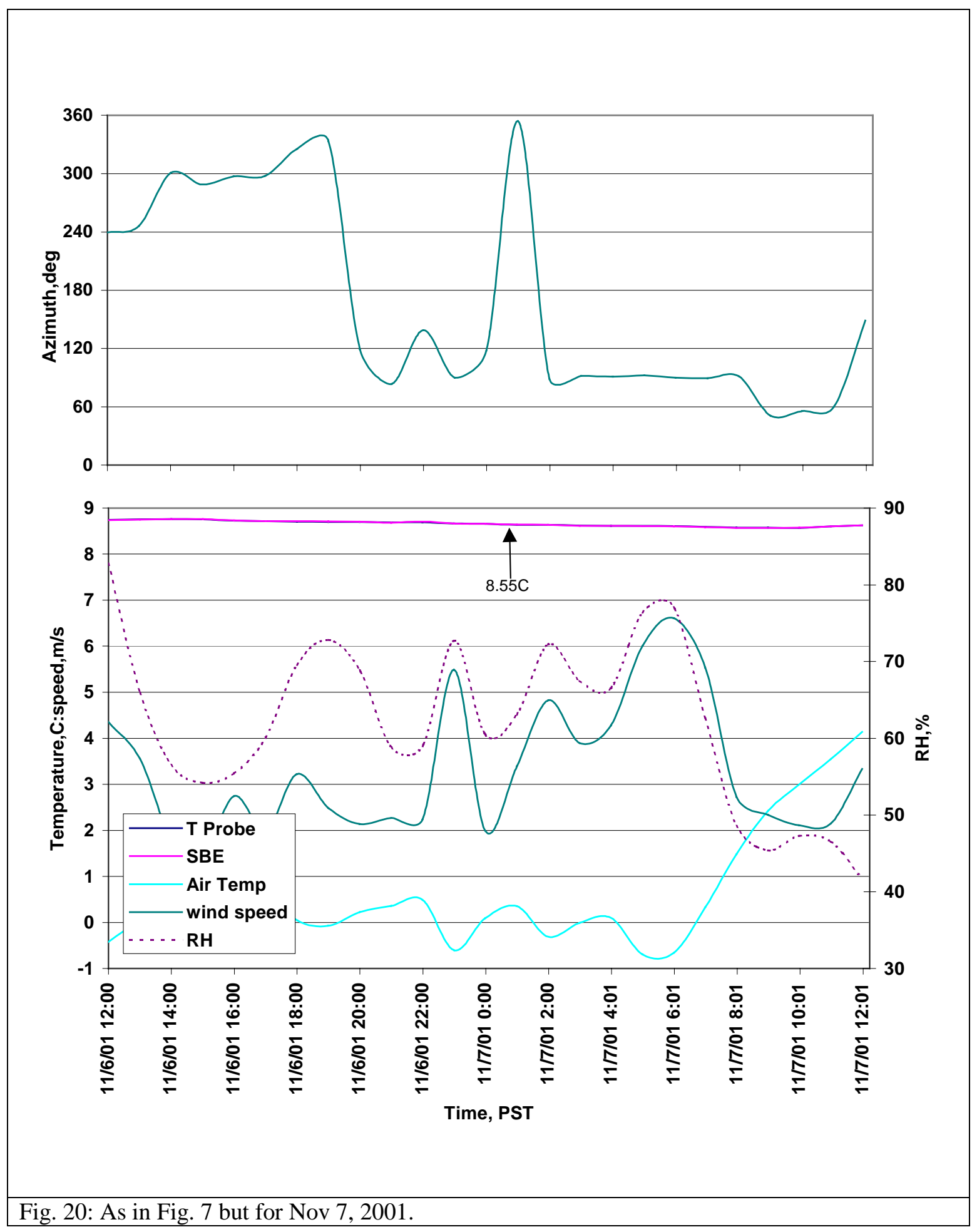



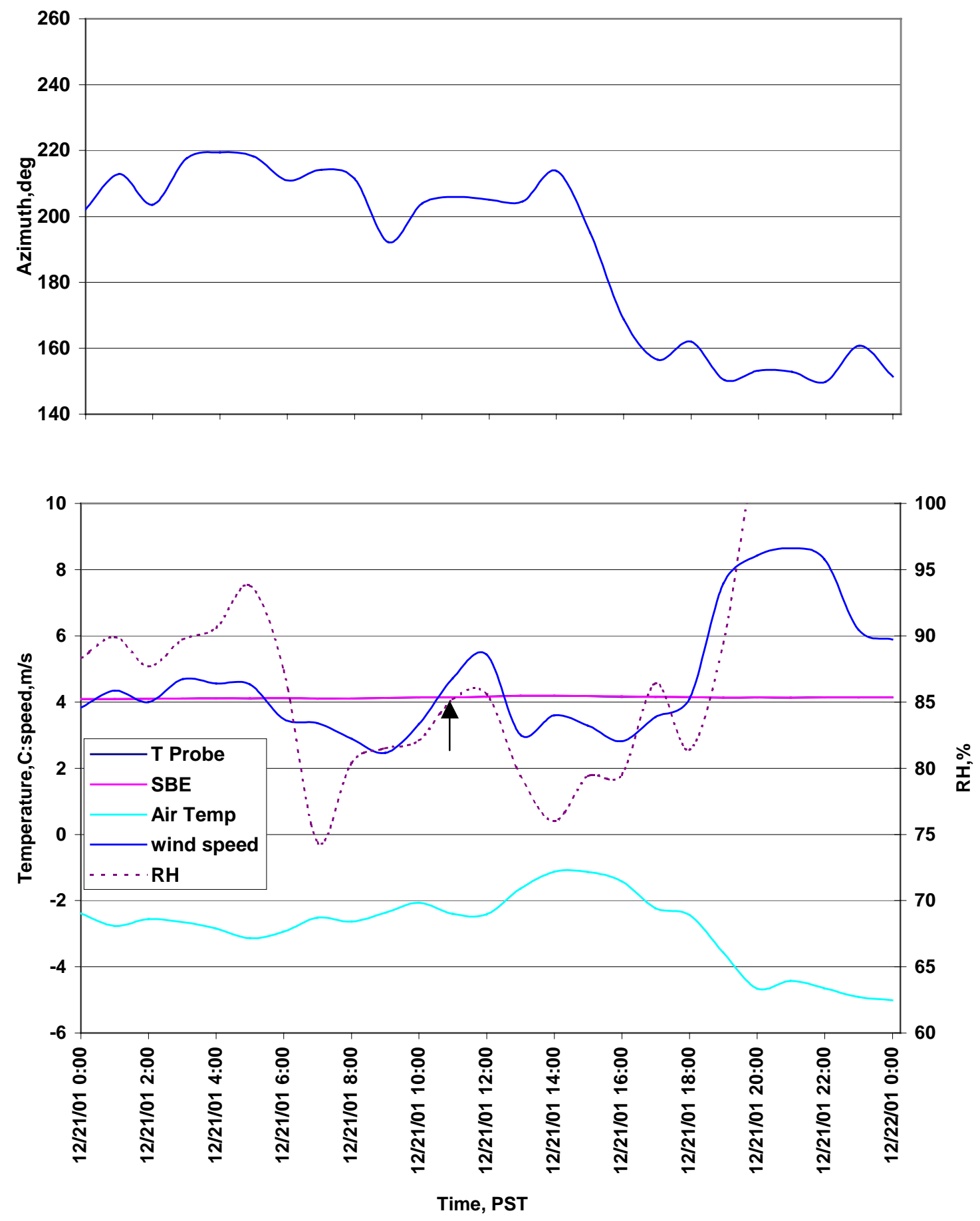

Fig 21: As in Fig. 7 but for Dec 21, 2001. 

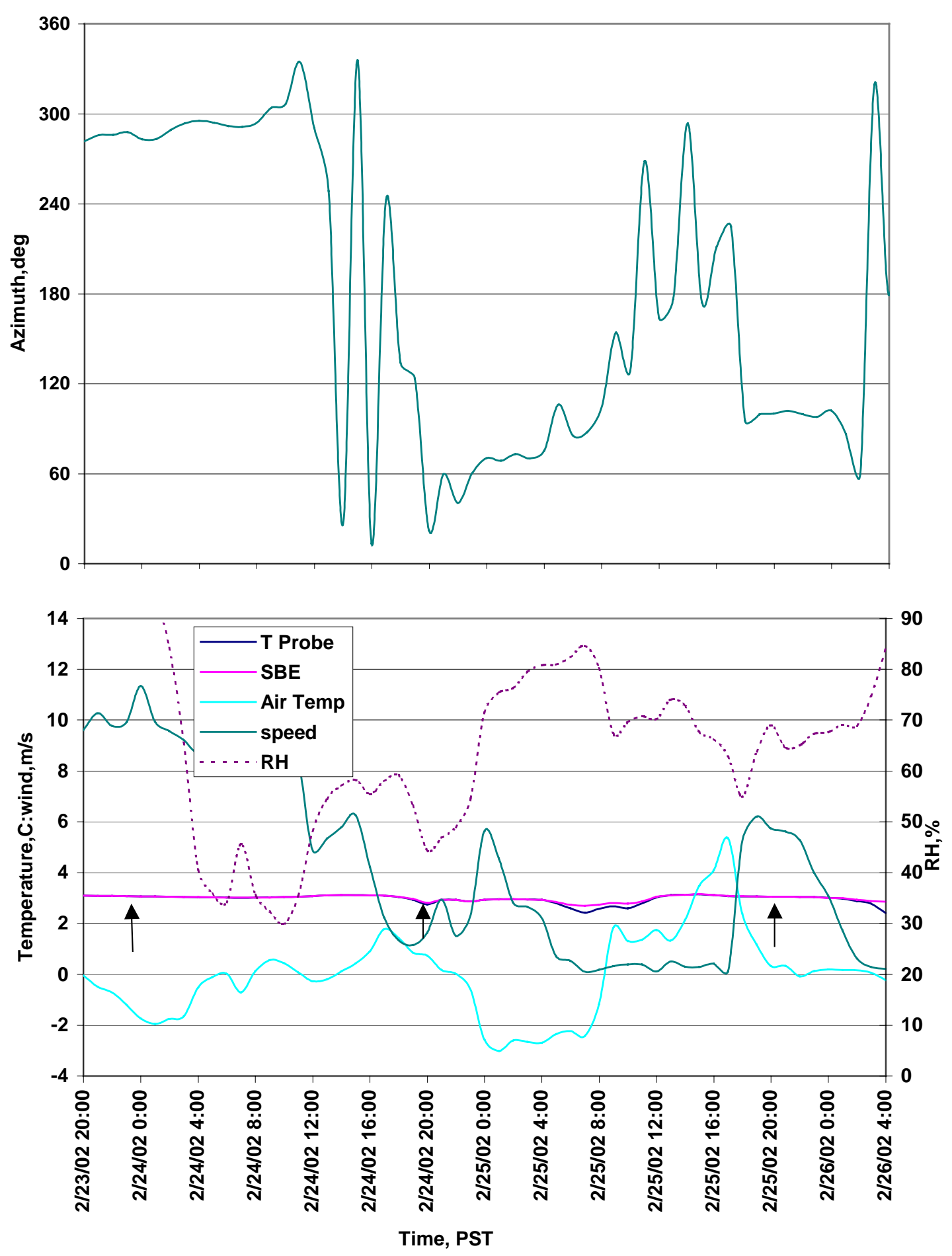

Fig 22: As in Fig. 7 but for Feb 23-26, 2002. 


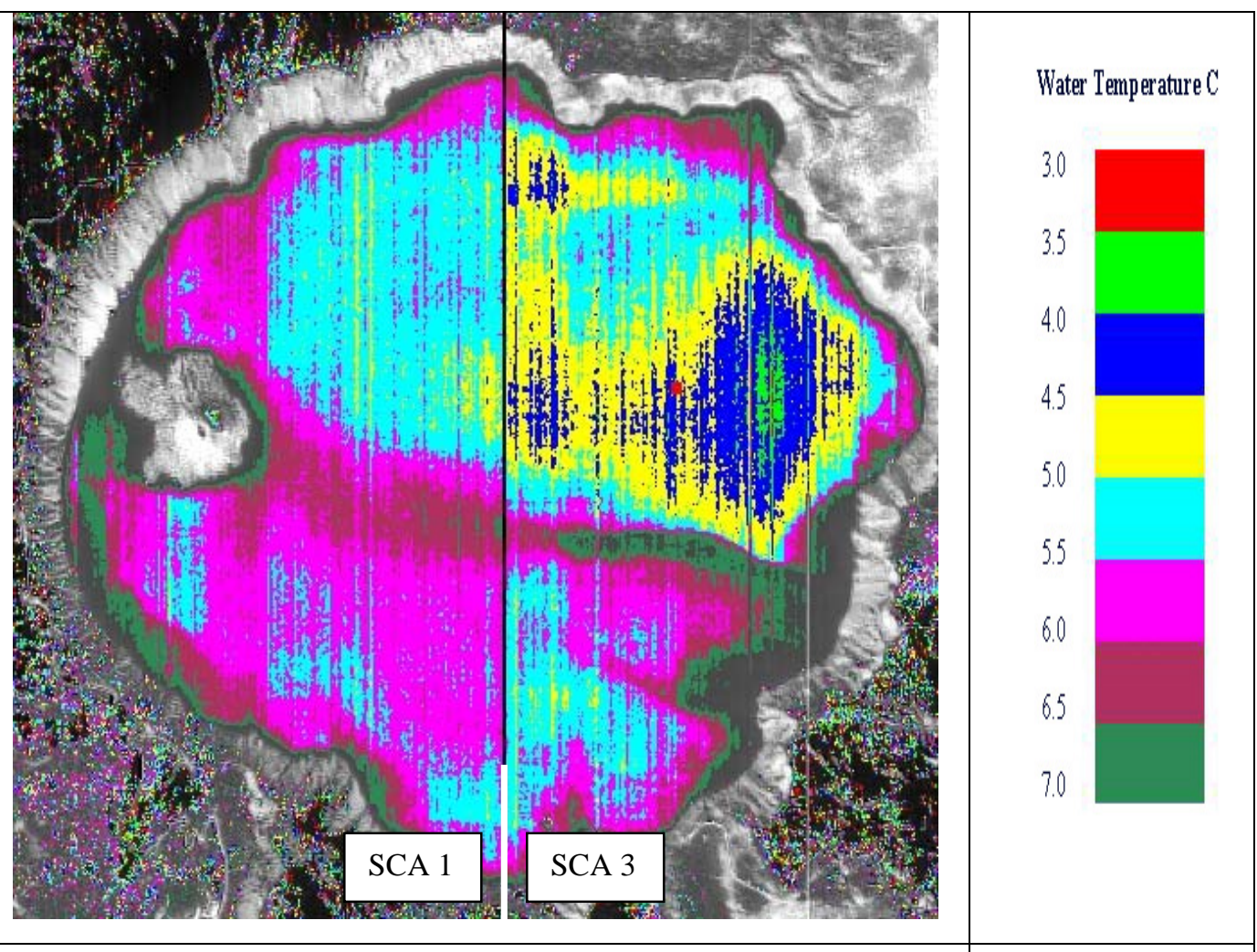

Fig. 23: Robust WST on June 16, 2000.

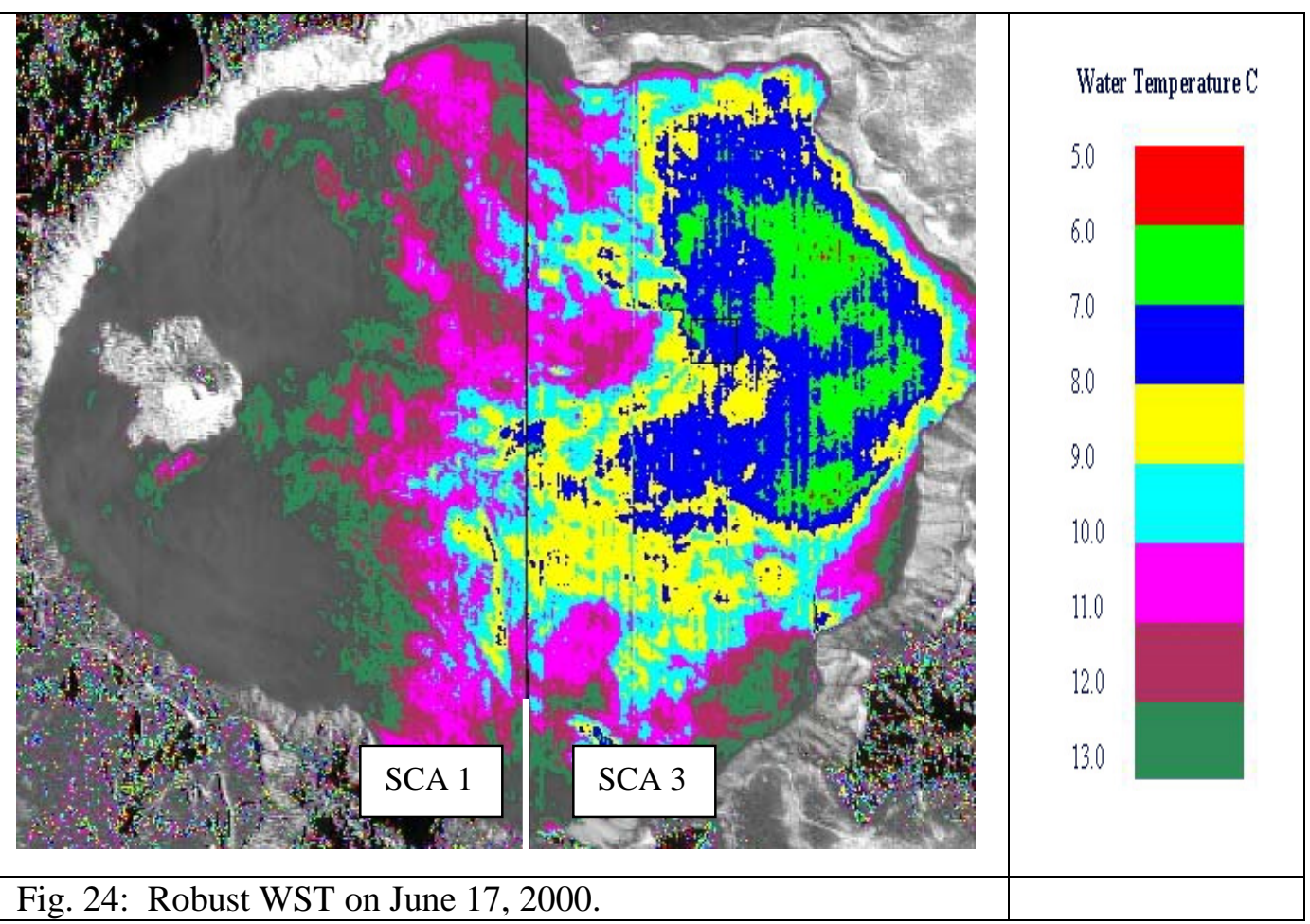



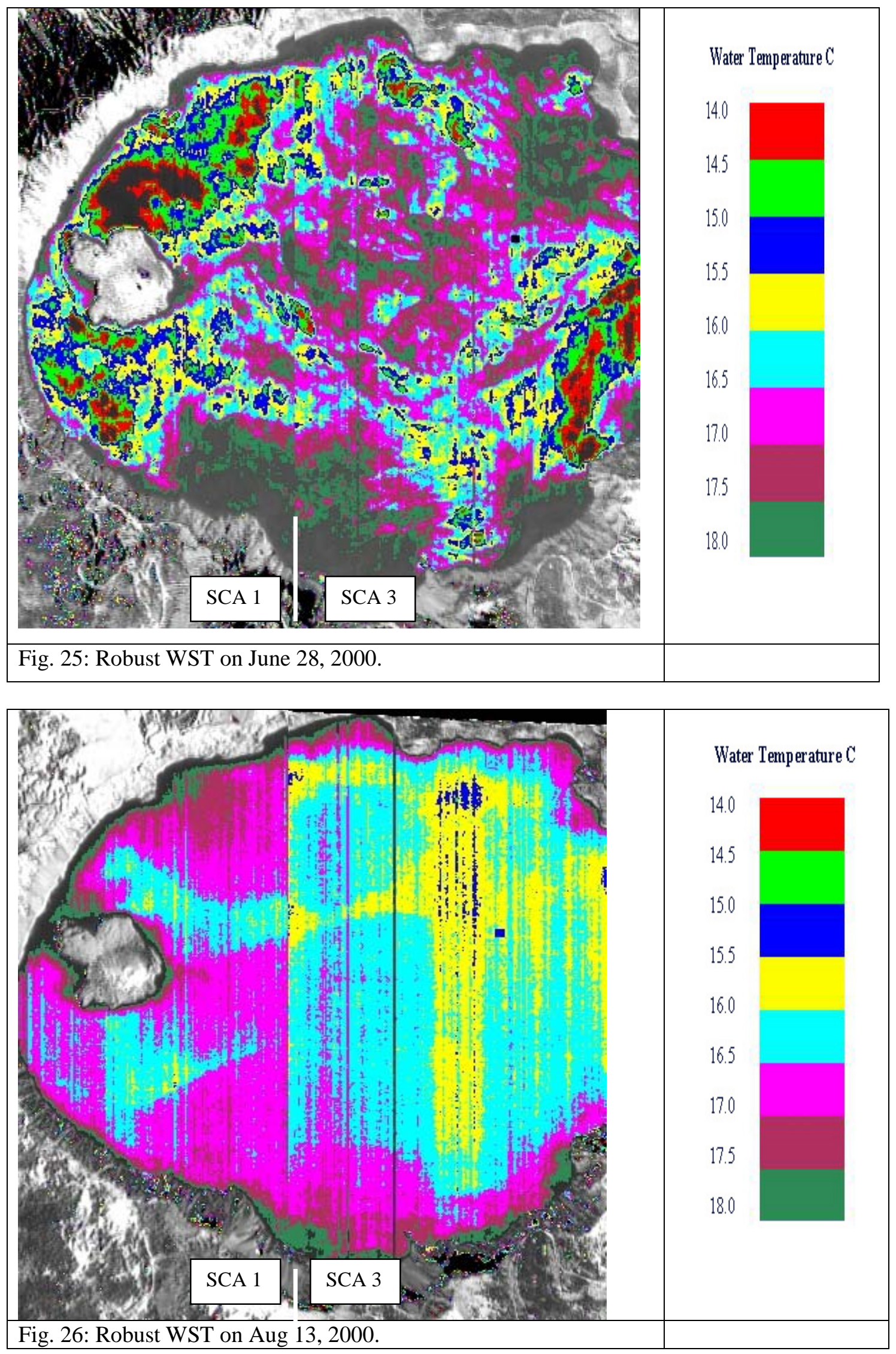

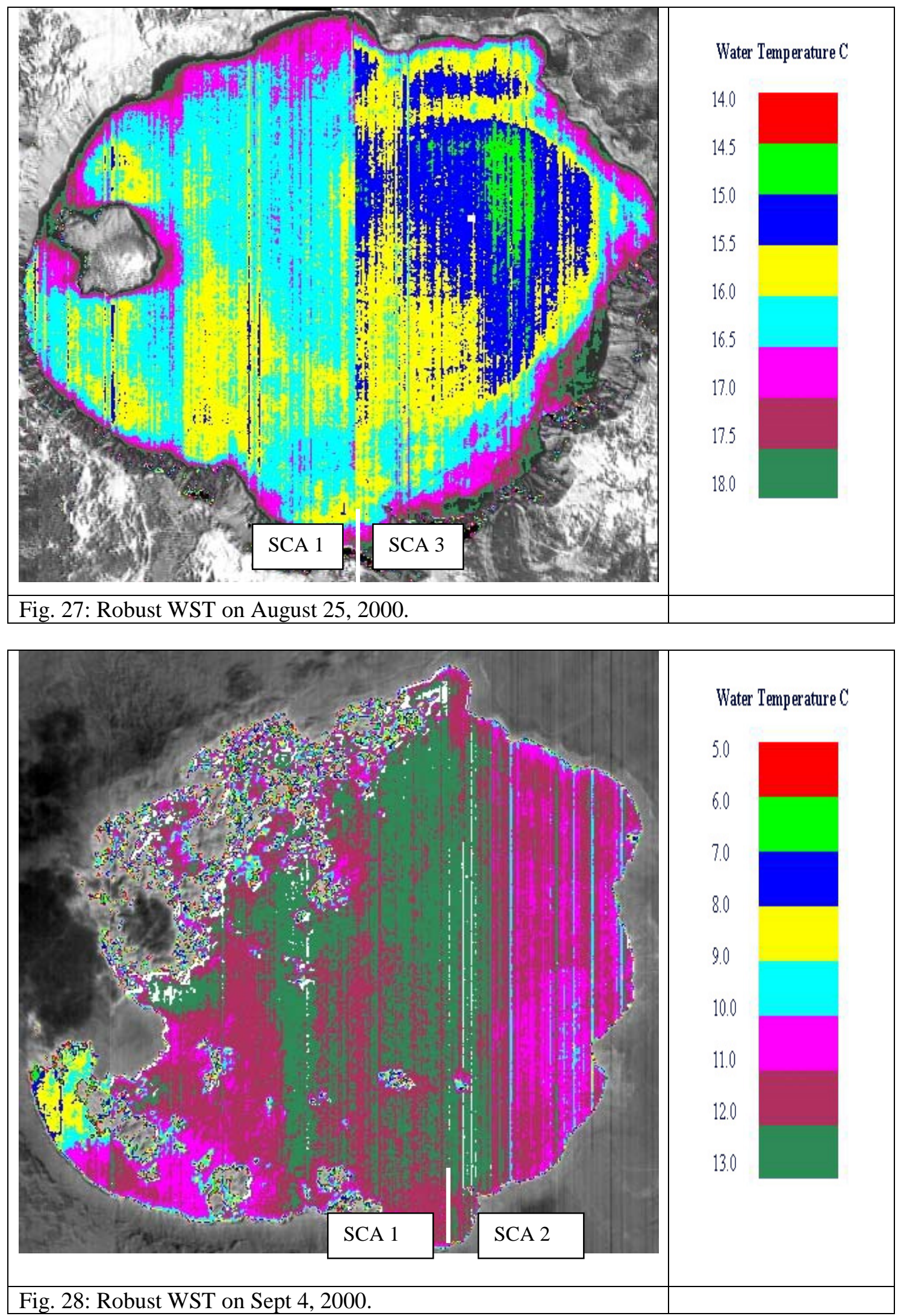


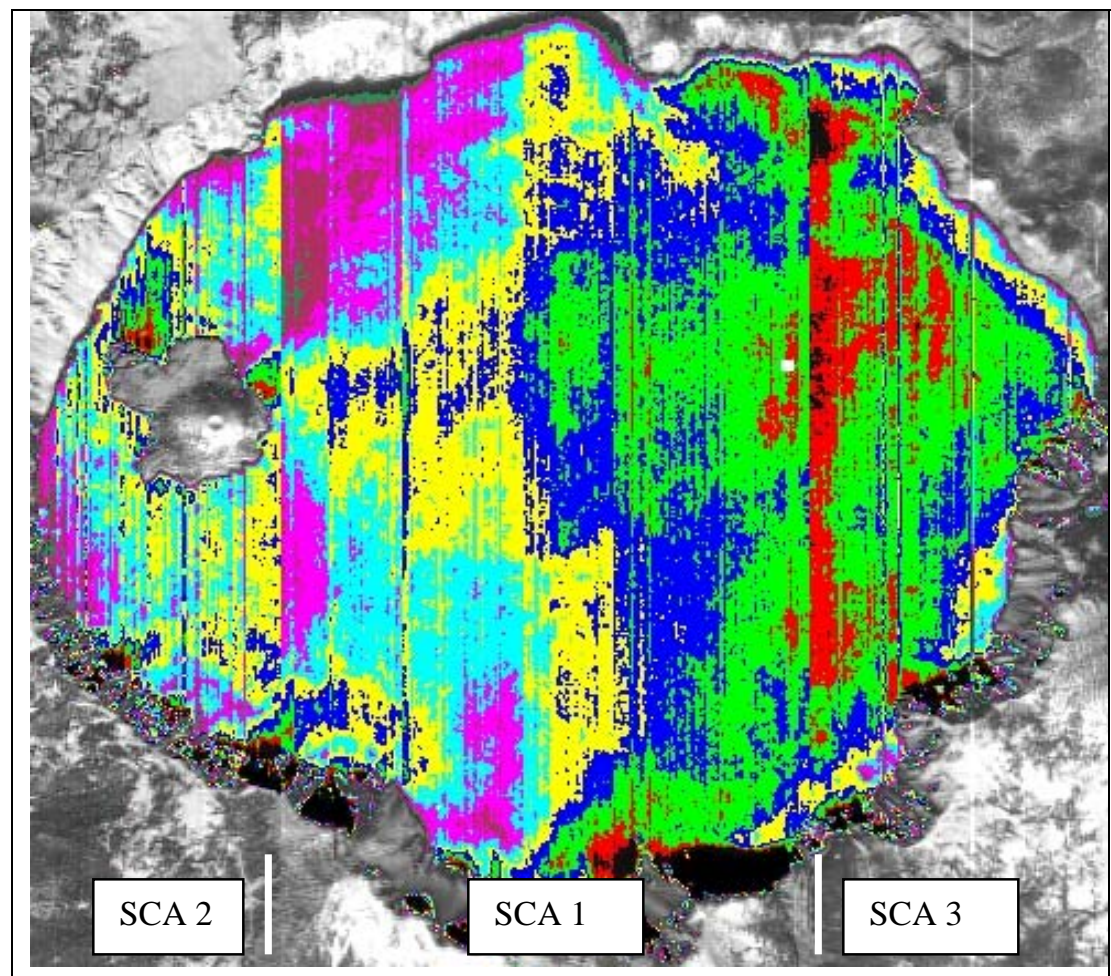

Water Temperature C

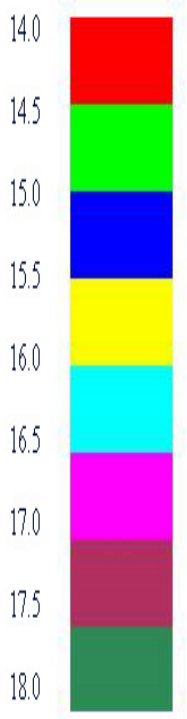

Fig. 29: Robust WST on Sept 18, 2000.

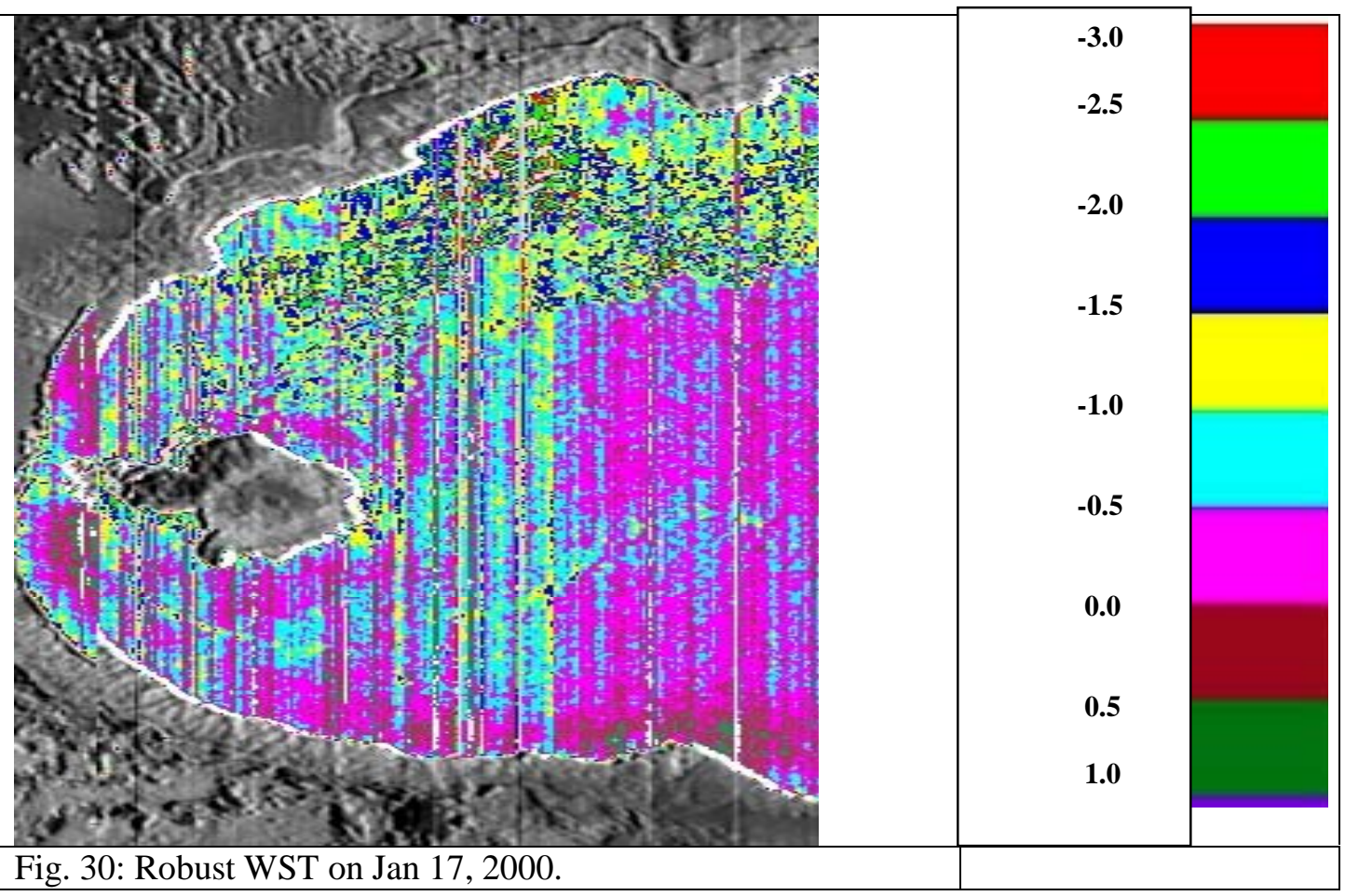



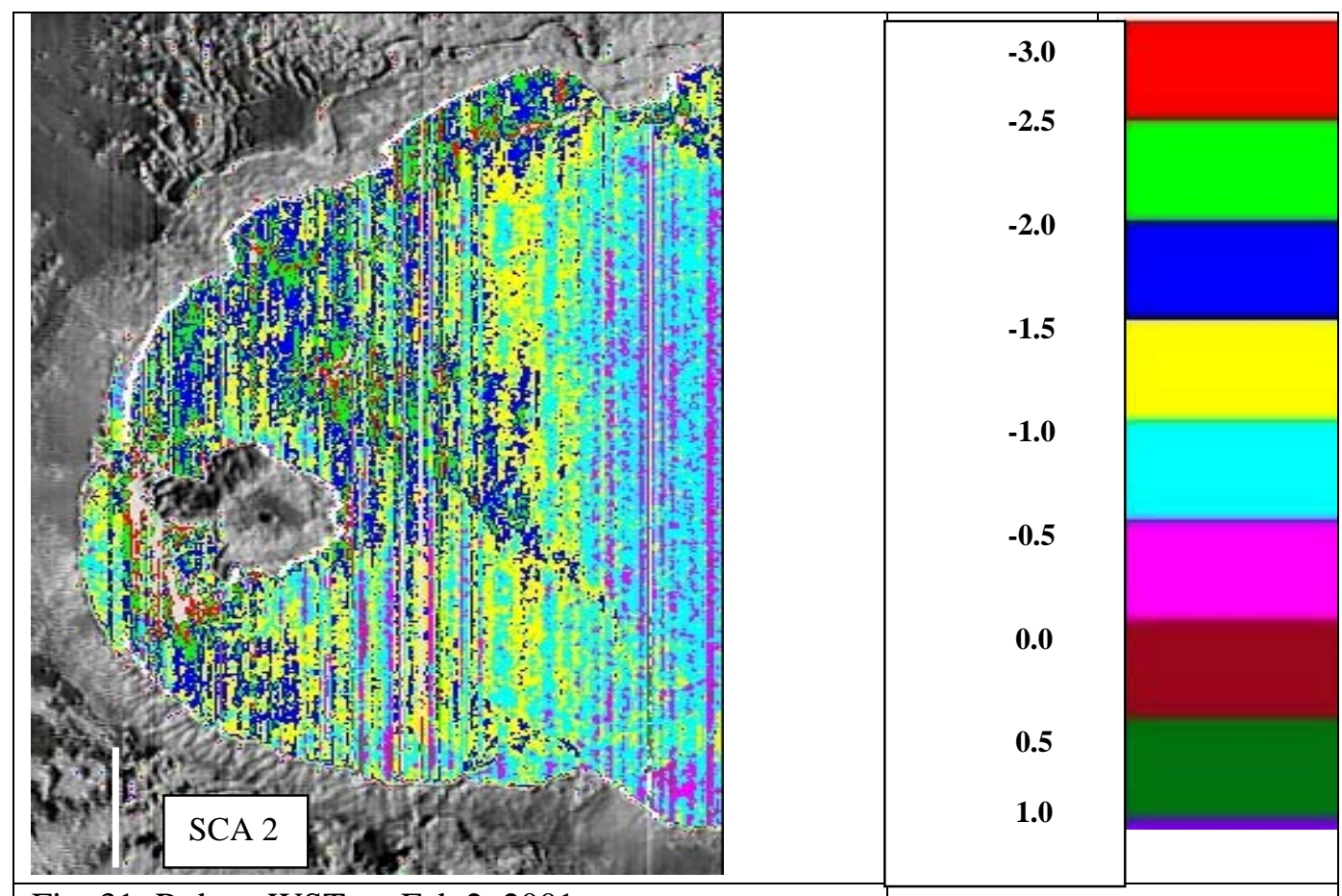

Fig. 31: Robust WST on Feb 2, 2001.

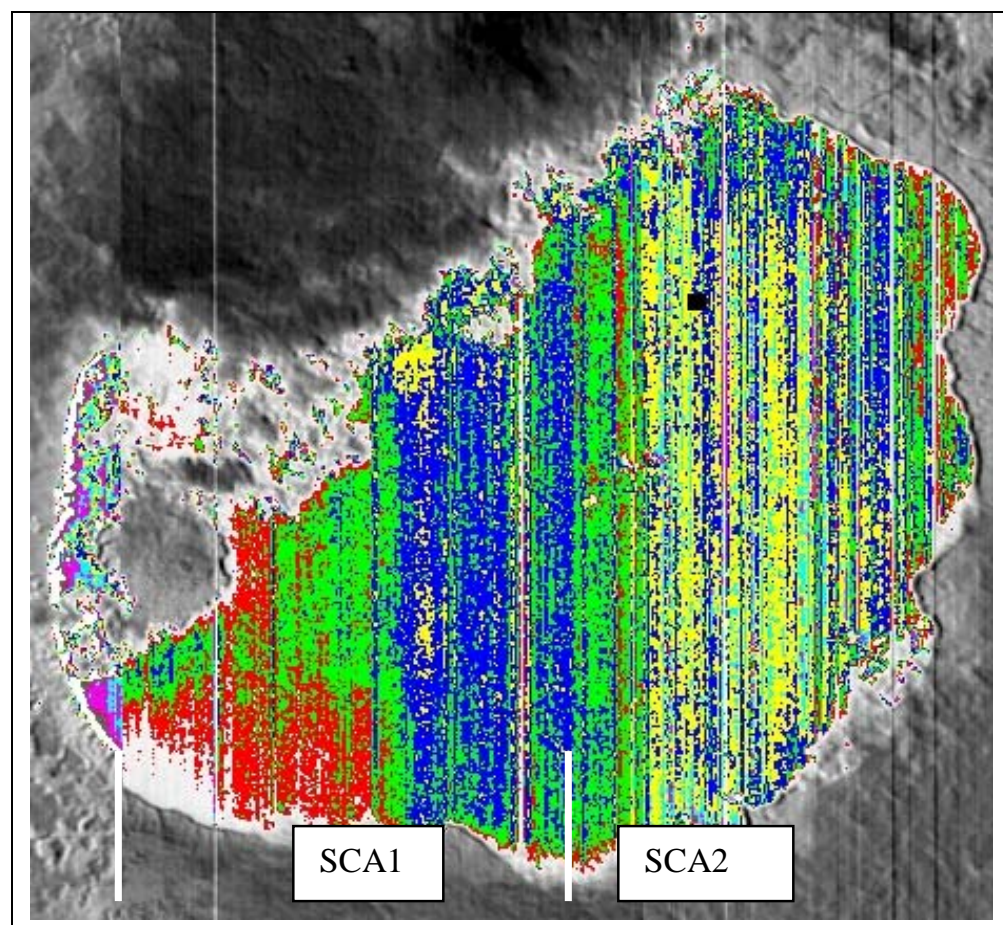

Water Temperature C

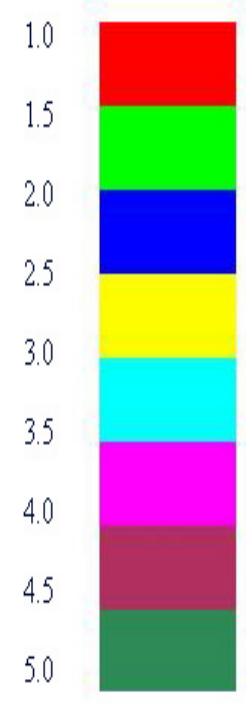

Fig. 32: Robust WST on Feb 20, 2001 

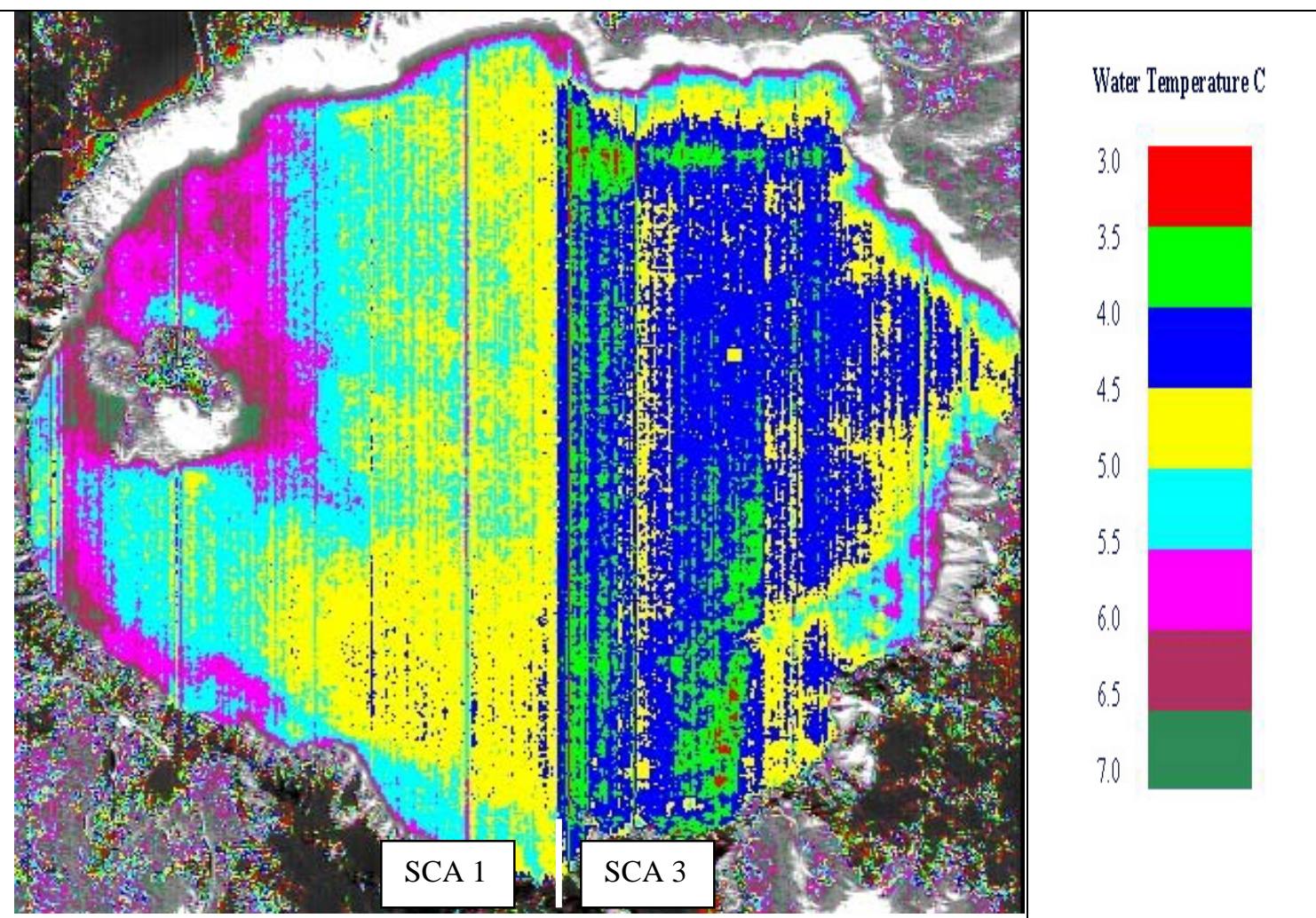

Fig. 33: Robust WST on May 3, 2002.

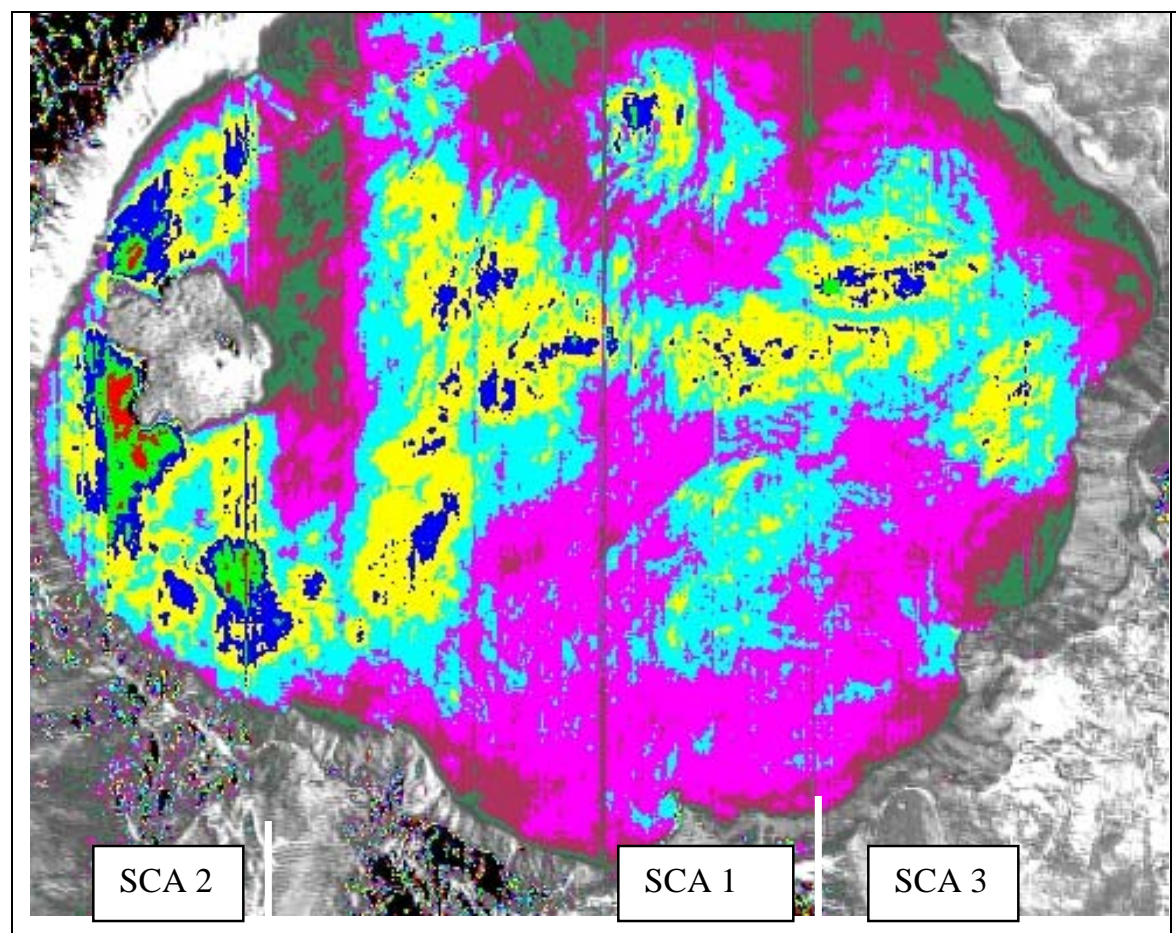

Water Temperature C

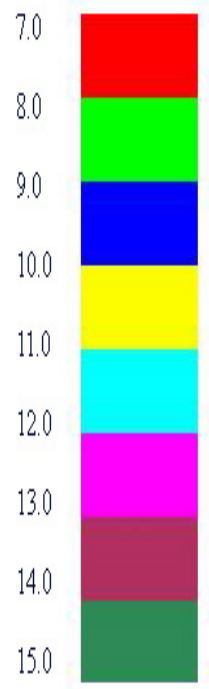

Fig. 34: Robust WST on May 25, 2001. 


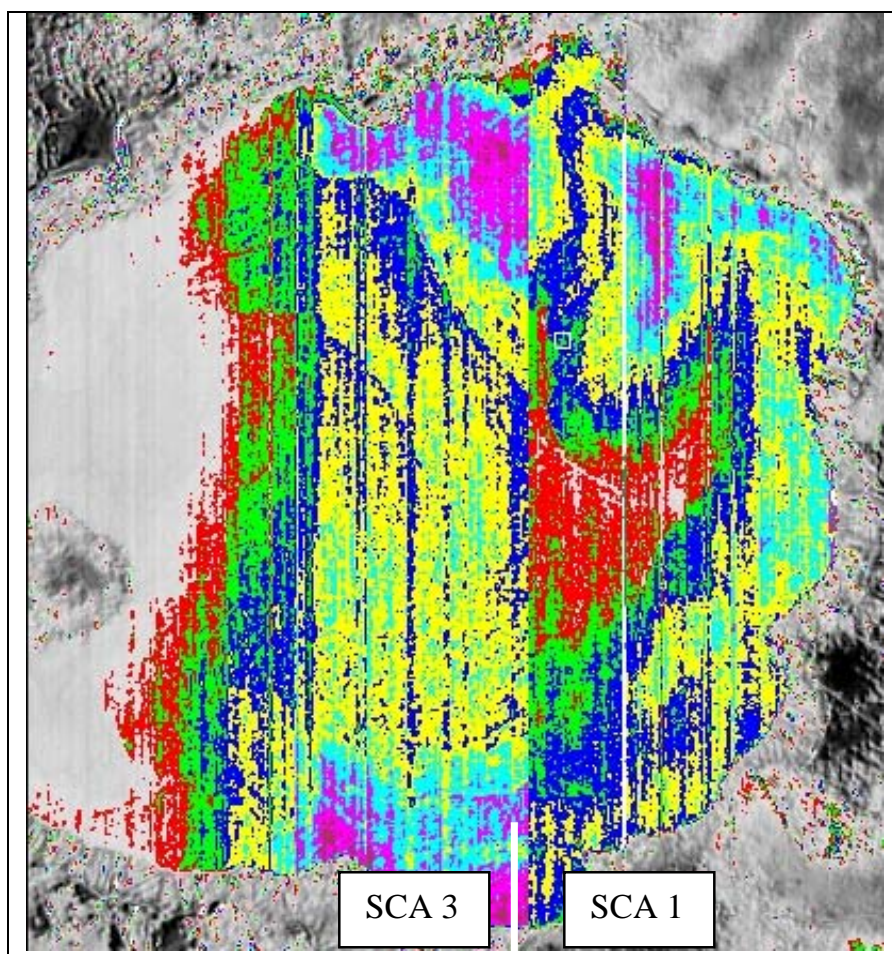

Water Temperature C

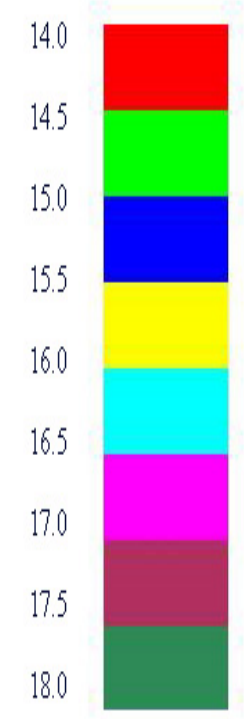

Fig. 35: Robust WST on August 12, 2001.

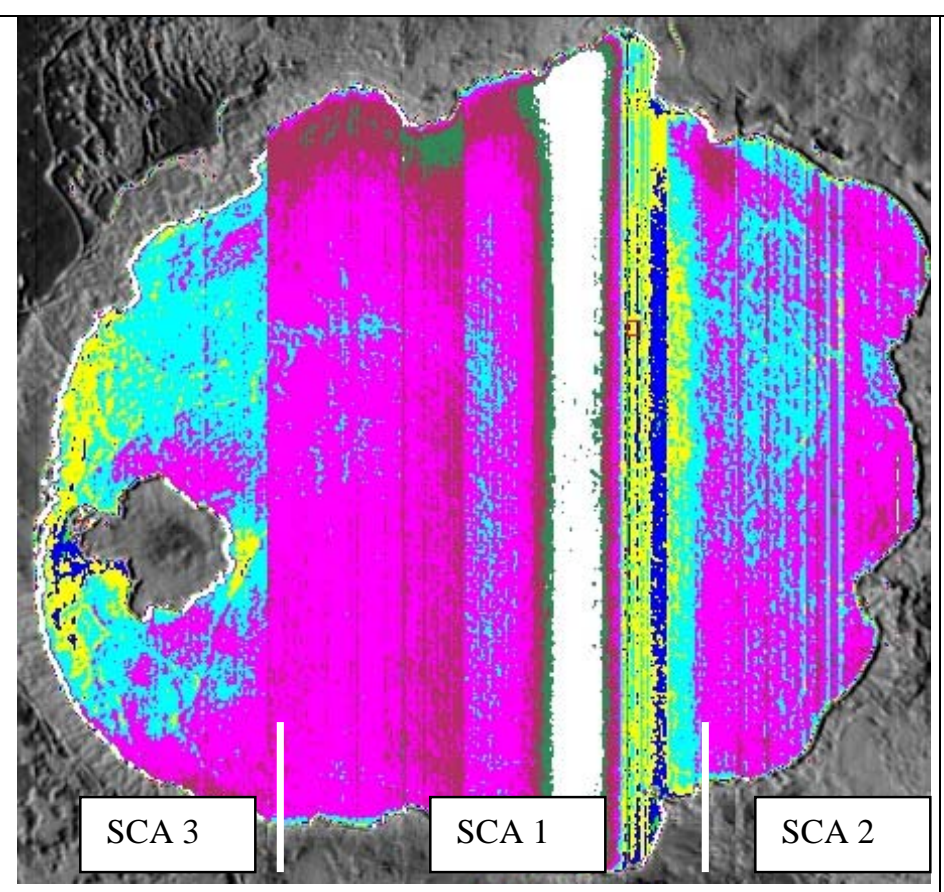

Water Temperature C

Fig. 36: Robust WST on Sept 6, 2001. 


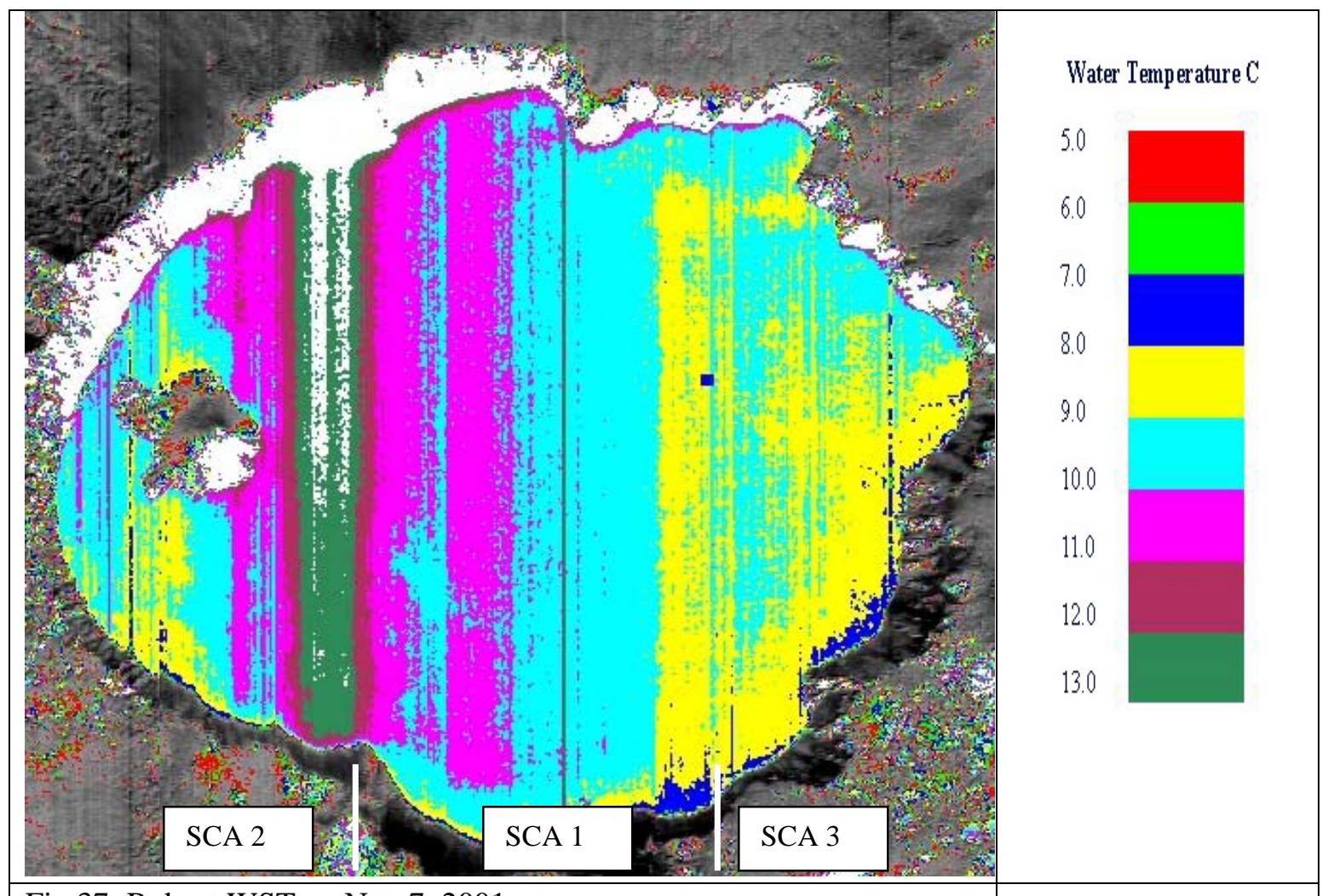

Fig 37: Robust WST on Nov 7, 2001.

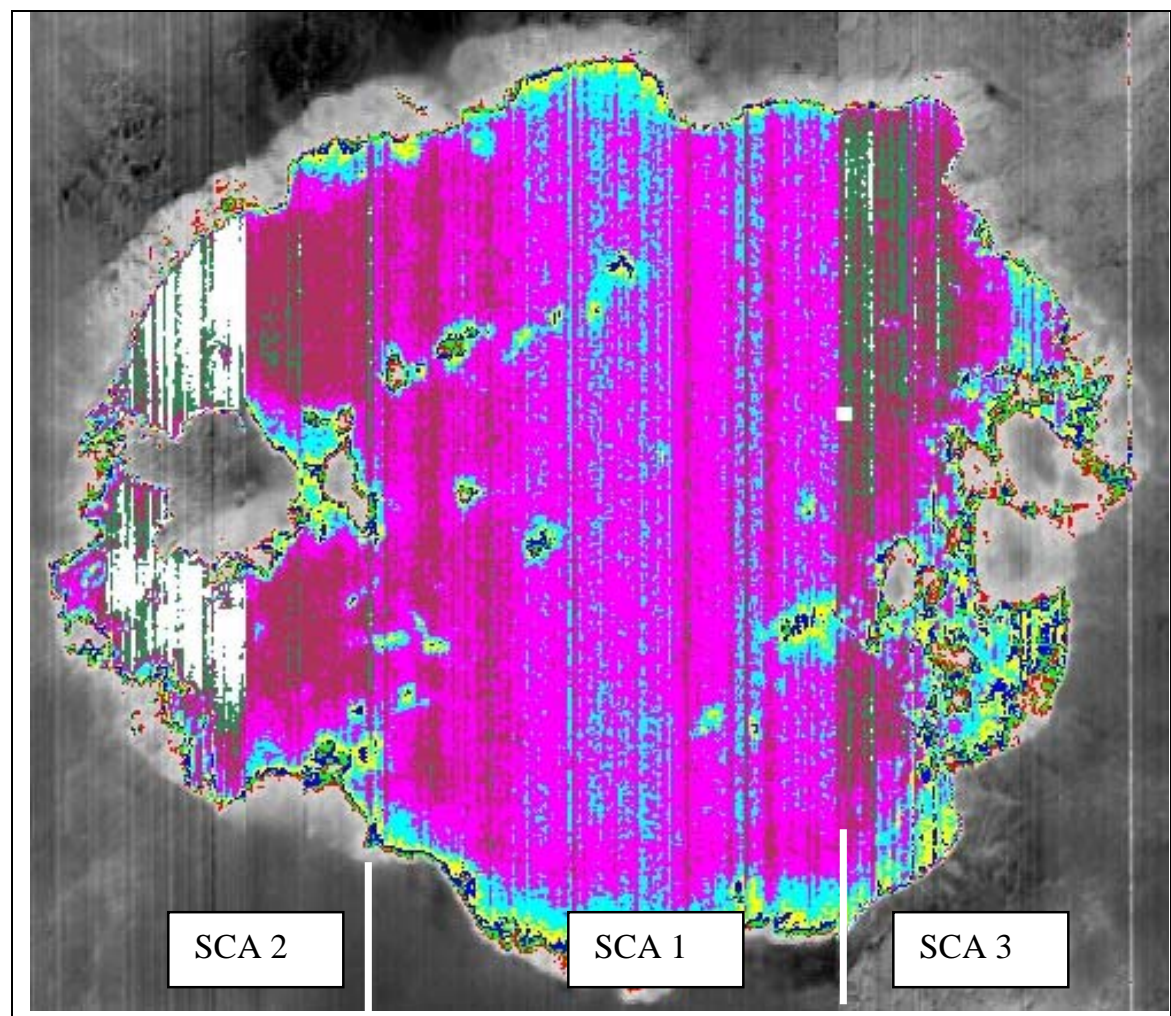

Water Temperature C

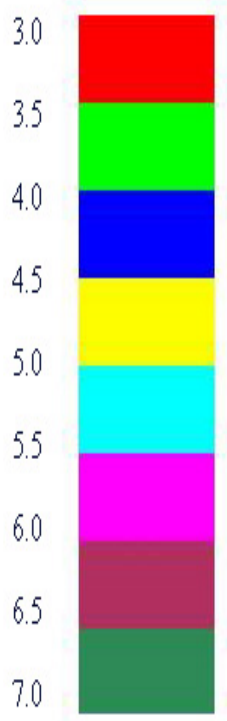

Fig 38: Robust WST on Dec 21. 2001. 


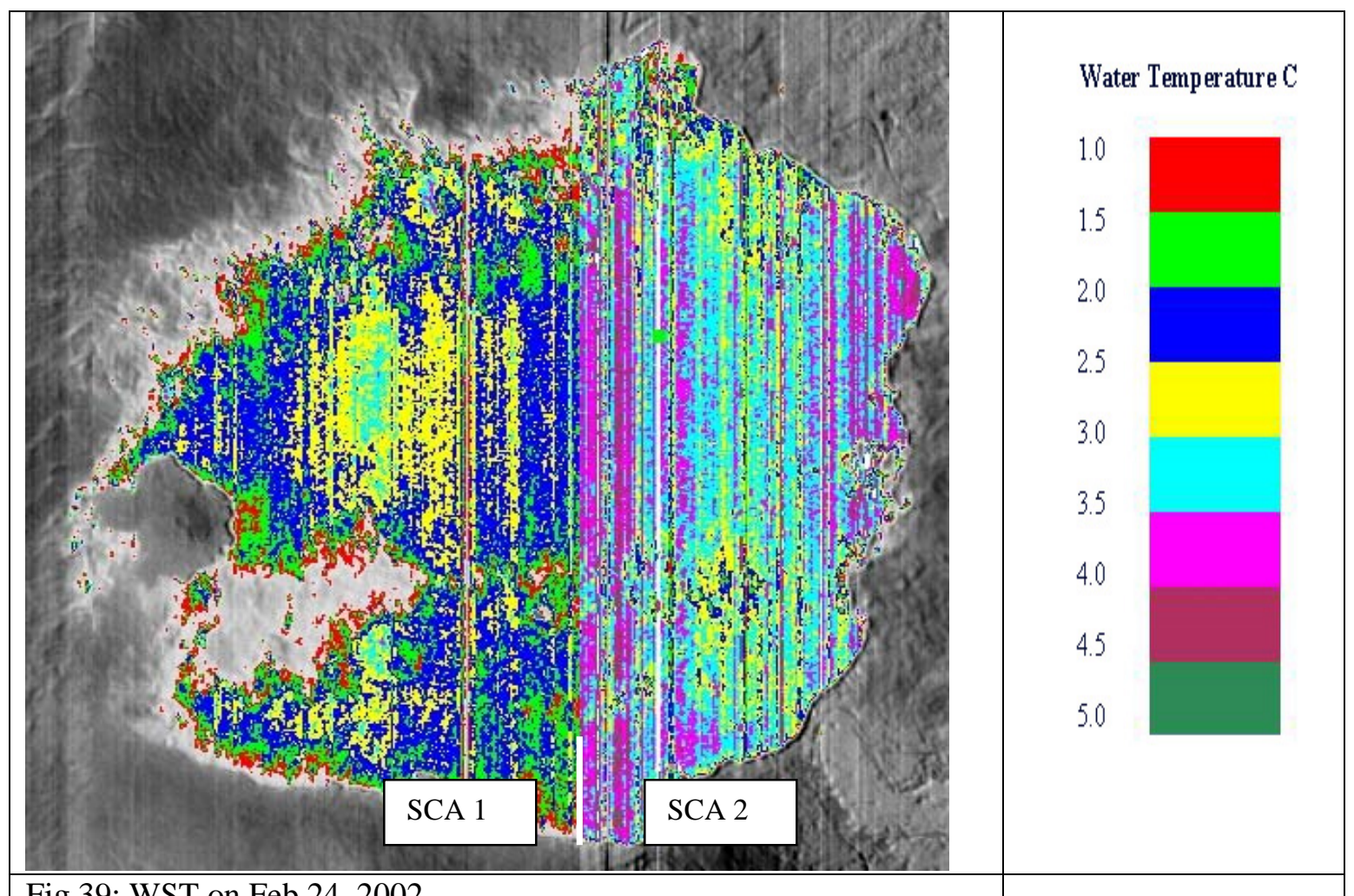

Fig 39: WST on Feb 24, 2002

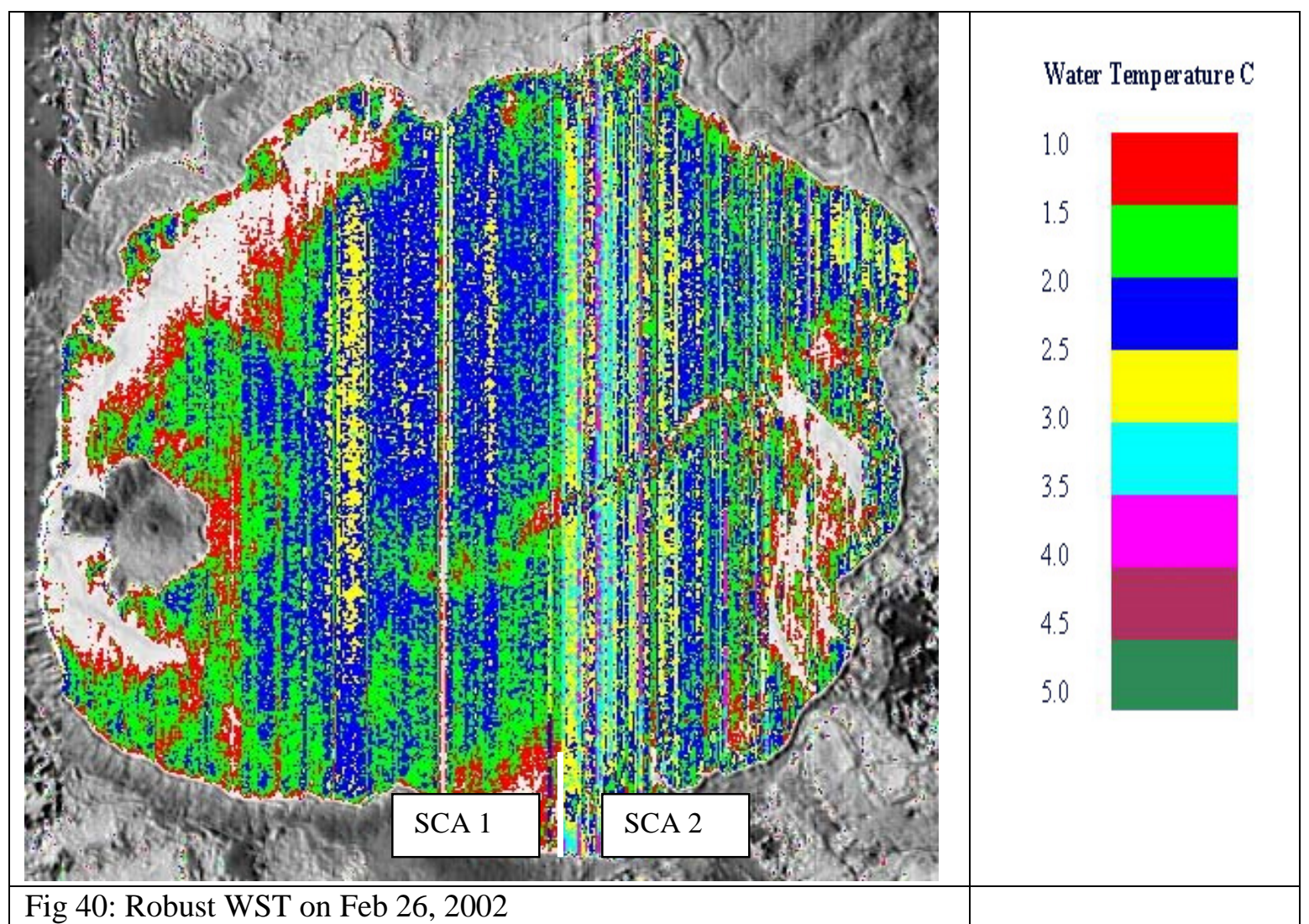



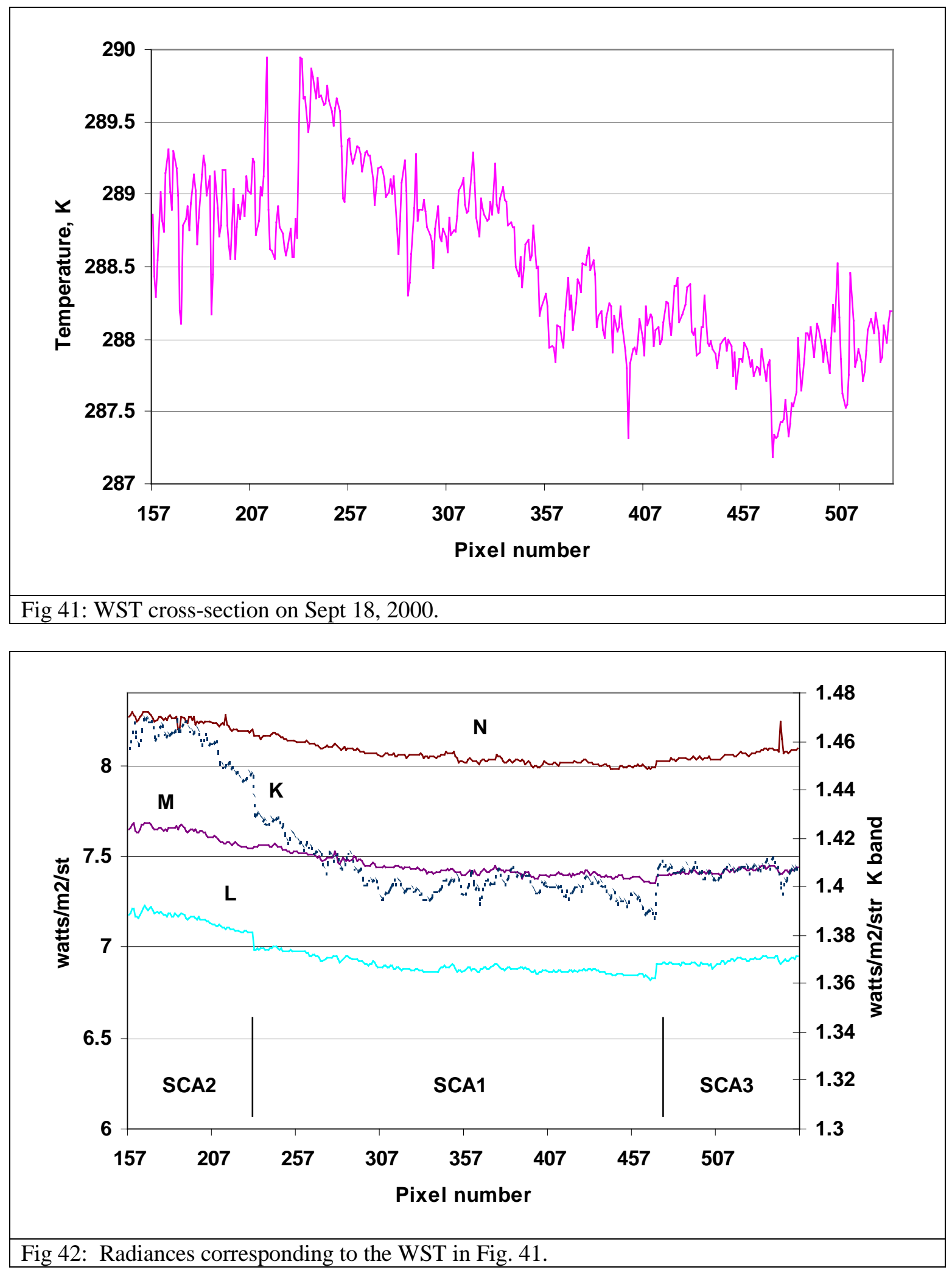

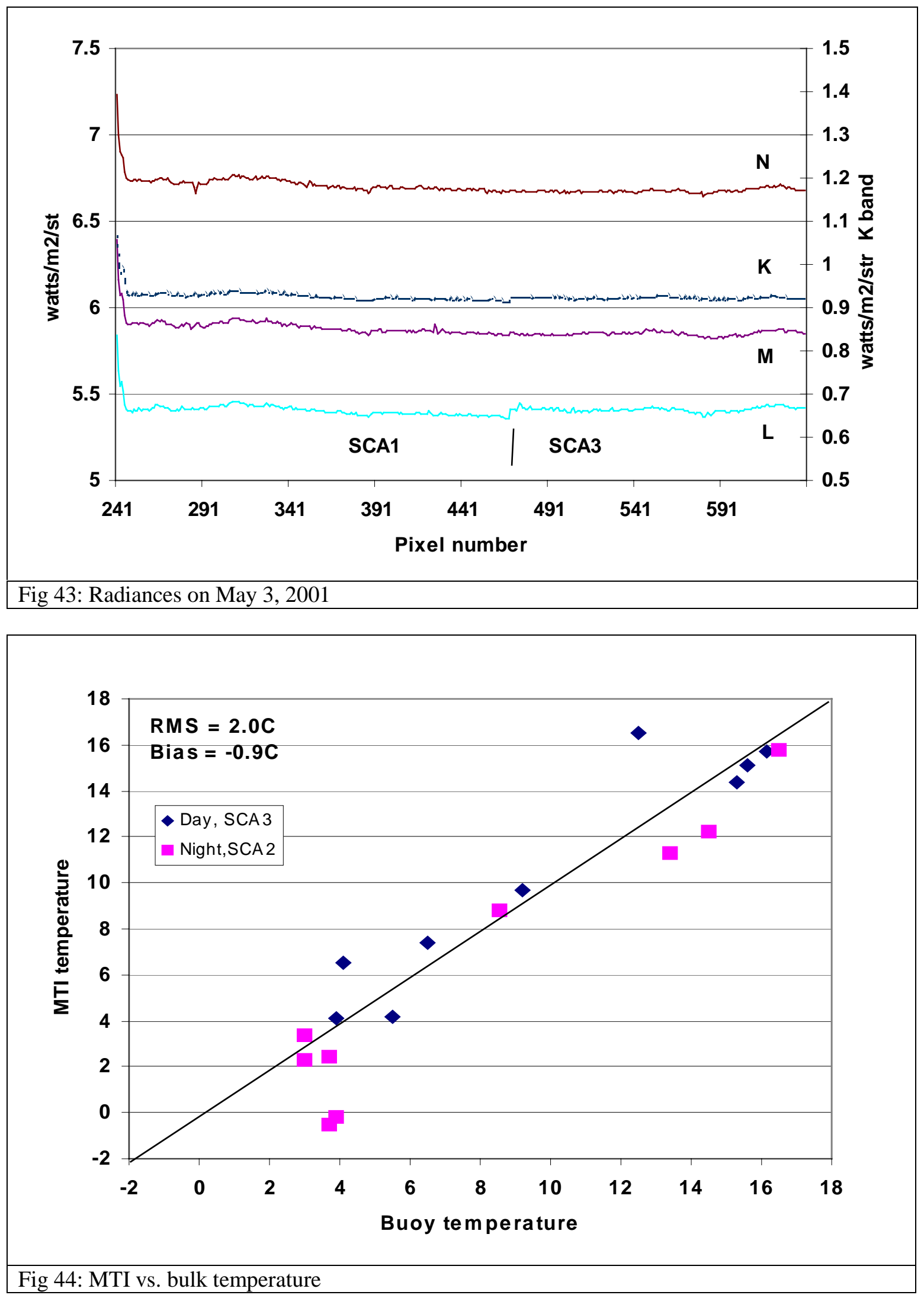


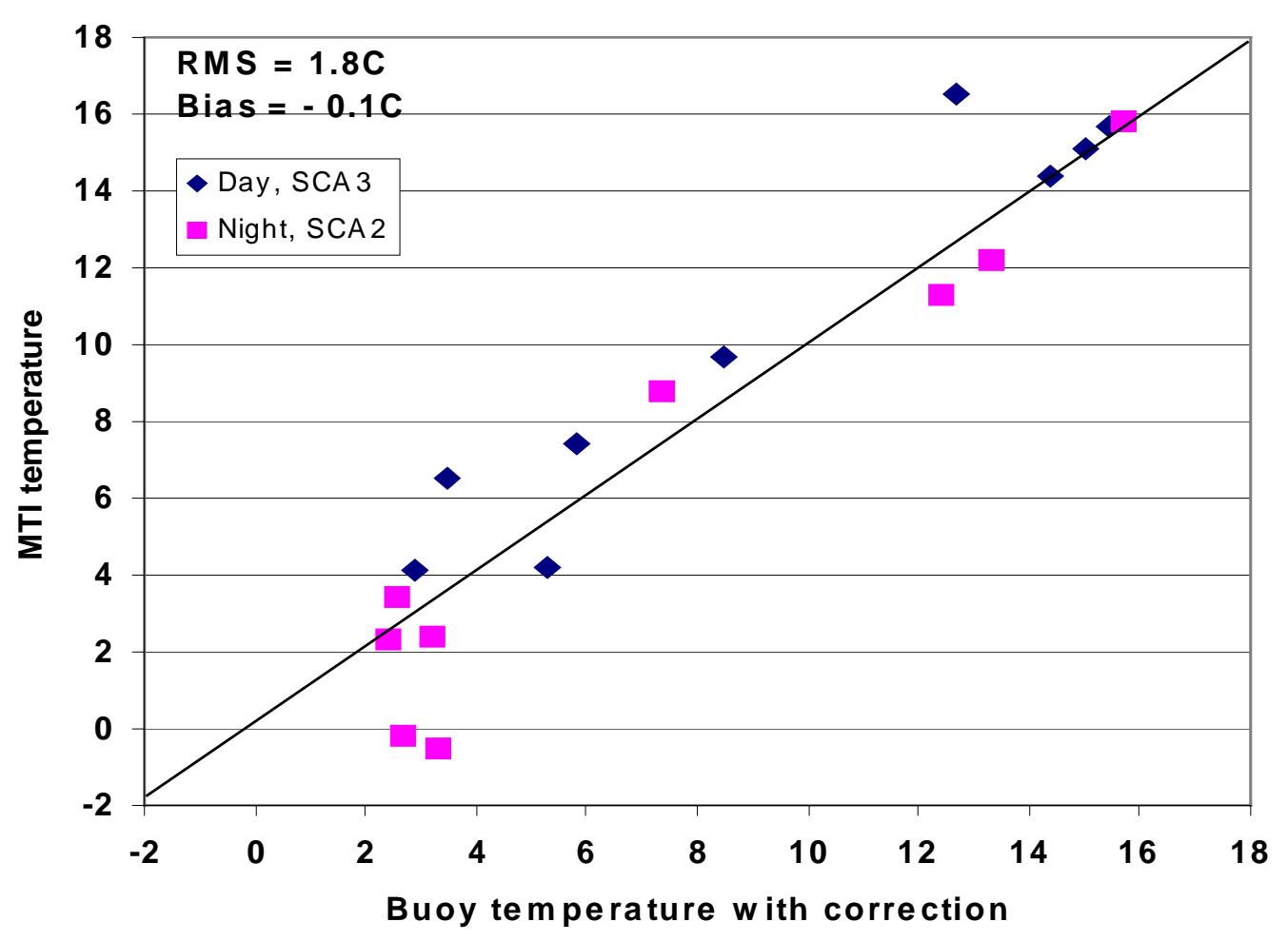

Fig 45: MTI vs corrected buoy temperature

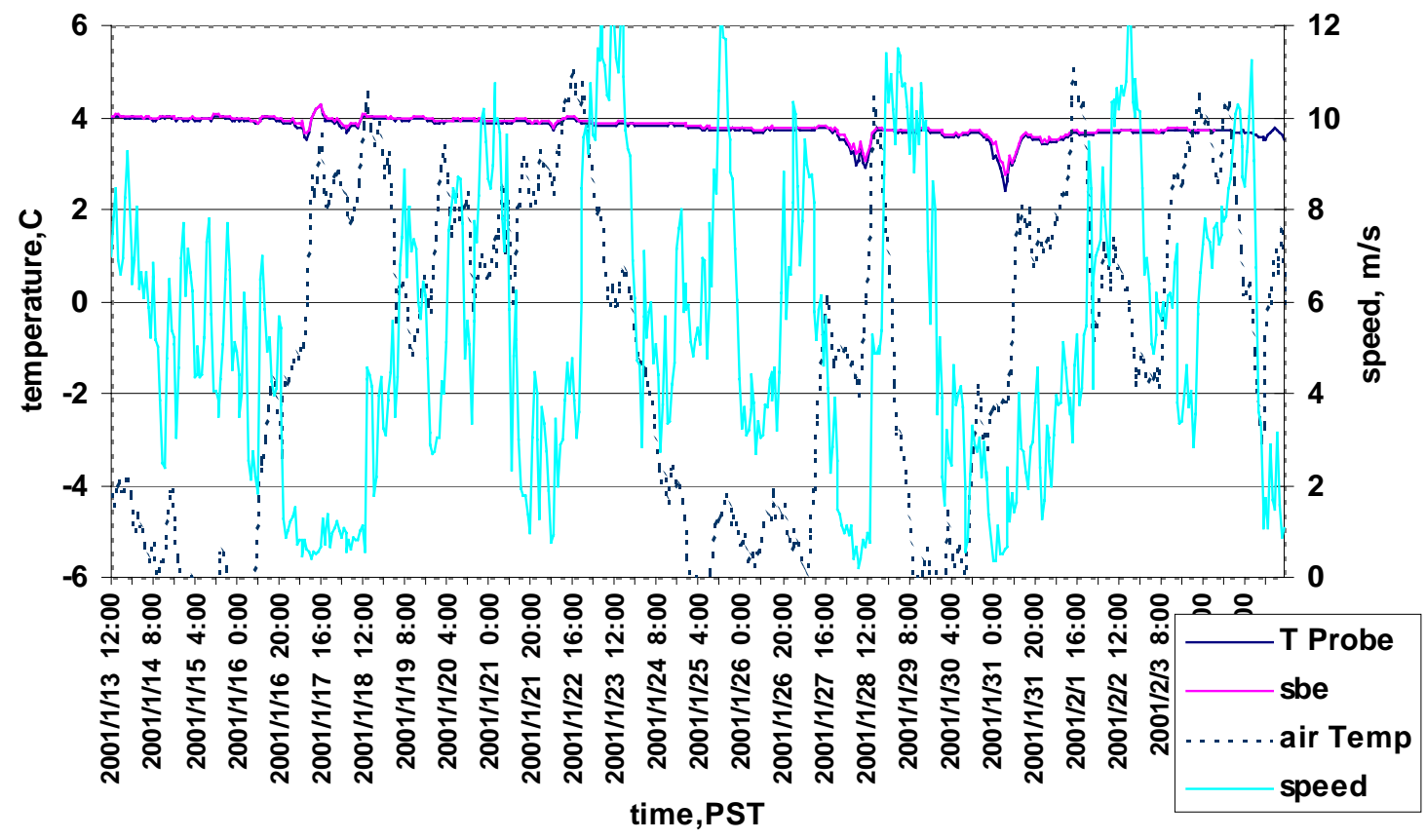

Fig 46: OSU buoy data Jan 13, 2001 to Feb 5, 2001. 


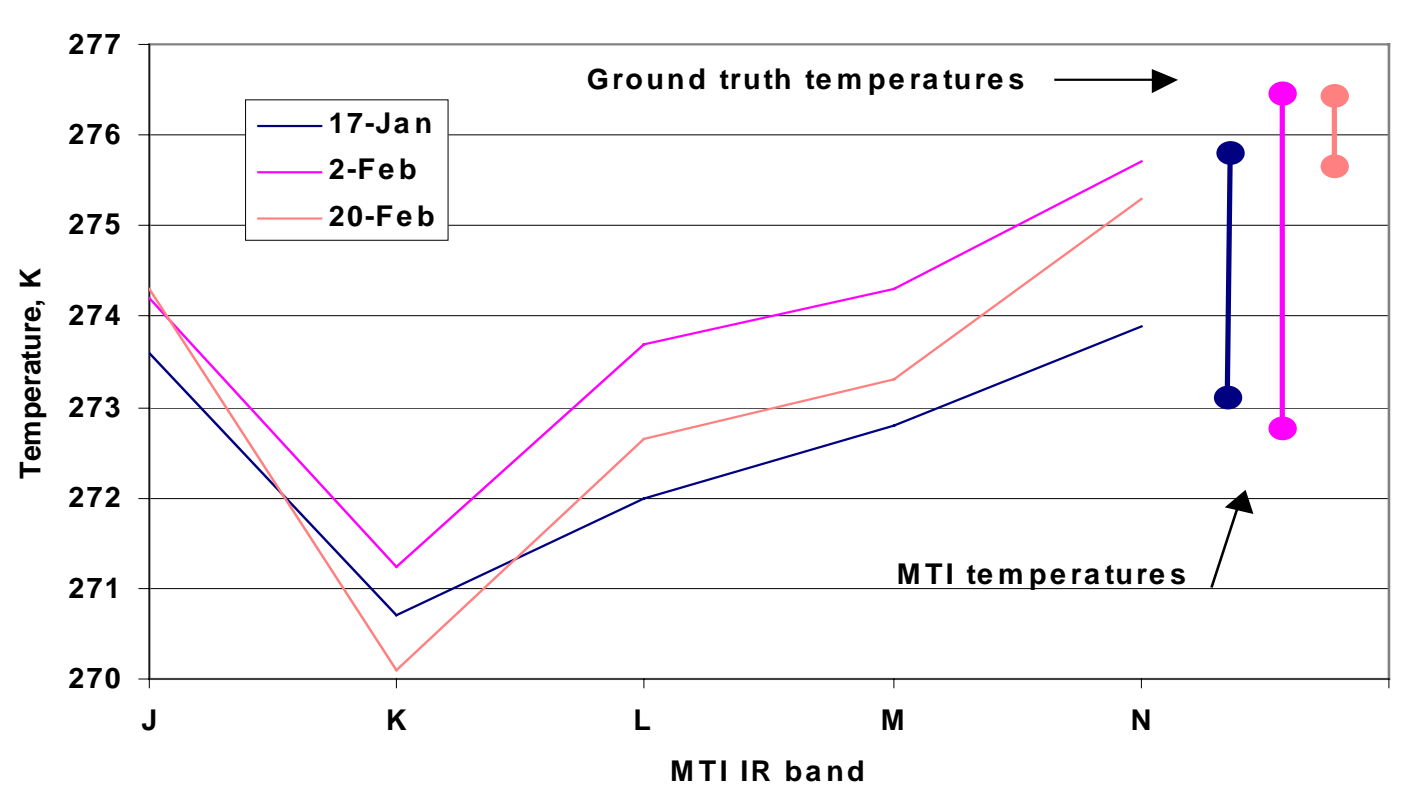

Fig. 47: Brightness temperature at the center of Crater Lake on Jan 17, Feb 2, and Feb 20 of 2001. The bars at the right show the corrected water surface temperature at the buoy (top) and the MTI water surface temperature at the middle of the lake (bottom). 
Sounding for MFR, 12 UTC, 17-JAN-2001

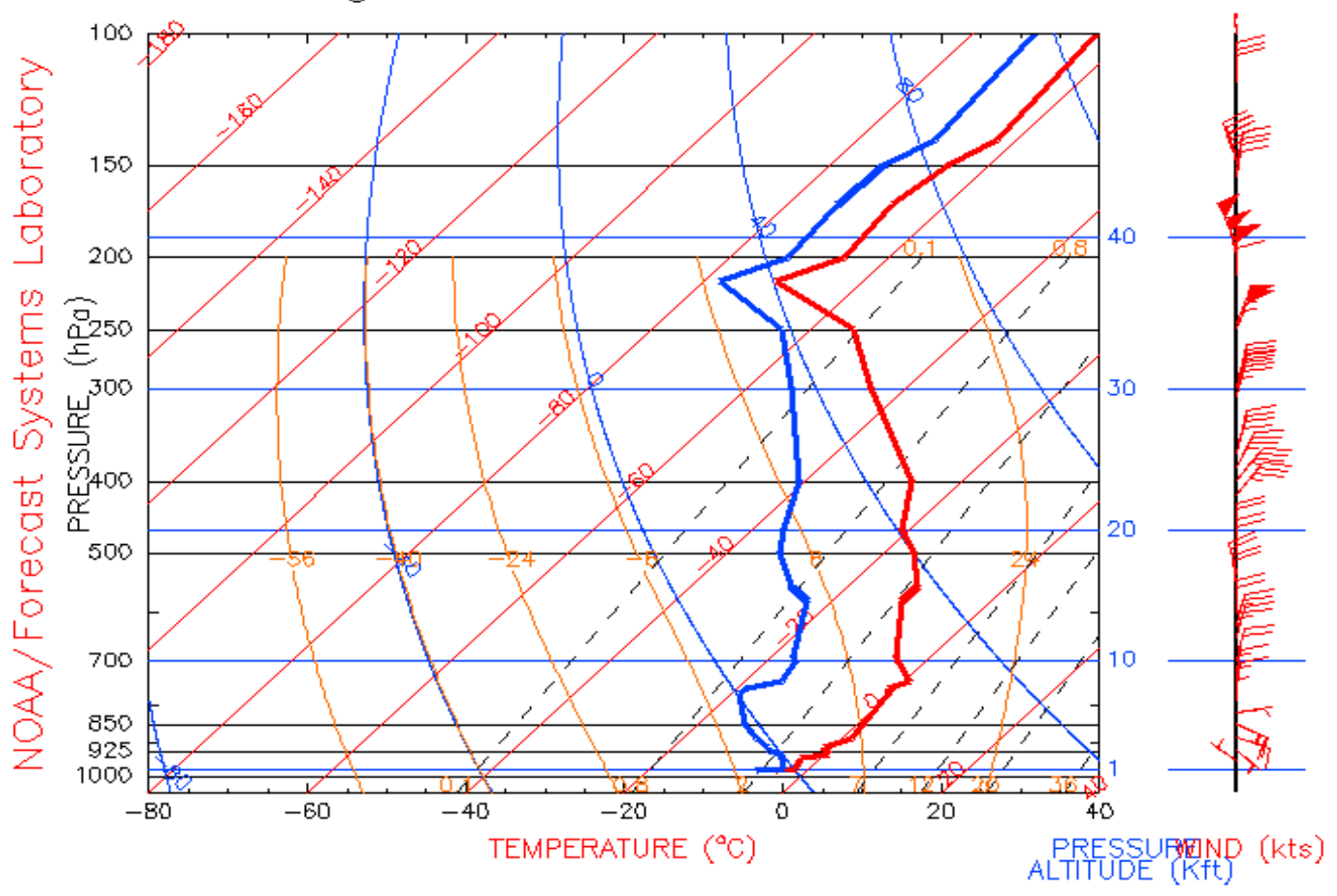

Fig. 48: Rawinsonde for Medford, OR on Jan 17, 2001 at 12z.

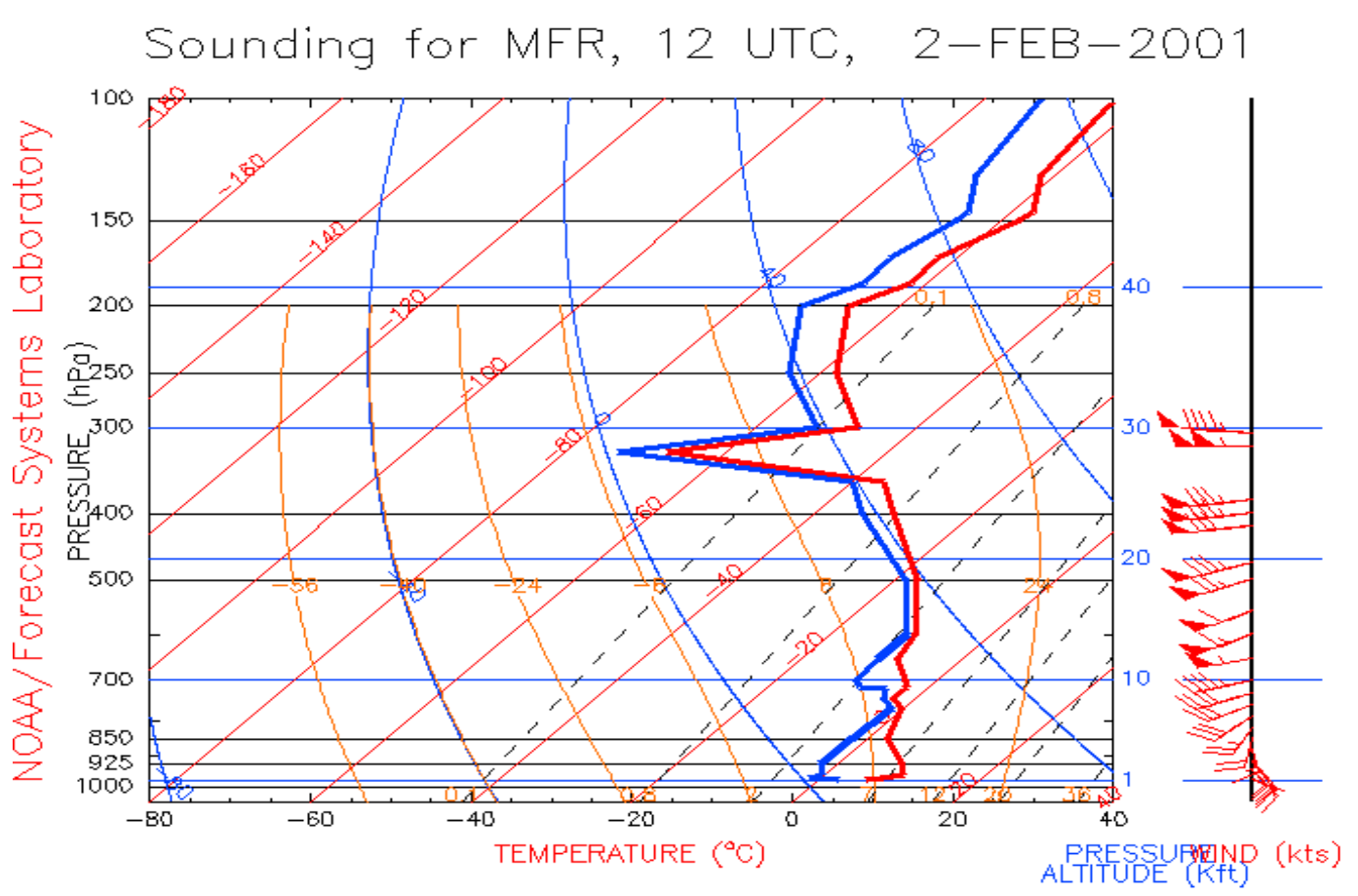

Fig. 49: Rawinsonde for Medford, OR on Feb 2, 2001 at 12z 
Sounding for MFR, 12 UTC, 20-FEB-2001

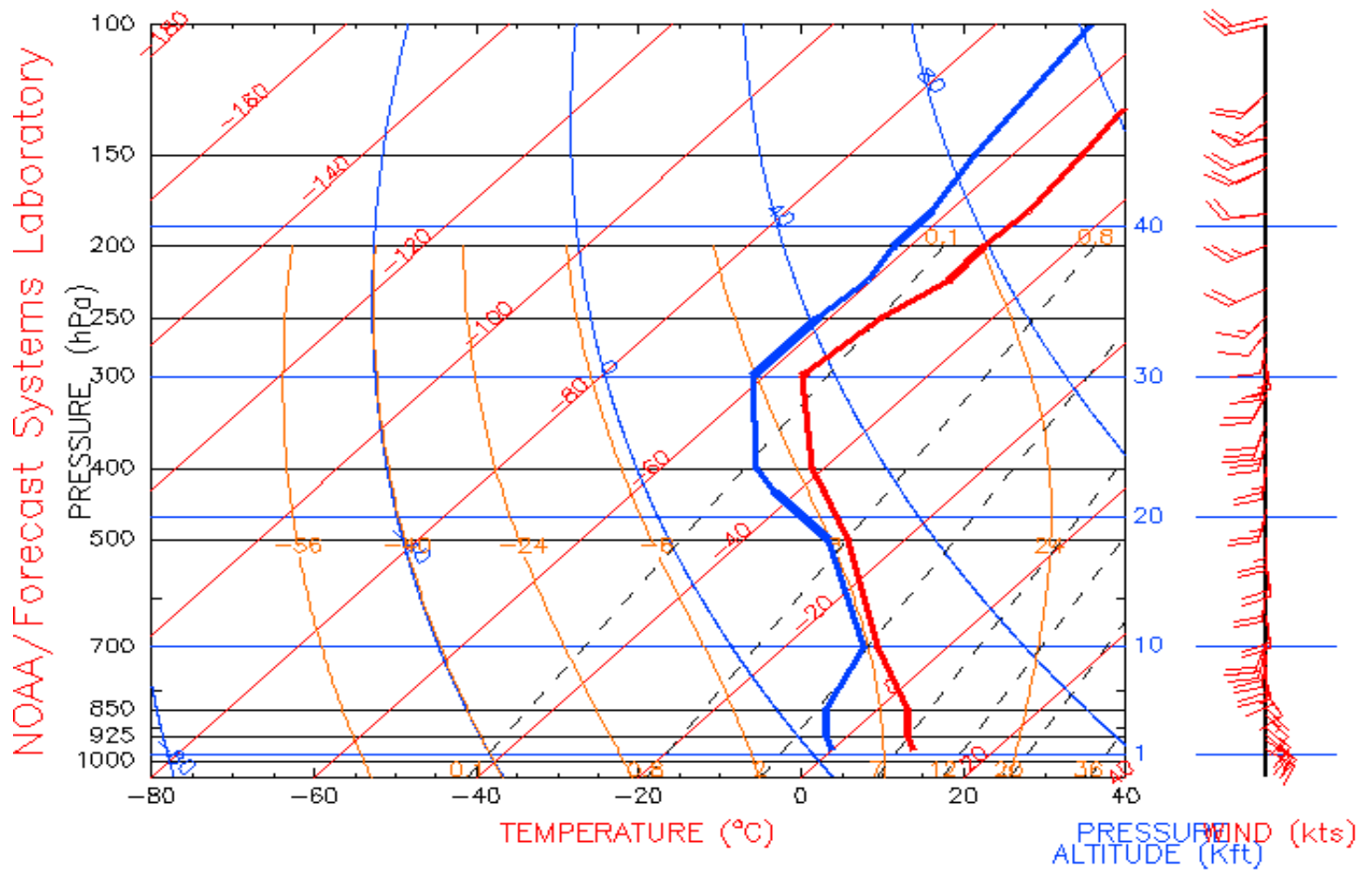

Fig. 50: Rawinsonde for Medford, OR on Feb 20, 2001 at 12 